\title{
THE SERUM IRON IN HEALTH AND DISEASE
}

Mary D. Smith,

M.B.,Ch.B., F.R.F.P.S.G., M.R.C.P. (Ed.) 
ProQuest Number: 13838402

All rights reserved

INFORMATION TO ALL USERS

The quality of this reproduction is dependent upon the quality of the copy submitted.

In the unlikely event that the author did not send a complete manuscript and there are missing pages, these will be noted. Also, if material had to be removed, a note will indicate the deletion.

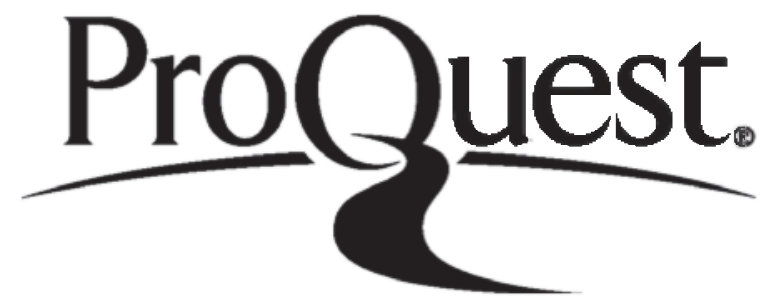

ProQuest 13838402

Published by ProQuest LLC (2019). Copyright of the Dissertation is held by the Author.

All rights reserved.

This work is protected against unauthorized copying under Title 17, United States Code Microform Edition (C) ProQuest LLC.

ProQuest LLC.

789 East Eisenhower Parkway

P.O. Box 1346

Ann Arbor, Ml $48106-1346$ 


\section{PREFACE}

The investigations described in this thesis were carried out in the Muirhead Department of Medicine at the Royal Infirmary, Glasgow, from 1948 to 1950, during tenure of a Hall Tutorial Fellowship in liedicine. The clinical observations were made in the wards of the Royal Infirmary and at the Haematological Clinic. I an indebted to Professor I.J. Davis for access to the clinical material and for guidance auring the course of the investigations. The withdrawal of most blood specimens, the performance of sternal punctures, the estimation of serum iron, and the staining of marrow preparations for iron were carried out personally, but I am indebted to Dr. S.I. Tompsett, biochemist to the Royal Infirmary at the time, for several estimations of tissue iron by the ashing technique which are recorded in the earlier part of the work. I am also most grateful to Mr.J.D. Devlin of the Department for his assistance in the photographing of the charts, and in the preparation of colour transparencies of histological specimens. 
INDEX.

PART I.

PAGE.

INT RODUCT ION

1

PAFT II.

A SHORT REVIEW OF IRON METABOLISM ................ 4 PAFT III.

RELIABILITY OF SELECTED INETHODS FOR SERUM IRON

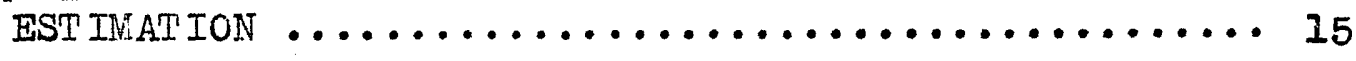

Ort hophenanthroline Technique

Collection of blood

Reagents required

Analytical procedure

Effect of haemolysis on iron content of serum

Accuracy of blank.

Potassium Ferricyanide Technique.

Reagents required

Analytical procedure

Comparis on of methods.

SUMMARY

29

PART IV.

SERUM IRON IN NORIAL INDIVIDUAIS AND ITS RELATION TO

$A G E, S E X$, AND TIME OF DAY ................ 30

Material examined

Normal values

The influence of age on serum iron

Sex difference in relation to serum iron

Diurnal variability of serum iron

The influence of diet and control by the liver. 
PART V.

PAGE.

SERUM IRON LEVELS IN PATHOLOGICAI CONDITIONS ........ 47

Single Observations on Serum Iron in Various

Types of Anaemia before Treatment.

Iron deficiency anaemia

Pernicious anaemia

Haemolytic anaemia

Infective, neoplastic and toxic states

Infective hepatitis and other liver

disorders

Nephritis and uraemia

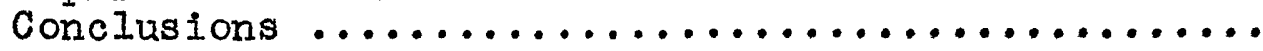

Serfal Observations of Serum Iron Concentration

during course of 1 ilness.

Iron deficiency anaemia

Pernicious anaemia

Myelold leukaemia

Iymphadenoma and carcinoma

Uraemia, myxoedema, and carcinoma

Conclusions $\ldots \ldots \ldots \ldots \ldots \ldots \ldots \ldots \ldots \ldots \ldots \ldots \ldots$

PART VI.

INTRAVENOUS IRON DISAPPEARANCE TESTS ............. 80

Suitability of Substances for Intravenous iron tosts 81

Method of investigation and variables affecting method 88

Recovery of iron from "Iviron"

Iron-binding capacity in relation to "Iviron"

Absorption and dialyzing properties of "Iviron" and excretion

Interpretation of intravenous iron disappearance tests

Application of method to patients with anaemia

Material

Results:-

in relation to iron-binding capacity

in relation to rate of disappearance of iron from the serum. 
ORAI IRON ABSORPTION TESTS ................. 112

Me thod

114

Material

Curves obtained in normal subjects

Analysis of oral iron curves in chronic

hypochromic anaemia

In relation to:

Age and sex

Gastric acidity

Haemoglobin level and utilization

Rate of disappearance of iron from the serum

Comparison of oral curves in essential and posthaomorrhagic chronic iron deficiency

Oral absorption curves in gastro-enterostomy

Oral absorption curves in perniclous anaemia

Oral absorption curves in anaemia associated with toxic, infective and nooplastic disease

SUMMARY

\section{Part VIII.}

HISTOLOGICAL IRON IN STERNAI PUNCTURE MATERIAL ..... I44

Storage Iron.

Haomosiderin

Ferritin

Relationship and functions of ferritin and haomosiderin

Site and extent of iron storage.

Material examined

In relation to expected iron reserves

Marrow siderosis in relation to transport, absorption and ssimilation of iron

Consideration of findings in relation to Granick's "Mucosal block" theory

Stainable iron as a guide to intravenous iron therapy. 
PAGE.

Conclusions

162

SUMMARY

164

PAPT IX.

GENERAL SUMMARY AND CONCLUSIONS ........... 165

Reliability of selected methods for estimation of serum iron

Tho serum iron in hoalth

The serum iron in disease

The value of oral iron absorption and Intravenous iron disappearance tests in conjunction with histological iron in the marrow.

Results in relation to iron motabolism 
PART I.

\section{INTRODUCTION.}

The work to be recorded was undertaken to assess the value of serum iron estimation in the investigation of anaemia and as a guide to therapy, use being made of intravenous and oral iron tests and demonstration of stainable iron in sternal puncture material. With this purpose in view, the following studies were undertaken.

(1) The reliability of certain chemical methods for serum iron estimation was assessed.

(2) The range of normel serum iron concentration was determined, and the effect upon it of age, sex, and time of day investigated.

(3) Alterations in serum iron as a result of disease were observed and changes in concentration followed during the course of the illness.

(4) Saccharated iron oxide was investigated as to its suitability as an intravenous test substance and intravenous and oral iron tests applied to the investigation of anaemia.

(5) Examination of bone marrow biopey specimens for stainable iron was used to supplement the information gained from other sources.

It is recognised that the use of radionctive iron is probably the best means avallable for tracing the intricacies 
of iron absorption, transport, storage, and utilization. Nevertheless the apparatus required is elaborate, and the difficulty of obtaining activated iron is considerable. Moreover, radio-active iron is unsuitable for routine clinical studies, and the recent introduction of saccharated iron oxide in a form which can safely be given intravenously in therapeutic doses has increased the need for a method of assessment of iron balance in the individual patient, so that the occasional case of refractory normoblastic anaemia amenable to parenteral iron therapy may be identified. Valquist (1944) suggested that a standardized oral iron absorption test might prove of clinical value, but he was handicapped in its development by lack of a suitable substance for measuring the rate of disappearance of iron from the blood during the time of performing such a test, and by ignorance of the size of existing iron stores in the body. Saccharated iron oxide itself offered a substance worth investigating as to its usefuliness for assessing the rate of disappearance of iron from the plasma, and, recently, limited studies have indicated that stainable iron in sternal puncture specimens is approximately representative of total body stores. With a reliable method for estimation of the serum iron, and a knowledge of the limits of variation in serum iron in health and disease, a study of iron balance appeared possible using oral iron absorption curves, Intravenous iron disappearance 
tests, and demonstration of stainable iron in sternal puncture specimens.

All serum iron estimations and the preparation of sternal puncture smears for demonstration of iron were carried out personally by the writer. The results are discussed in relation to their usefulness in clinical investigation and to the information ylelded regarding intermediary iron metabolism. It appears possible that a tendency to malabsorption of iron exists in a few cases of "idiopathic" iron deficiency and may be revealed by low oral absorption curves, but in the writer's experience malabsorption was never sufficient to prevent a satisfactory response to oral iron given in therapeutic dosage. In refractory normoblastic anaemias associated with chronic diseases, alimentary iron absorption is normal and stainable iron is often present in the marrow. This evidence of iron accumulation suggests that parenteral iron is unlikely to have a place in treatment of these patients. This opinion is supported by the lack of response observed when a group of such cases were treated with intravenous iron. 


\section{PART II.}

\section{A SHORT REVIEW OF IRON METABOLISM.}

Written accounts of iron as a therapeutic substance appeared in medical literature long before anything was known regarding distribution of the element in the body. A detalled account of a medicinal preparation of iron was given by Monardes (1596), the preparation consisting of iron and steel filings steoped in vinegar and subsequently ground until an extremely fine suspension was obtained. The author gave no clear account of indications for its use, and prescribed that the patient ought to be let blood prior to Its administration. Sydenham (1661) was the first to prescribe iron as a specific remedy, and gave an accurate account of its usefulness in the treatment of patients with chlorosis. He preferred to use the preparation of steel filings, but also recommended the use of naturally-occurring iron-containing waters. A further account of the clinical use of iron was given by willis (1684). He hesitated to use iron filings in delicate patients lest they cause damage to the organs, and often prescribed a solution of ferrous sulphate. He was aware that the latter might prove dangerous if given in excess. Absorption of iron from the alimentary canal into 
the blood had been considered by Willis as directly responsible for the improved colour of chlorotic patients after treatment, but it was not until 1746 that iron was discovered by Menghini to be a constituent of the blood, and demonstrable in its corpuscular elements. The significance of this advance was not immediately appreciated, and even in 1789, cullen wrote that he considered it unnecessary to take any particular notice of the iron present in the blood, or of how it had reached there. Menghini's work he considered had simply demonstrated clearly that iron acting in the stomach had the power of increasing the appetite and improving the vigour of the circulation. During the first half of the nineteenth century iron was therefore still being prescribed in many diverse diseases. Anaemia was, however, becoming recognised as a specific indication for its administration, and already a refractory group was being segregated, as is indicated by the writings of Pereira (1854) who described the anaemia of cancer, renal and cardiac disease as failing to respond to iron. Blaud (1831) maintained that in chlorotics the blood was incapable of fulfilling its functions adequately because it was deficient in an essential pigment. This colouring matter, the active principle, could be restored by giving iron, and the function of the blood thereby improved. 
That the blood iron was reduced in chlorosis was demonstrated by Foedisch in 1832. In 1898 came the first account of two distinct blood iron fractions when Abderhalden showed that there was more iron in the peripheral blood than could be accounted for by the haemoglobin iron in red cells. The next year, Hasermann demonstrated iron present in nonhaemolysed blood plasma, a fact wich was confirmed by Fowell in 1915. The complex history of iron in the blood and tissues was now beginning to unfold itself, and the systematic studies by Barkan (1925, 1927, 1933) of the non-haemoglobin iron, and his definition of the essential nature of the serum iron stimulated further research and led to a more comprehensive understanding of intermediary iron metabolism.

The iron present in the serum at any one time is an extremely small proportion of the total body iron. Its importance from a clinical point of view lies in the fact that it is the transport iron of the body, and as such is affected by the amount of iron absorbed, stored, utilised, and excreted, and must be in equilibrium with the reserve stores and the iron of the gastro-intestinal tract, as well as with the site of destruction and site of origin of red cell haemoglobin. Changes in its concentration consequently reflect alterations in the intermediary iron metabolism, and although the turnover of iron between a normal man and his 
environment is small, probably less than a milligram daily, the internal turnover within the haemoglobin cycle is in the region of $25 \mathrm{mgm}$. daily. Other non-haemoglobin iron fractions such as muscle haemoglobin iron and the iron of cellular enzyme systems are relatively fixed fractions, which are essential for the functioning of cells. As far as is known, they are never depleted however great the demand for iron by anaemia, pregnancy or growth, and they must meantime be regarded as constants in discussing changes in non-haemoglobin iron.

Normal human serum contains an average of about $115 \mathrm{ug} . \%$ of non-haemoglobin iron, the concentration tending to be higher in men than in women. The iron is present as a complex organic compound with an iron-binding protein, which Cohn et al. (1946) have proved to be a $\beta$ - globulin. Normally this protein is only 30-40\% saturated but at any time iron reaching the blood in excess of the total saturation capacity is rapidly eliminated from the circulation (Waldenstrom, 1944; Laurel1, 1947). The excess is probably deposited in the tissues and such deposition may account for the toxic effects associated with massive parenteral administration of iron (Holmberg \& Laurell, 1945). The amount of iron binding protein and the degree of saturation (i.e. the serum concentration) vary in different forms of anaemia, but the 
changes in each show no obvious relationship. The proportion of protein remaining unsaturated probably bears the closer relationship to the quantity of iron assimilated and stored (Laurell, 1947).

Provided it is in soluble form, iron is absorbed throughout the whole length of the alimentary tract, but to the greatest extent in the stomach, duodenum and upper jejunum (Hahn et al, 1943; Copp \& Greenberg,1946). Les efficient absorption further down the tract is due, at least in part, to increased alkalinity of the environment causing the formation of insoluble iron salts (Hahn 1937). Ingested iron compounds are broken down in the stomach in the presence of hydrochloric acid and iron liberated in an ionized and reduced form. An acid medium is required to maintain this state, and that it may be the state in which absorption occurs was shown by thein vitro experiments of Tompsett (1940) in which he demonstrated conversion of ferric to ferrous iron in pepsin-hydrochloric acid mixtures, and by the observations of Bergeim \& Kirch (1949) indicating that iron which had been fed in the ferric form was demonstrable thirty minutes later in samples of gastric juice in the ferrous form. The presence of phytic acid will impair absorption owing to the formation of insoluble phytates (McCance et al. 1943), while absence of phosphorus, and 
pyridoxin deficiency will enhance it to the extent of producing haemosiderosis (Cartwright et al.1949). Ascorbic a.id raises the amount of iron absorbed when given along with iron, but its deficiency in the body has never been proved to inhibit iron uptake (Powell, 1944). Lederer (1940) claimed that there is a specific enzyme in the stomach which in the presence of hydrochloric acid is responsible for liberating iron from organic complexes in food.

Once past the intestinal barrier, the iron appears in the blood stream and not at all in the lymph channels (Moore et al. 1939). That which is not immediately required for haemoglobin synthesis is stored in the liver, spleen and bone marrow in the closely related intracellular protein complexes ferritin and haemosiderin. Parenterally admininstered iron which is ionizable is also largely taken up by the parenchymal cells of the liver and spleen, and to a small extent in the convoluted tubules of the kidney, but unionizable forms are selectively taken up by the reticuloendothelial system (Polson, 1928, 1929, 1933; Cappell, 1930; Finch, 1950). The deposition of iron normally liberated from effete erythrocytes also occurs primarily in the reticuloendothelial cells. The ultimate distribution of all forms 
is probably similar. Storage iron in health comprises about $20 \%$ of the total body iron content but is enough to replace only about one fifth of the circulating haemoglobin (Hynes, 1949). It is possible that administration of large amounts of iron parenterally promotes the development of specific tissue receptors which may then augnent the storage capacity (Finch, 1950).

Under normal circumstances excretion of iron from the body is negligible. Even after large amounts of iron intravenously the greatest urinary excretions recorded are 4.4\% (Crawley, 1951, personal communication) and 5\% (Scott \& Govan, 1951), and of iron liberated by multiple blood transfusion or phenylhydrazine induced haemolysis only about $0.5 \%$ appears in urine and faeces together. Human bile contains 0.08 to $0.40 \mathrm{mg} . \%$ and although animal experiments indicate that biliary excretion can be increased tenfold as a result of haemolysis, the amount of iron accounted for in the bile is still less than $3 \%$ of that which has been liberated by red cell breakdown (Hawkins \& Hahn, 1944). Mitchell and Hamilton (1949) claim that iron in humans is excreted in the sweat, but their finding is difficult to accept, because the daily loss of $6.5 \mathrm{mg}$. which they record exceeds the amount 
normally absorbed in that period.

In view of this very limited capacity to excrete iron, McCance \& Widdowson (1937) observed that if haemochromatosis is to be avoided, there must be selective absorption. Two years later Hahn et al, using radioactive iron, demonstrated that in dogs with chronic post-haemorrhagic aneemia, the absorption of iron was much greater than in normal animals, and Balfour et al. (1942) showed, in humans, that iron absorption is ten to twenty times better when iron stores are depleted than it is in health. Control of absorption is probably partially effected by a protein complex, apoferritin, in the intestinal mucosa. According to Granick ( $1946 \mathrm{a}$ and b) this substance combines with iron intracellularly to form a ferric compound, ferritin, which is retained as a reserve from which to maintain saturation of the mucosal cells with ferrous iron, the form in which absorbed iron is passed on from the cells to the serum when the concentration of iron there is lowered. Only when the ferritin reserve becomes inadequate to maintain mucosal saturation is more iron absorbed from the intestinal lumen. Fully saturated mucosal cells therefore act as a "block" to intestinal absorption.

This conception of iron metabolism has largely been achieved as a result of experimental work in animals, in 
vitro experiments, estimation and histological demonstration of iron in post-mortem specimens, and investigations with radio-active iron in animals and humans. Appreciation of the fact that ingestion of iron was followed by a rise in serum iron led to some clinical investigations by means of oral iron absorption curves. Moore et al. (1939a) were able to show that in the same subject given the same dosage of iron, similar curves could be reproduced, and in his investigations in anaemic subjects, obtained higher curves than normal in patients with chronic post-haemorrhagic haemoglobin deficiency. In untreated pernicious anaemia, the curves were flatter than normal, but reverted after adequate treatment. Vanott1 and Delachaux (1946) obtained less consistent results, and their findings of some flat curves amongst patients with severe iron deficiency led them to the conclusion that such a means of investigation was unreliable. Flat curves were obtained in patients with chronic infection by Cartwright et al.(1946), and they assurned that both in infection and in iron deficiency, they might be accounted for by rapid diversion of iron from the serum. Interpretation of oral absorption tests was therefore hampered by lack of knowledge regarding the rate at which iron was 
simultaneously disappearing from the blood stream. The presence of an iron-binding protein limiting the maximum amount of iron which can remain in the blood has already been mentioned, but in the literature less attention has been paid to the rate at which the bound iron disappears. Using chemical methods, Tutterman (1949) showed a rapid disappearance in infection, and various other reports on very small numbers of cases indicate that there is also a rapid disappearance in haemoglobin deficiency states. There has been no investigation performed making use of combined oral and intravenous iron tests except by Thedering (1948) who claimed by this means to differentiate a group of iron deficiency anaemias in which malabsorption of iron could be regarded as a contributory factor in aetiology. Powell (1944) stated that, in her experience, resistance to oral iron treatment was sometimes due to failure of absorption of iron from the alimentary tract. The report of Wilkinson and Slack (1949) supports this view and suggests that refractory hypochromic states due to intestinal malabsorption of iron are not rare and are amenable to parenteral iron therapy. The availability of intravenous iron preparations for general use has made more imperative the accurate diagnosis of such cases. The elimination of others unlikely to respond to either oral or parenteral 
iron is of equal importance in view of the limited excretion of iron from the body and the danger which theortically could result from iron accumulation. 


\section{PART III.}

RELIABILITY OF SELECTED METHODS

FOR SERUM IRON ESTIMATION.

The circulating non-haemoglobin iron of the blood is an organic complex and, since the plasma loses none of its iron in the process of clotting, estimation of the iron may be carried out on serum as well as on plasma. Use of serum has the advantage of avoiding anticoagulants which may interfere with colour development during the estimation. The analytical procedure is first dependent upon digestion of the serum with hydrochloric acid in order to release the iron from its organic combination. The subsequent aim is to form a coloured complex which, by colorometric measurement of the colour intensity, permits of quantitative determination of its iron content on comparison with freshly prepared solutions of known strength.

Vannotti and Delachaux (1946) claimed to demonstrate four iron fractions. They observed that one iron fraction in serum could be split off by dilution of the serum with doubly distilled water and subsequent removal of the proteins with trichloracetic acid. The weakly acid medium was 
probably responsible for splitting off this fraction. A bigger fraction was obtained by addition to serum of hydrochloric acid, the amount of extraction being dependent upon the strength of the acid. A third fraction was recognizable after ashing of the $\mathrm{HCl}$. filtrate, iron being found present in excess of that which could be estimated directly in the extract. A fourth fraction completely resisted acid extraction and could be isolated in the protein precipitate. No other workers claim such detailed fractionation, but considerable argument has arisen regarding the significance of a fraction obtained by Barkan in his original work, and designated "easily split-off iron". It has since been shown that this is probably an artefact arising from oxidation of the prosthetic group of the haemoglobin molecule by oxygen released from oxy-haemoglobin by acids. Its formation can be prevented by conversion of oxy-haemoglobin to carboxyhaemoglobin with carbon monoxide (Iemberg \& Iegge, 1941). Grimstein and Moore (1949) using radioactive iron showed that this appeared at the same rate in the "easily split-off" iron as it did in haemoglobin, and concluded that the fraction was therefore artificial. There is the possibility that a small iron fraction may be derived from blood catalase and intra-erythrocytic verdo-haemoglobin, but there is no convincing evidence that the latter exists or that 
degredation of haemoglobin begins within the red cell.

Three reagents are at present in use for estimating the serum iron concentration - (1) potassium thyocyanate (Kennedy, 1927; Moore et al. 1937); (2) orthophenanthroline (Heilmeyer \& Plotner, 1937; Barkan \& Walker, 1940; Tompsett, 1940 ); (3) potassium ferricyanide (Fitzpatrick \& Howells, 1949) In the present work, Tompsett's modification of the orthophenanthroline technique and Fitzpatrick's potassium ferricyanide method were used for estimation of the serum iron. Both methods have the advantage of simplicity, particularly the latter, which uses fewer reagents and requires less time for colour development. In both, the chemicals used are reasonably readily obtainable, and can be prepared free from iron.

ORTHOPHENANTHROLINE TECHNIQUE.

All glassware was steeped in dilute hydrochloric acid overnight, thoroughly washed in glass-distilled water and dried.

Collection of Blood: About $10 \mathrm{cc}$. of blood was collected from an antecubital vein in an acid-washed "Pyrex" glass test tube, using a stainless steel needle without a syringe. After the serum had separated, it was centrifuged, and cell free samples thus obtained. 
Reagents Required:

(1) Hydrochloric Acid, 1.2\%

(2) Trichloracetic acid; 20\% solution.

(3) Sodium acetate solution saturated.

(4) 2.M acetate buffer solution, $\mathrm{pH} 4.5$, prepared by mixing 90 volumes of 2.M sodium acetate and 110 volumes of $2 . \mathbb{I I}$ acetic acid.

(5) Hydrazine sulphate, 1\% Solution in 2.M acetate buffer of $\mathrm{pH} 4.5$. This was always freshly prepared before use.

(6) Orthophenanthroline, $0.1 \%$ solution in water.

All solutions were prepared with glass-distilled water and filtered through Whatman's No.42 filter paper, which had previously been steeped in dilute hydrochloric acid, washed in glass-distilled water, and dried. Analytical Procedure: A mixture of $4 \mathrm{ml}$. of serum and $2 \mathrm{ml}$. if $1.2 \%$ hydrochloric acid was placed in an incubator at $37{ }^{\circ}$. for $1 \frac{1}{2}$ hours. After cooling to room temperature, the proteins were precipitated by addition of $2 \mathrm{ml}$. of $20 \%$ trichloracetic acid solution and the mixture centrifuged. The supernatant fluid was passed through a No.42. Whatman filter paper which had been washed with dilute hydrochloric acid and distilled water and dried. To $4 \mathrm{ml}$. of the filtrate $1 \mathrm{ml}$. of buffered $1 \%$ hydrazine sulphate solution, $1 \mathrm{ml}$. of $0.1 \%$ o-phenanthroline solution, and $1 \mathrm{ml}$. of glass-distilled water 


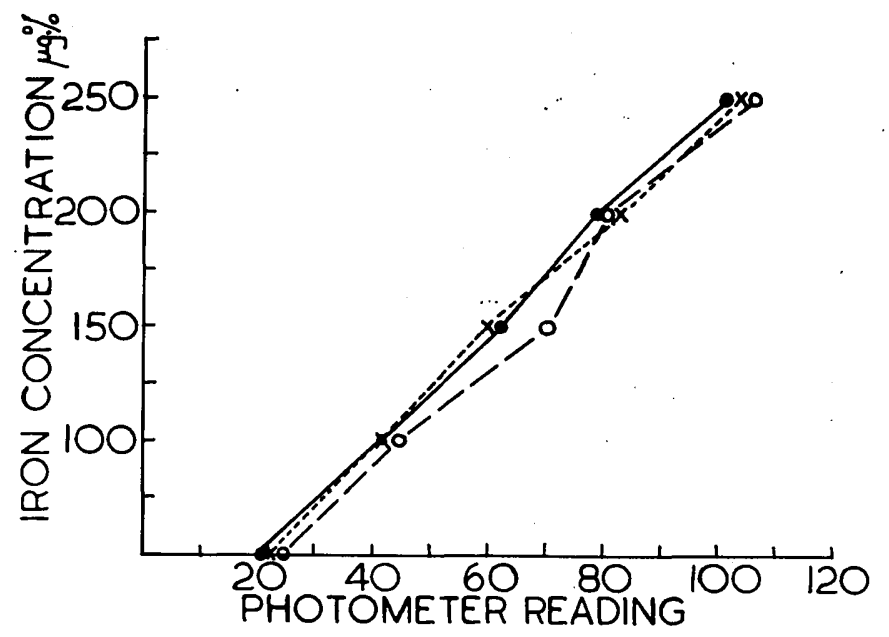

Fig. 1. Curves obtained on estimating the iron content of serial dilutions of ferrous sulphate of known concentration - orthophenanthroline method. 
Table 1. fiecovery of iron firom aqueous ferrous sulphate solutions of known iron concentration - orthophenanthroiine method.

\begin{tabular}{|c|c|c|c|}
\hline $\begin{array}{l}\text { Sample } \\
\text { No. }\end{array}$ & Cal Iron Con & $\frac{\text { in } \mu g \cdot f}{\text { Estimated }}$ & Ditference \\
\hline 1 & 50 & $\begin{array}{l}50 \\
60\end{array} 55$ & +5 \\
\hline 2 & 100 & $\frac{106}{105} 106$ & +6 \\
\hline 3 & 200 & $205\} 208$ & +8 \\
\hline 4 & 50 & $\begin{array}{l}54 \\
52\end{array} 53$ & +3 \\
\hline 5 & 200 & $\begin{array}{l}189 \lcm{1994} \\
199\end{array}$ & -6 \\
\hline
\end{tabular}

No significant difference between calculated and estimated values.

Table 2. Iron content of serum before and a fter addition of a known amount of ferrous sulphate - orthophenanthroline method.

\begin{tabular}{|c|c|c|c|c|c|}
\hline $\begin{array}{l}\text { Sample } \\
\text { Io. }\end{array}$ & $\begin{array}{l}\text { Before add- } \\
\text { ition of } \\
\text { iron, ug. }\end{array}$ & $\begin{array}{l}\text { Amount of } \\
\text { iron added, } \\
\text { ug. } \%\end{array}$ & $\begin{array}{l}\text { After add- } \\
\text { ition of } \\
\text { iron, ug. }\end{array}$ & $\begin{array}{l}\text { Iron re- } \\
\text { covered } \\
u_{g} . \%\end{array}$ & $\begin{array}{l}\text { Diff- } \\
\text { erence. }\end{array}$ \\
\hline 1 & $\left.\begin{array}{l}105 \\
110 \\
100\end{array}\right\} 105$ & 100 & $\left.\begin{array}{l}198) \\
201 \\
206\end{array}\right\} 202$ & 97 & -3 \\
\hline 2 & $\begin{array}{l}170) \\
162) 164 \\
161\end{array}$ & 100 & $\left.\begin{array}{l}260 \\
258 \\
271\end{array}\right\} 263$ & 99 & -1 \\
\hline 3 & $\left.\begin{array}{l}114 \\
129 \\
116\end{array}\right) 120$ & 150 & $\begin{array}{l}270) \\
278) 274 \\
273\end{array}$ & 154 & +4 \\
\hline 4 & $\left.\begin{array}{l}82) \\
90 \\
88\end{array}\right\} 87$ & 150 & $\left.\begin{array}{l}242 \\
245 \\
238\end{array}\right\} 242$ & 155 & +5 \\
\hline 5 & $\begin{array}{c}100) \\
108) 102 \\
99)\end{array}$ & 200 & $\begin{array}{l}290) \\
294) 291 \\
286)\end{array}$ & 189 & -11 \\
\hline
\end{tabular}

No signiticant difterence between "Before + Amount added" and "After vaiues". 
were added in that order, mixing after each addition. The mixture was placed in an incubator at $37^{\circ} \mathrm{C}$. for $1 \frac{1}{2}$ hours, and the depth of colour evaluated in a double photocell absforptiometer using blue and blue-green filters.

A blank was prepared using $4 \mathrm{ml}$. glass-distilled water in place of serum.

A standard curve was obtained by graphing the photoelectric readings for serial dilutions of ferrous sulphate of known strength. Such curves were reasonably readily reproducible (Fig. I) and a composite curve was satisfactory as a standard from which to measure the iron content of other solutions. The results of recovery experiments on solutions of ferrous sulphate in distilled water and of ferrous sulphate added to serum are shown in Tables land 2. From these results it is appreciated that recovery does not obtain such a very high degree of accuracy. Even on triplicate estimation the error can be as great as $20 \%$ in very low dilutions but statistical evaluation shows that there is no significant difference between the calculated and estimated values over the whole range investigated. Many investigators do not record figures indicative of the accuracy with which they can make their estimations, but some, e.g. Powell (1944), claim accuracy to within 3\% on duplicate readings. When Tompsett published the method, he claimed a maximum error of $12 \%$. 
Table 3. Effect of moderate haemolysis on serum iron concentration - orthophenanthroline method.

\begin{tabular}{|c|c|c|c|c|}
\hline Sample & $\begin{array}{l}\text { Iron content of } \\
\text { clear serum, ug. } \%\end{array}$ & Ho $\frac{\text { Haemolysed }}{\% \text { content }}$ & $\frac{\text { specimen }}{\substack{\text { Iron content } \\
u g \cdot \%}}$ & Diff- \\
\hline 1 & $\begin{array}{l}140) \\
130) 137 \\
140)\end{array}$ & 5 & $\begin{array}{l}135) \\
130) 134 \\
136\end{array}$ & -3 \\
\hline 2 & $\left.\begin{array}{r}100 \\
95 \\
105\end{array}\right\} 100$ & 8 & $\left.\begin{array}{c}103 \\
98 \\
99\end{array}\right) 100$ & 0 \\
\hline 3 & $\left.\begin{array}{l}121 \\
115 \\
115\end{array}\right\} 117$ & 8 & $\left.\begin{array}{l}116 \\
110 \\
109\end{array}\right\} 112$ & -5 \\
\hline 4 & $\left.\begin{array}{l}160 \\
152 \\
153\end{array}\right\} 155$ & 10 & $\left.\begin{array}{l}170 \\
173 \\
189\end{array}\right\} 177$ & +22 \\
\hline 5 & $\left.\begin{array}{r}100 \\
92 \\
89\end{array}\right) 95$ & 15 & $\left.\begin{array}{l}110 \\
109 \\
102\end{array}\right\} 107$ & +13 \\
\hline
\end{tabular}


Effect of Haemolysis on Iron Content of Serum: The quantity of iron in the serum is so very small when compared with the iron content of haemoglobin that it is of paramount importance to be certain that haemoglobin iron does not interfere with the results. Every precaution was taken to obtain blood-free samples of serum, but it still remained desirable to know just bow much interference the presence of haemoglobin could cause. As the proteins are precipitated by addition of trichloracetic acid to the serum, any haemoglobin molecules which are present should, theoretically, be removed with their iron attached. It is possible, nevertheless, that the previous incubation with hydrochloric acid might split ' off some haemoglobin iron. Serum from slightly haemolysed blood specimens was therefore analysed as to its iron content, the haemoglobin concentration being estimated photo-electrically in a portion of the same sample. The results showed that up to 10 per cent haemoglobin could be present before the serum iron level was affected. This represented fairly gross macroscopic haemolysis (Table 3). On these findings, it can be accepted that a slight degree of haemolysis does not significantly interfere with the estimation of the nonhaemoglobin serum iron.

Basic Salt Formation: In dealing with such low dilutions of a metal, the possibility of basic salts forming a fine insoluble precipitate, and so interfering with light 
absorption during photo-electric estimation, had to be considered. To eliminate the possibility of formation of such a salt, $1 \mathrm{ml}$. concentrated sulphuric acid solution was added at each estimation over a short period. It became obvious that there was no change in the results obtained and its addition was discontinued. Accuracy of the Blank: The blank usually gave a reading of 15-25ug.\% when compared with distilled water, but was never more than $35 \mathrm{ug}$. \%. Variation of the blank itself might therefore have been partly responsible for errors recorded in analyses.

POTASSIUM FERRICYANIDE TECHNIQUE.

Fitzpatrick and Howell's potassium ferricyanide method was also investigated as to its reliability. Its greatest advantage was the saving of time in making estimations.

Reagents Required:

(I) Hydrochloric Acid, $5 \%(\mathrm{~V} / \mathrm{V})$.

(2) Trichloracetic acid, 20\% (W/V).

(3) Hydrazine sulphate, $1 \%(\mathrm{~W} / \mathrm{V})$, prepared fresh before use.

(4) Potassium ferricyanide, 10\% (W/V). 


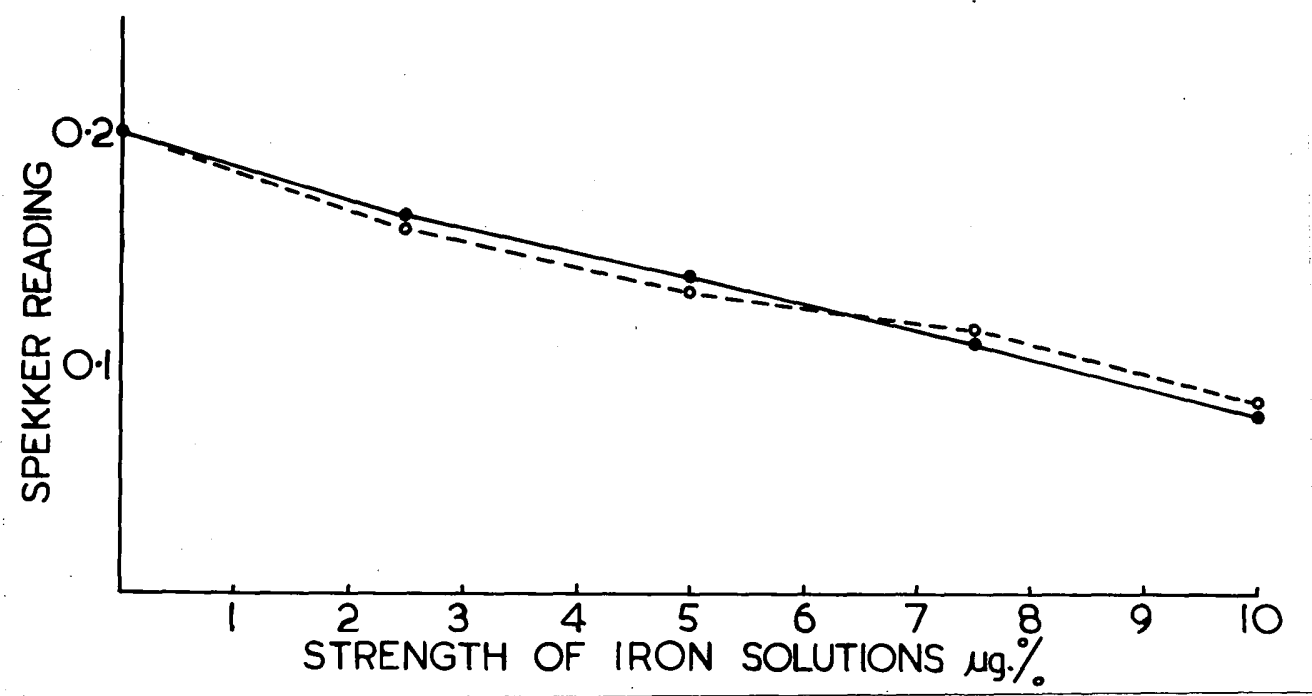

Fis.2. Curves obtained on estimating the iron content of serial dilutions of ferrous sulphate of known concentration - ferricyanide method. 
All solutions were filtered through Whatman's No.42 filter paper which had been washed in acid, rinsed in double distilled water and dried.

Analytical Procedure: A mixture of $4 \mathrm{ml}$. of serum and $2 \mathrm{ml}$. of $5 \%$ hydrochloric acid was incubated at $37^{\circ} \mathrm{C}$. for $1 \frac{1}{2}$ hours. After cooling to room temperature, $2 \mathrm{ml}$. of $20 \%$ trichloracetic acid solution was added to precipitate the proteins. The mixture was allowed to stand overnight and was then centrifuged. $4 \mathrm{ml}$. of the supernatant fluid was transferred to another test tube, and to this was added successively $1 \mathrm{ml}$. of $1 \%$ hydrazine sulphate solution, $1 \mathrm{ml}$. of potassium ferricyanide solution and $4 \mathrm{ml}$. of glassdistilled water. The material was well mixed after each addition. After 15 minutes, the depth of colour was estimated in a Spekker Photo-electric Absorptiometer, using a $1 \mathrm{~cm}$. cell and a Spekker red filter OR2.

The blank was prepared using $4 \mathrm{ml}$. of glass-distilled water in place of serum.

A satisfactory standard curve was obtained by estimation of samples of ferrous sulphate solution of known iron content, and in this method also, the curve was easily reproduced (Fig. 2). Colour development was static between 15 minutes and $2 \frac{1}{2}$ hours from adding the last of the reagents.

Recovery of known quantities of iron from ferrous sulphate solutions in water and from serum with ferrous 
Table 4. Recovery of iron from aqueous ferrous sulphate solutions of known iron concentration - potassium ferricyanide method.

\begin{tabular}{|c|c|c|c|}
\hline \multirow{2}{*}{$\begin{array}{l}\text { Sample } \\
\text { No. }\end{array}$} & \multicolumn{2}{|c|}{ Iron content, ug.\% } & \multirow[t]{2}{*}{ Difference } \\
\hline & Calculated & Estimated & \\
\hline 1 & 50 & $\begin{array}{l}42) \\
48\end{array} 45$ & -5 \\
\hline 2 & 100 & $\begin{array}{r}106 \\
98 \\
103\end{array}$ & +3 \\
\hline 3 & 200 & $200) 196$ & -4 \\
\hline 4 & 300 & $\begin{array}{l}305 \lcm{298} \\
290\{\end{array}$ & -2 \\
\hline
\end{tabular}

No significant difterence between calculated and estimated values.

Table 5. Iron content of serum before and after addition of a known quantity of iron as ferrous sulphate - potassium ferricyanide method.

\begin{tabular}{|c|c|c|c|c|c|}
\hline $\begin{array}{l}\text { Sample } \\
\text { No. }\end{array}$ & $\begin{array}{l}\text { Before add- } \\
\text { ition of } \\
\text { iron, ug. }\end{array}$ & $\begin{array}{l}\text { Amount of } \\
\text { iron added, } \\
\text { ug. }\end{array}$ & $\begin{array}{l}\text { After add- } \\
\text { ition of } \\
\text { iron, } u g . \%\end{array}$ & $\begin{array}{l}\text { Iron re- } \\
\text { covered }\end{array}$ & $\begin{array}{l}\text { biff- } \\
\text { erence }\end{array}$ \\
\hline 1 & $\begin{array}{l}60) \\
56) \\
48\}\end{array}$ & 100 & $\begin{array}{l}150) \\
148) 148 \\
146)\end{array}$ & 93 & -7 \\
\hline 2 & $\left(\begin{array}{l}130 \\
126 \\
130\end{array}\right) 129$ & 100 & $\begin{array}{l}236\} \\
239 \\
230\}\end{array}$ & 106 & +6 \\
\hline 3 & $\left(\begin{array}{l}160 \\
151 \\
160\end{array}\right) 157$ & 200 & $\left.\begin{array}{l}352 \\
342 \\
348\end{array}\right\} 347$ & 190 & -10 \\
\hline 4 & $\left.\begin{array}{l}125 \\
119 \\
116\end{array}\right) 120$ & 50 & $\begin{array}{l}174) \\
170) 171 \\
170)\end{array}$ & 51 & +1 \\
\hline
\end{tabular}

No significant difference between "Before + Amount added" and "After " values. 
Table 6. Comparison of results obtained by orthophenanthroline and potassium ferricyanide methods of estimations ror serum iron.

\begin{tabular}{|c|c|c|c|}
\hline \multirow{2}{*}{$\begin{array}{l}\text { Serum } \\
\text { Sample } \\
\text { No. }\end{array}$} & \multicolumn{2}{|c|}{ Iron Content in ug. $\%$} & \multirow{2}{*}{$\begin{array}{l}\text { Differ- } \\
\text { ence } \\
\text { ? }\end{array}$} \\
\hline & $\begin{array}{l}\text { Orthophenanthroline } \\
0\end{array}$ & Ferricyanide & \\
\hline I & 56 & 60 & 4 \\
\hline 2 & I09 & I02 & 7 \\
\hline 3 & I80 & I60 & 20 \\
\hline 4 & IIO & II5 & 5 \\
\hline 5 & $203-$ & I96 & 7 \\
\hline 6 & 90 & 92 & 2 \\
\hline 7 & II4 & $I 20$ & 6 \\
\hline 8 & I40 & I32 & 8 \\
\hline 9 & I38 & 130 & 8 \\
\hline IO & I58 & 146 & $I 2$ \\
\hline
\end{tabular}

No significant difference statistically between orthophenanthroline and ferricyanide'methods. 
sulphate added show an error similar to that obtained by the orthophenanthroline method and not statistically significant (Tables 4 \& 5). In this method also, haemolysis of slight degree caused no interference in estimation of the iron content of the serum. Comparison of Methods.: Analyses of the same sera by each method showed very satisfactory agreement, the differences between one method and the other not being statistically significant (Table 6). This satisfactory agreement meant that the one method could be substituted for the other at any time. SUMMMARY.

Investigation as to the reliability of the orthophenanthroline and potassium ferricyanide techniques for serum iron estimation, and for recovery of iron added to water and serum, has shown that consistent results can be obtained by both methods, and that these results are closely comparable. No interference is caused by the presence of small amounts of haemoglobin iron, or by basic salt formation. 
PART IV.

SERUM IRON IN NORMAL INDIVIDUALS

AND ITS RELATION TO AGE, SEX, AND TIME OF DAY.

The orthophenanthroline technique of Tompsett and the potassium ferricyanide method of Fitzpatrick have been shown to be reliable for estimation of serun iron. Before applying the methods to the study of pathological cases, it was necessary to establish the range of serum iron levels compatible with health.

Material Examined:

For this purpose, estimations of serum iron were made on 120 healthy individuals of both sexes, with ages ranging from 18 to 69 years. Samples of blood were taken between 9 and $10 \mathrm{a.m}$. after a breakfast of tea and toast only. Of this group, 6 men and 6 women were followed weekly for 8 weeks. In 3 men and 3 women, samples of blood were taken at short intervals following a substantial meal. In 30 individuals, samples were taken at intervals during a whole day.

Normal Values:

Surveys of normal values for serum iron levels have been published by numerous workers. Their results show fairly close agreement, in some instances differences possibly being due to the method chosen for estimation rather than to 
Table 7. Serum iron concentration in normal individuals as observed by various investigations.

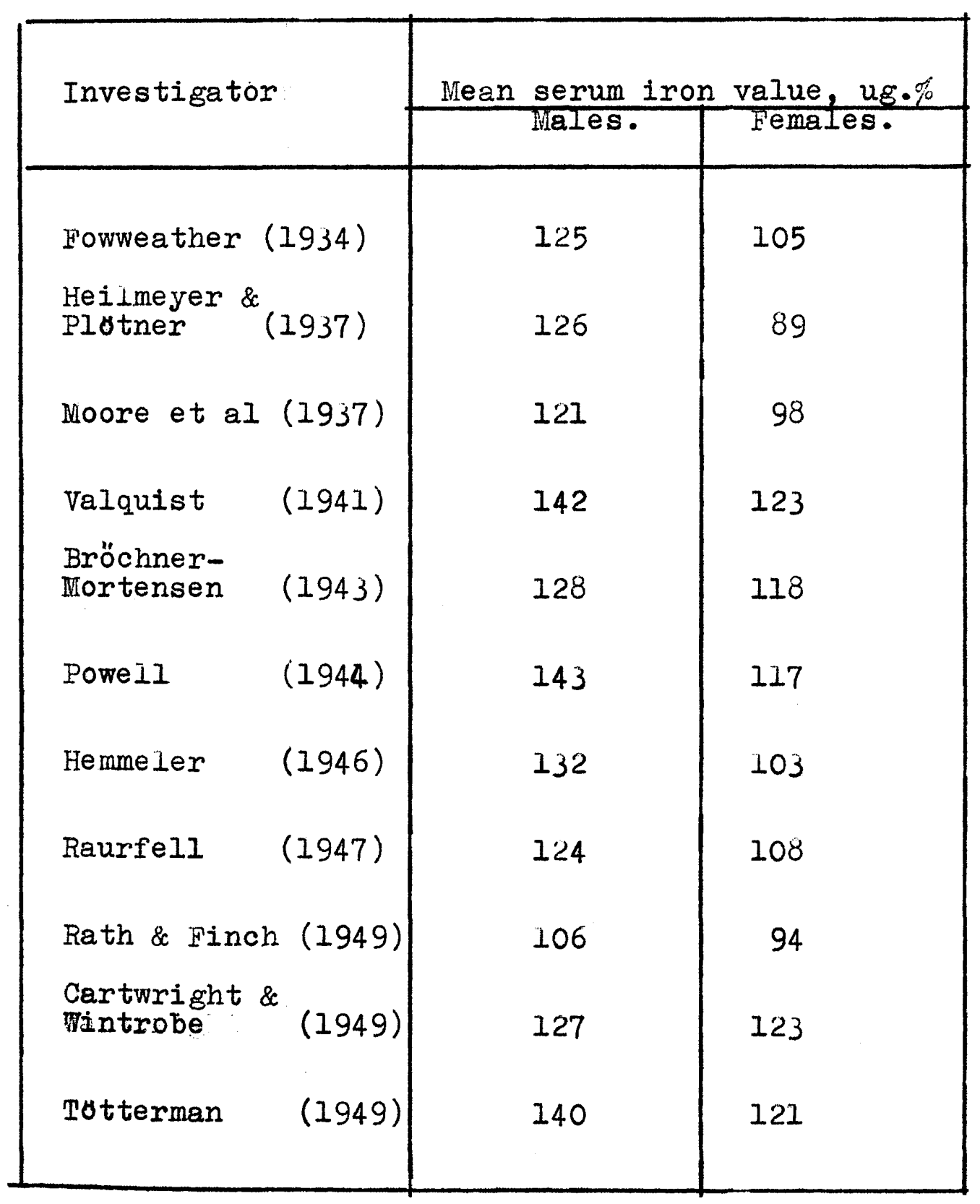




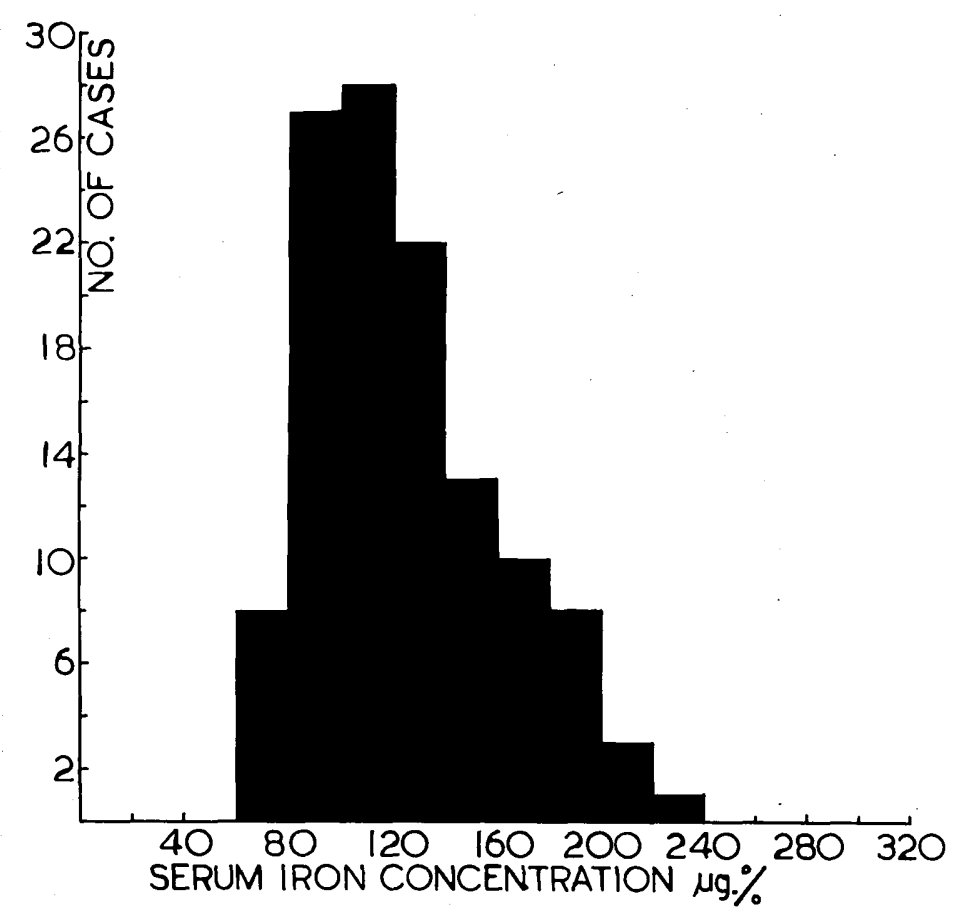

Fig. 3. Distribution of serum iron levels in normal people (I20 subjects). 


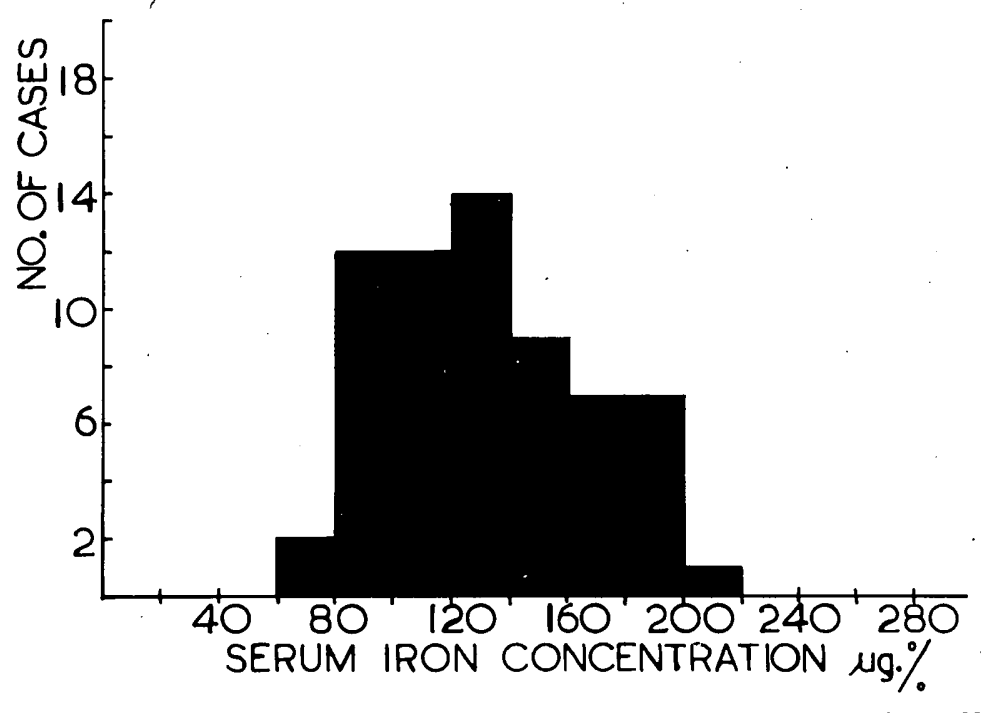

Fig.4. Distribution of serum iron levels among: males of the series. (64 subjects)

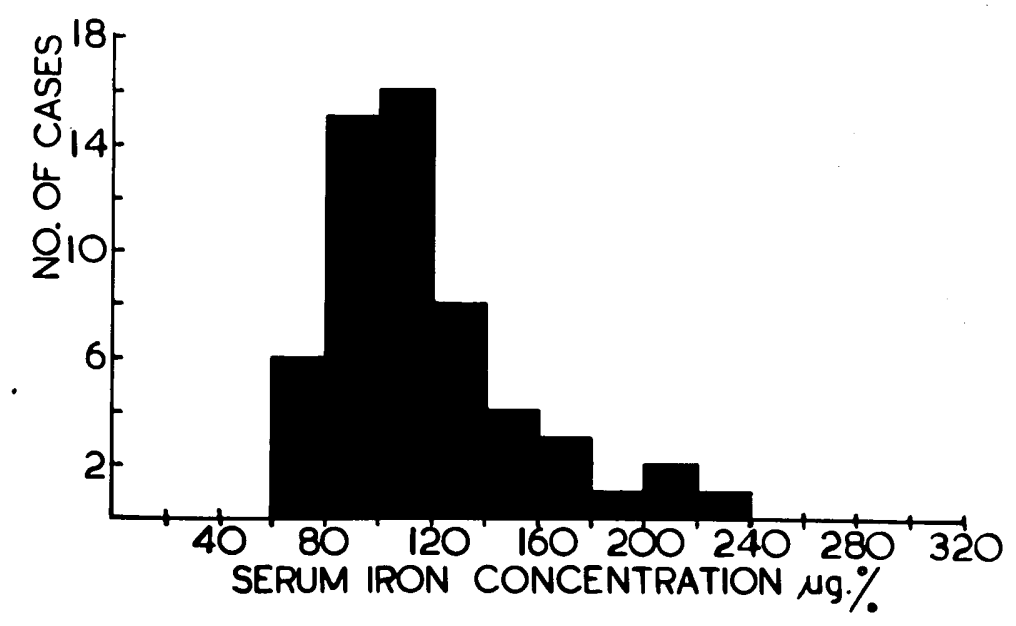

Fig. 5. Distribution of serum iron levels among females of the series. ( 56 subjects) 
the clinical material used. All except Cartwright and Wintrobe (1949) find a sex difference (Table 7). Tytterman (1949) after making a detailed review of all the figures available, concluded that normal values range from 65-180 ug.\% for females and from 70-210 ug.\% for males. Values of over $200 \mathrm{ug. \%}$ tend to be isolated occurrences. Valquist mentioned one such case. Tutterman recorded it in 2 females and 7 males, and indeed found levels of up to 298 ug.\% associated with no observable clinical abnormality. In the opinion of most authors, these very high levels are simply representative of a physiological hypersideraemia. Hoyer (1946) did not conform to this belief, but gave no reason why he considered such levels pathological. The lower border of normality is $60-70$ ug.\% but occasional values below $60 \mathrm{ug} . \%$ have been found in people not apparently ill.

The results obtained in this investigation are presented in Figs. 3, 4 \& 5. The group showed a range of $65-220 \mathrm{ug} . \%$. Males showed levels of 65-205 ug.\% with a mean of $129 \mathrm{ug} . \%$, while females varied from 60-220 ug.\% with a mean of $113 \mathrm{ug} . \%$. The diagrams representing distribution indicate clearly that, although the expected range of readings for each sex is approximately the same, only about a third of the women have levels over $120 \mathrm{ug} . \%$ while nearly two thirds of the men exceed this level. The difference is significant statistically. The reason for the large difference between one 
35

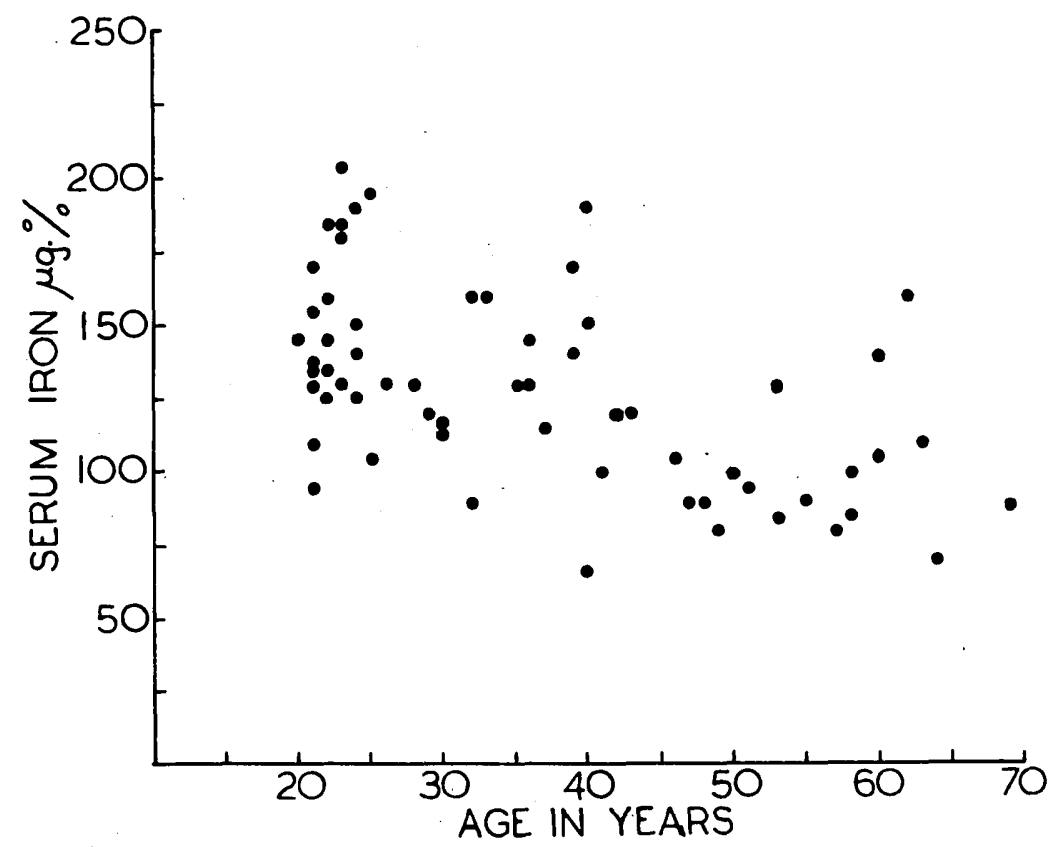

Fig. 6. The relationship of serum iron to age in normal males ( 64 cases).

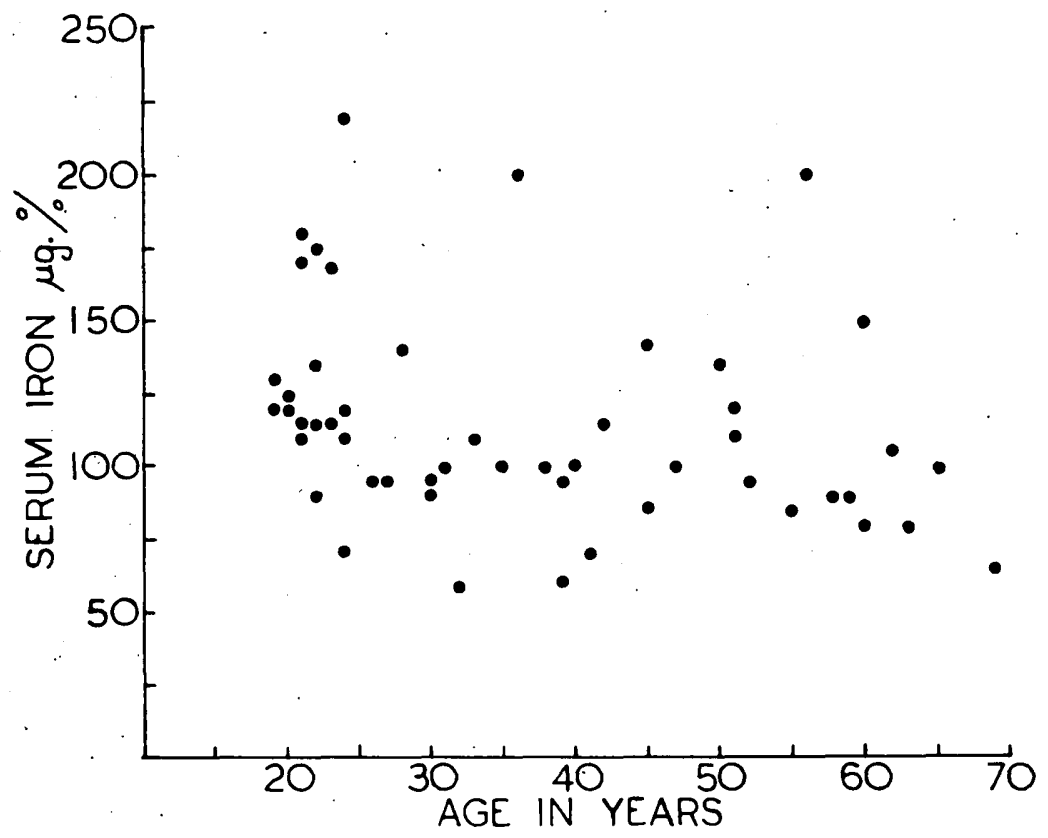

Fig. 7. The relationship of serum iron to age in normal females ( 54 cases). 
individual and another, and for the marked sex difference, has not yet been satisfactorily explained. The influence of age on the serum iron:

The effect of age has not often been considered. Valquist (1941) found that, below the age of 7 years, the serum iron level for both sexes was relatively low. It subsequently showed a rise until puberty when the sex difference developed due to a flattening-out of levels amongst females and a continued slight rise amongst males. A fall in old age was demonstrated by Albers (1941) and Eckerstrom (1944), both workers dealing with groups of mixed sexes.

Analysis of the present material, split into male and female groups, showed that there was a tendency for the level to fall with increasing age in males (Fig. 6). This was not apparent in females (Fig.7). As the level for males was higher than for females in the younger age groups, this meant that, with advancing years, the concentration in males approximated to the level maintained by females through-out adult life. Valquist's observation that sex differences in serum iron levels first developed at puberty suggested that endocrine function rather than age itself influenced the concentration.

Sex difference in relation to serum iron:

The sex difference was assumed by Heilmeyer \& PI Utner (1937) and Skouge (1939) to be the result of iron loss due 
to menstruation. If this were true, Valquist expected that it should be corrected by administration of oral iron to menstrual women. He was, however, unable to raise the average semum iron level in a group given intensive oral iron treatment and as he was also unable to demonstrate a higher average in women who had undergone hysterectomy, he was of opinion that the sex difference was not due to blood loss, but was probably of endocrine origin. AIbers (194I) and Eckerstrom (1944) found no difference in the average serum iron level of post-menopausal women and menstruating women. The data of Guthman (1931), Powell (1944), and Dahl (1948), however, revealed a lower serum iron level in women during the actual phase of menstrual blood loss and Dahl (1948) and Hemmeler (1939) found a lower average level for women during their menstrual Iife than for girls just before puberty or for women after the menopause. This they regarded as evidence that menstrual blood loss was at least in part responsible for lower levels in women. They infer that the changes were caused by whole blood loss, and do not refer to any possibility of endocrine control.

In the present series of females, analysis according to whether or not menstruation was occuring at the time of making single estimations showed no correlation between serum iron concentration and the menstrual cycle. The 


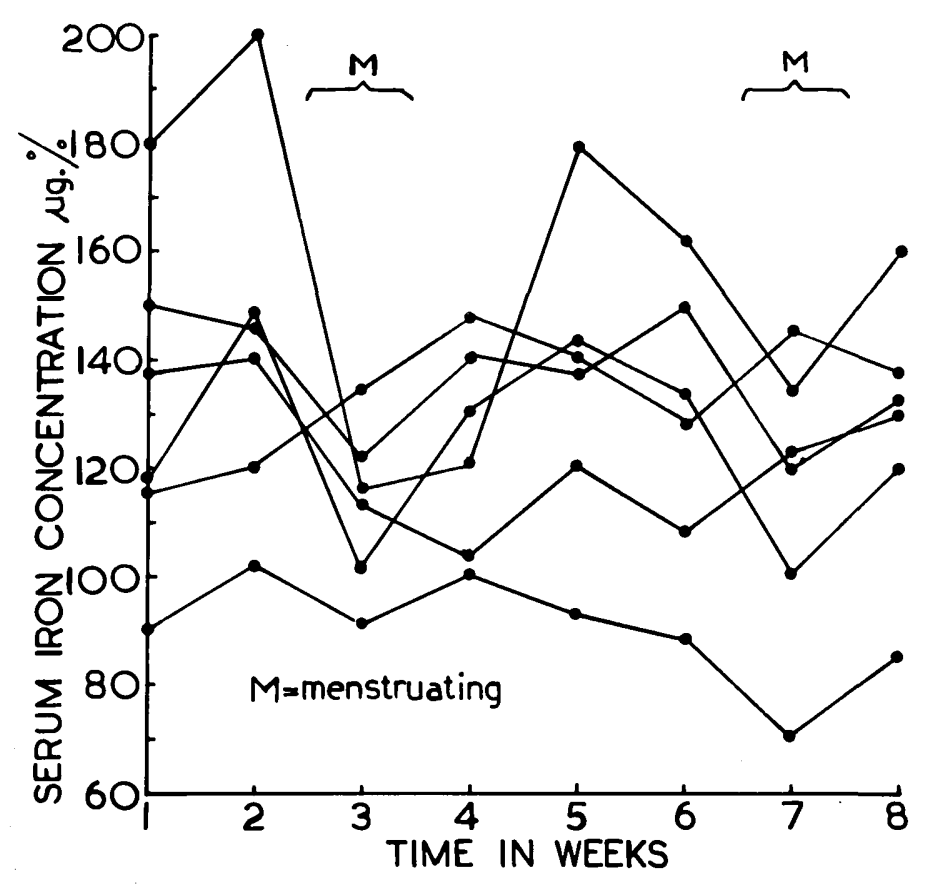

Fig. 8. Weekly serum iron levels in 6 normal women of menstrual age.

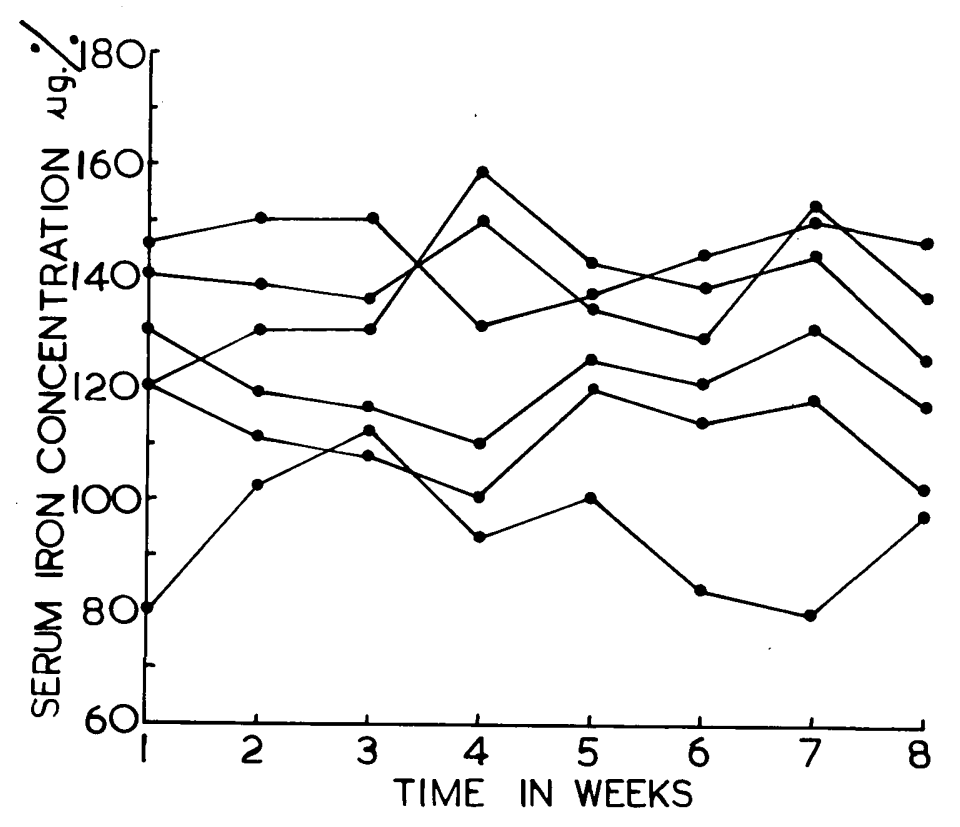

Fig. 9. Weekly serum iron levels in 6 normal men. 
curves obtained for six normal women followed weekly for 8 weeks do, however, show a distinctive pattern. This pattern is not evident in 6 men followed in similar manner (Fig. $8 \& 9$ ). In 4 of the females, the lowest values were recorded during the actual period of blood 1oss. In the two others, although the variation was not rhythmic in association with menstruation, it was wider than that observed in any of the men. In the 6 males, fluctuation in level was less marked, ana showed no constant cyclic pattern.

In interpreting these findings, two factors must be borne in mind; firstly, the possible direct effect of blood loss in altering the serum iron, and secondly, the possibility of endocrine control influencing iron metabolism. All workers who note changes in serum iron concentration in association with menstruation are agreed that there is a reduction in level during the time of menstrual flow. It seems unreasonable to attribute this reduction to the blood loss, as various workers have shown that when iron stores are adequate, there is no immediate change in the serum iron following relatively massive haemorrhage, any fall being delayed until stores are called upon for blood regeneration. This is usually observable about 7-10 days later. If menstrual blood loss were going to affect the serum iron, it would not therefore become apparent until the following 
week. Moreover, it has been shown that repeated monthly bleeding of healthy males in amounts to correspond to menstrual blood loss has no effect on the serum iron. It therefore seems that an endocrine influence, as suggested by Valquist (1941), is the more likely controlling factor, but further direct proof that such operates in relation to the serum iron level in humans is lacking. It is of interest in this connection that Shaerer and Rechenberger (1948) found an increase in storage iron in men from young adult life onwards, and in women not until late middle life, while Steenbock et al. (1936) and Rose \& Hubbell (1938) caused a decrease in iron storage in adult female rats by ovariectomy and an increase in storage in immature female rats by administration of follicular hormone. Diurnal variability of serum iron:

In addition to fluctuation in serum iron levels from week to week, diumal variability has often been reported. Lower serum iron levels in the evenings were reported by Valquist (1941), Hemmeler (1944), Hoyer (1946), and Waldenstrom (1946), but Westral (1944) found a rise in the evening, and Moore (1936) no consistent directional change, although in his series fluctuation was as great as 35 ug. \% . 
l'able 8. Values tor diurnal serum iron levels in 30 normal people $-u ̛ \cdot \%$

\begin{tabular}{|c|c|c|c|c|c|}
\hline No. & 9 a.m. & 1 p.m. & 9 p.m. & $\left(\begin{array}{l}9 \text { a.m. } \\
\text { day. })\end{array}\right.$ ('2na & $\begin{array}{l}\text { Maximum } \\
\text { Variation. }\end{array}$ \\
\hline $\begin{array}{l}1 \\
2 \\
3 \\
4 \\
5 \\
6 \\
7 \\
8 \\
9 \\
10 \\
11 \\
12 \\
13 \\
14 \\
15 \\
16 \\
17 \\
18 \\
19 \\
20 \\
21 \\
22 \\
23 \\
24 \\
25 \\
26 \\
27 \\
28 \\
29 \\
30\end{array}$ & $\begin{array}{r}158 \\
162 \\
160 \\
170 \\
145 \\
206 \\
176 \\
159 \\
135 \\
105 \\
100 \\
112 \\
100 \\
115 \\
130 \\
112 \\
108 \\
120 \\
125 \\
100 \\
87 \\
103 \\
100 \\
132 \\
103 \\
75 \\
75 \\
65 \\
60 \\
71\end{array}$ & $\begin{array}{r}163 \\
150 \\
159 \\
157 \\
120 \\
180 \\
166 \\
150 \\
143 \\
122 \\
105 \\
99 \\
90 \\
105 \\
100 \\
116 \\
100 \\
144 \\
145 \\
120 \\
95 \\
80 \\
112 \\
140 \\
93 \\
95 \\
80 \\
75 \\
67 \\
80\end{array}$ & $\begin{array}{r}150 \\
125 \\
130 \\
185 \\
165 \\
160 \\
151 \\
152 \\
140 \\
90 \\
130 \\
100 \\
95 \\
115 \\
103 \\
105 \\
70 \\
120 \\
122 \\
125 \\
80 \\
85 \\
97 \\
150 \\
80 \\
90 \\
90 \\
85 \\
90 \\
70\end{array}$ & $\begin{array}{r}170 \\
150 \\
158 \\
178 \\
145 \\
187 \\
170 \\
160 \\
130 \\
100 \\
96 \\
98 \\
105 \\
120 \\
126 \\
110 \\
114 \\
131 \\
134 \\
116 \\
105 \\
102 \\
102 \\
126 \\
96 \\
77 \\
90 \\
81 \\
58 \\
65\end{array}$ & $\begin{array}{l}70 \\
37 \\
30 \\
28 \\
45 \\
46 \\
19 \\
18 \\
8 \\
32 \\
34 \\
14 \\
15 \\
15 \\
30 \\
11 \\
44 \\
24 \\
23 \\
25 \\
25 \\
23 \\
15 \\
24 \\
15 \\
20 \\
15 \\
20 \\
32 \\
15\end{array}$ \\
\hline
\end{tabular}

After correcting for the difference between individuals it is found (by analysis of variance) that there is no significant diurnal variation. 


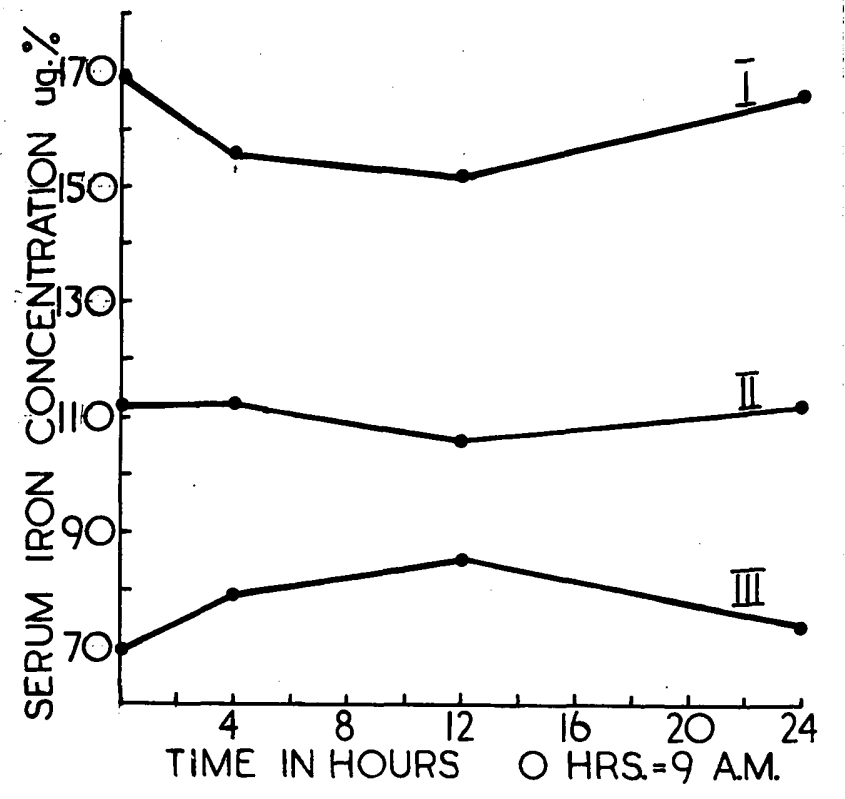

Fig.IO. Mean diurnal variations in serum iron when cases are divided into 3 groups according to the height of the morning value.

Group I:- I40 ug.\% and over; Group II:- 80 - I39 ug.\% Group III:- 79 ug.\% and under.

Statistical evaluation (by analysis of variance) shows no significant difference between the groups. 
In a group of 30 normal individuals on an ordinary light diet, the serum iron was estimated at intervals during 24 hours. Samples of blood were taken at 9 a.m., I p.m., 9 p.m., and 9 a.m. on the following day. There was no uniform directional change, (Table 8), but when the series was divided into three groups according to whether the initial levels were high, average or low, the mean curve for each group appeared to be distinctive (Fig. 10). Statistical evaluation, however, revealed (by analysis of variance) that, after correcting for the difference between individuals, there was no significant diurnal variation. It had appeared that individuals with a relatively high morning level showed a fall during the day-time and a rise during the night, while those with low initial levels showed reverse changes. There was no characteristic directional variation in the middle group, Arelationship between the direction of diurnal variation and the morning serum iron level was noticed by Thedering (1949) and attributed by him to autonomic influence. Statistical analysis by him of all figures previously given by other workers for 24 hours showed an exactly similar pattern with a variability which was just significant. It is doubtful whether division of the cases in this manner adds any information of value. The fact that such curves can be drawn suggests a 24-hour 


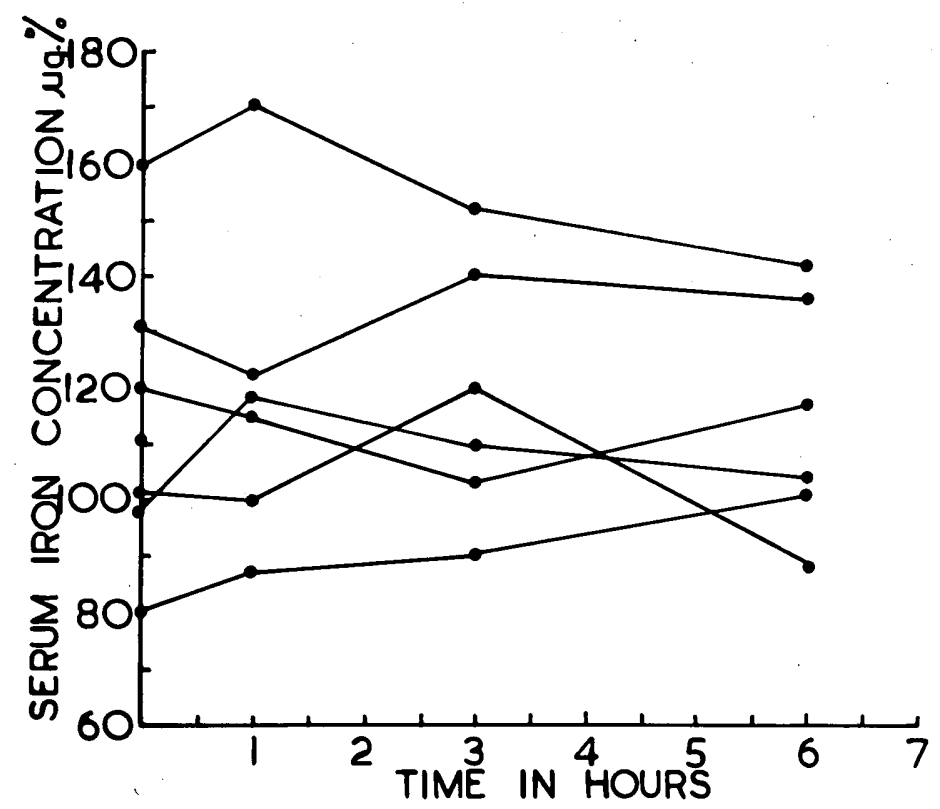

Fig. 11. Variations in serum iron concentration following a meal of average iron content. 
rhythm, but the direction which the curve appears to follow must be dependent upon the point at which the cycle is interrupted to obtain the initial specimen. The influence of diet and control by the liver:

To observe the possible effect that the taking of meals may have had during the day, the serum iron level was followed more closely after a substantial meal. In 3 normal men and 3 normal women, it was evaluated immediately before and at 1,3 , and 6 hours after a meal containing meat, green vegetables and fruit (Fig. 11). No consistent change was found, and it was concluded that an average diet does not significantly influence the serum iron. Similar negligible changes were reported by Heilmeyer \& Pl 8 tner, (1937), Skouge, (1939), and Moore et al. (1939a). Waldenstrom (1946) believed that food may nevertheless have an indirect effect on serum iron concentration through promoting changes in liver function, and he suggested that the differences in hepatic metabolism during the hours of waking and of eating, as compared with during sleep, may provide the explanation of diurnal variation. Finch et al. (1950) in discussing the pathophysiology of iron storage, state that the ability of the liver to store iron will regulate the level obtained in the serum. 
SUMMIARY.

In agreement with other workers, the range of normal for serum iron concentration has been found to be wide, and to show a distinct sex difference. The average level for men is 129 ug.\% and for women 113 ug.\% In women menstruation is associated with a decrease in serum iron. Present evidence favours this being due to endocrine influence rather than to blood loss. In men between 20 and 65 years, there is a tendency for the serum iron to fall with age, a finding that is not observed in women. It may be masked in women because of the lower levels relative to men in the middle-aged group. Endocrine influence rather than age itself may again be the more important factor in producing this difference. A diurnal cycle is observed causing changes in serum iron concentration of an average of $25.7 \mathrm{ug} . \%$ within the 24 hours, but the variation on the present work is not significant statistically. The taking of meals has not been demonstrated as affecting the serum iron but the possibility must be considered that changes in liver function as a result of its metabolic activity in relation to digestion are partly responsible for changes in serum iron concentration. 


\section{PART V.}

\section{SERUM IRON LEVELS IN PATHOLOGICAL CONDITIONS.}

\section{SINGLE OBSERVATIONS ON SERUM IRON IN VARIOUS}

TYPES OF ANAEMIA BEFORE TREATMENT.

The range of semum iron levels compatible with health having been investigated, attention was given to the changes which might be observed in disease. Estimations were made on blood samples taken between 9 and 10 a.m., from patients with various types of anaemia. The average values obtained are shown in Table 9. The results are in agreement with most reports published previously in which reasonable numbers of cases have been examined. Iron deficiency anaemia:

In the 59 cases of iron deficiency anaemia, whether of idiopathic or post-haemorrhagic type, the serum iron concentration was consistently below 63 ug.\% and actually exceeded $50 \mathrm{ug} . \%$ only in isolated instances (Fig.12). Valquist and Delachaux (1946) argued that reduction of the serum iron of the body was the first effect of iron deficiency, and might therefore actually precede any clinical symptoms, and probably preceded anaemia itself. Reference has already been made to the fact that they claimed to isolate 4 nonhaemoglobin iron fractions in serum. It is doubtful whether 
Table 9. Range of serum iron values in various types of anaemia before treatment.

\begin{tabular}{|c|c|c|c|}
\hline \multirow[t]{2}{*}{ Type of angemia } & \multirow[t]{2}{*}{ No. of cases } & \multicolumn{2}{|c|}{ Serum iron, $u_{0}$} \\
\hline & & Range & Average \\
\hline Iron deficiency & 59 & $I 5-63$ & 37 \\
\hline Pernicious anaemia & 34 & $34-273$ & I52 \\
\hline Haemolytic anaemia & I2 & $40-302$ & I58 \\
\hline Refractory normoblastic & 68 & $32-170$ & 67 \\
\hline Toxic states & I6 & $32-I 45$ & 72 \\
\hline Infections (other than & I8 & $45-92$ & 65 \\
\hline Neoplastic diseases & 34 & $38-I 70$ & 65 \\
\hline Infective hepatitis & 6 & $83-26 I$ & I59 \\
\hline
\end{tabular}




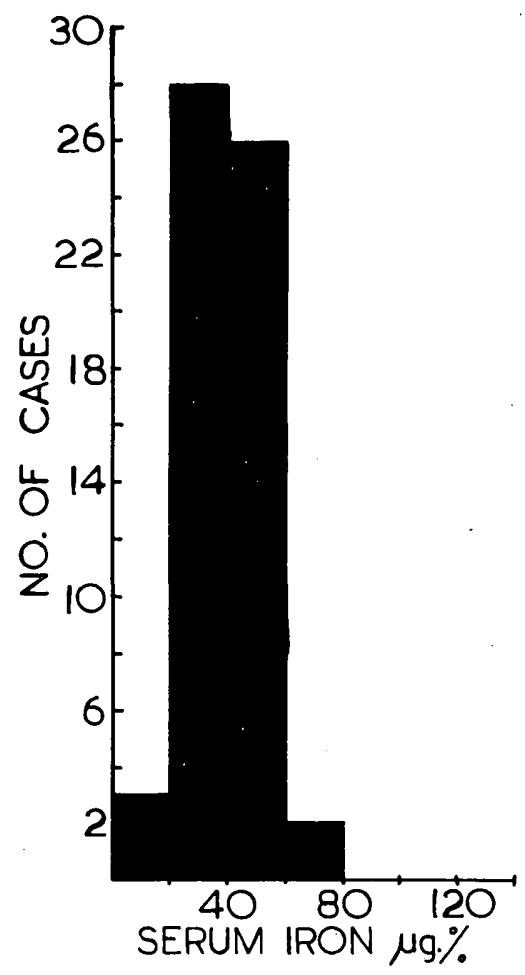

Fig. 12. Distribution of serum iron levels in iron deficiency anaemia ( 59 cases).

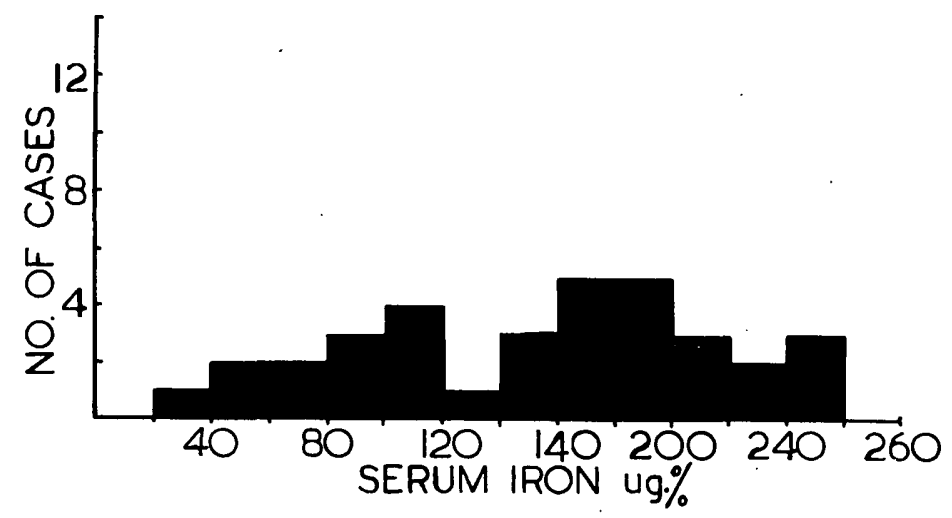

Fig. 13. Distribution of serum iron levels in untreated pernicious anaemia (34 cases). 
this fractionation had any clinical significance, but they maintained that they could demonstrate one factor particularly concerned with tissue oxidation. On this basis, they explained the rapid response of epithelial lesions in iron deficiency when medicinal iron was given to make good that deficiency. They described cases, not anaemic, in which koilonychia, glosgitis or cheilosis were the only pathological features which could be indicative of iron depletion, and in which oral administration of iron produced immediate and steady improvement. This supported their view that tissue hyposideraemia could exist apart from iron deficiency hypochromic anaemia. Their work gives a possible scientific background to clinical facts previously recognised. Amongst others, Waldenstrom (1938) gave excellent photographs of koilonychia, cheilosis, glossitis and oesophageal narrowing existing apart from anaemia, and disappearing completely after iron therapy. Pernicious anaemia:

In the 34 cases of pernicious anaenia, serum iron values were widely scattered (Fig. 13). The average level of 152 ug.\% was much in excess of normal and highly significant statistically. The relatively high levels are in ggreement with results already published. Low levels have 
Table 10. Serum iron values in pernicious anaemia as compared with results published by other investigators.

\begin{tabular}{|l|c|c|}
\hline Investigator & $\begin{array}{c}\text { No. of } \\
\text { Cases. }\end{array}$ & $\begin{array}{l}\text { Kange of serum iron } \\
\text { concentration, ug.\% }\end{array}$ \\
\hline Moore et al. (1939a) & 11 & $147-348$ \\
Brychner-ilortensen(1936) & 15 & $135-256$ \\
Laureil(194\%) & 17 & $113-286$ \\
Present work & 34 & $34-273$ \\
\hline
\end{tabular}

Table 11. Serum iron concentration in relation to blood values in untreated pernicious anaemia.

\begin{tabular}{|c|c|c|c|c|c|c|}
\hline No. & $\mathrm{Hb} \cdot-\mathrm{gm}$. & $\begin{array}{l}\mathrm{R} \cdot \mathrm{B} \cdot \mathrm{C} \cdot \mathrm{mills} \\
/ \mathrm{c} \cdot \mathrm{mm} .\end{array}$ & P.C.V. & $|\mathrm{H} \cdot \mathrm{C} \cdot \mathrm{V} \cdot|$ & $\mathrm{H} \cdot \mathrm{C} \cdot \mathrm{H} \cdot \mathrm{C}$. & $\begin{array}{l}\text { Serum } \\
\text { iron } \\
\text { ug. }\end{array}$ \\
\hline $\begin{array}{r}1 \\
2 \\
3 \\
4 \\
5 \\
6 \\
7 \\
8 \\
9 \\
10 \\
11 \\
12 \\
13 \\
14 \\
15 \\
16 \\
17 \\
18 \\
19 \\
20\end{array}$ & $\begin{array}{c}6.35 \\
5.2 \\
6.9 \\
5.2 \\
4.14 \\
6.1 \\
9.94 \\
7.4 \\
4.14 \\
4.7 \\
9.9 \\
5.33 \\
10.0 \\
7.6 \\
9.3 \\
9.35 \\
9.93 \\
8.6 \\
10.5 \\
7.87\end{array}$ & $\begin{array}{l}1.54 \\
1.31 \\
1.60 \\
1.59 \\
1.10 \\
1.54 \\
2.34 \\
2.24 \\
1.05 \\
1.42 \\
2.46 \\
1.45 \\
2.95 \\
2.71 \\
2.43 \\
2.27 \\
2.36 \\
2.85 \\
3.07 \\
1.77\end{array}$ & $\begin{array}{l}18 \\
16 \\
20 \\
16 \\
14 \\
17 \\
28 \\
23 \\
12 \\
18 \\
32 \\
16 \\
27 \\
28 \\
29 \\
32 \\
32 \\
29 \\
30 \\
24\end{array}$ & $\begin{array}{l}116.9 \\
125.5 \\
125 \\
100.5 \\
127 \\
110 \\
119.6 \\
103 \\
114.3 \\
126.7 \\
132 \\
110.3 \\
92.0 \\
103.5 \\
119.0 \\
141 \\
136 \\
101.5 \\
97.9 \\
135.6\end{array}$ & $\begin{array}{l}35.3 \\
31.7 \\
34 \\
32.5 \\
27.8 \\
36.0 \\
35.5 \\
30 \\
34.5 \\
26.1 \\
30.9 \\
32.4 \\
31.0 \\
23.2 \\
32.0 \\
29.3 \\
31.1 \\
29.6 \\
35.0 \\
32.8\end{array}$ & $\begin{array}{r}273 \\
116 \\
200 \\
221 \\
34 \\
230 \\
136 \\
201 \\
173 \\
52 \\
150 \\
136 \\
143 \\
91 \\
26 \% \\
105 \\
73 \\
61 \\
113 \\
100\end{array}$ \\
\hline
\end{tabular}


not been so frequently observed as in this work and as they have usually been isolated observations in patients who had infection or neoplasm in addition to pernicious anaemia, they have been excluded from previous series reported. Iaurell's group of 17 cases is, however, the largest published, (Table 10), and it is possible that the bigger number in the present series may be responsible for disclosing the wider range.

Haemolysis has always been thought partly responsible for the raised serum iron in perncious anaemia, and the arrested function of the marrow may further raise the level by damming back iron that is not needed for blood formation. There are no grounds for questioning these theories in accounting for the raised results, but it is not clear why some cases have distinctly subnormal values. There was no relationship between the serum iron value and the degree of anaemia as indicated by the haemoglobin and red cell count (Table 1I). Consistently low levels in iron deficiency anaemia suggested that perhaps the lower concentrations in some cases of pernicious anaemia might reflect concurrent haemoglobin deficiency. An analysis made of the mean corpuscular haemoglobin concentration estimated within the same week as the serum iron in 25 cases, suggests that the cases with lower levels of M.C.H.C. are those with subnormal serum 
iron. (Table 1I). The H.C.H.C. is below $30 \%$ in 5 cases and all of these have less transport iron than is usual in pernicious anaemia. After liver injections they recovered without additional iron being given so that iron deficiency is not conclusively demonstrated, but findings to be discussed later in relationship to stainable marrow iron support the possibility that it did in fact exist in mild degree.

Haemolytic anaemia:

In the presence of haemolysis the serum iron is usually reported as elevated. The report by Powell (1944) is exceptional, as her cases all had levels within the nomal range. She suggested that, in such cases, the iron was being removed from the serum for haemoglobin regeneration at approximately the same rate as haemoglobin breakdown was going on in the reticulo-endothelial cells. Simultaneous storage of iron might also be taking place, and a raised serum iron level could therefore only be expected during acute haemolytic crisès and when haemoglobin breakdown exceeded iron utilization and storage.

The results of my own investigations are shown in Table 12. In cases 1 and 4 haemolysis was certainly severe. In cases ? and 3., it was of low grade chronic type. The relatively lower serum iron levels in the latter two are therefore in keeping with the idea that less rapid release of haemoglobin and the resultant smaller demand for red 


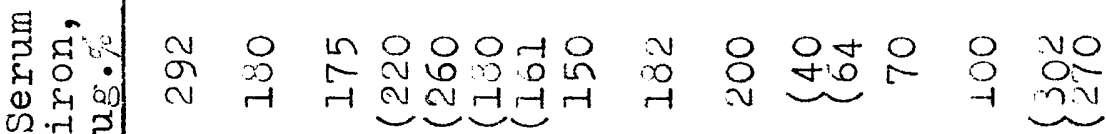

|

S

.

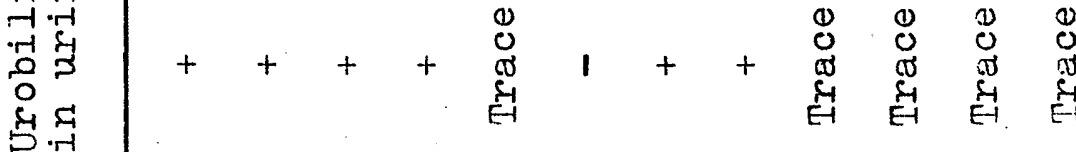

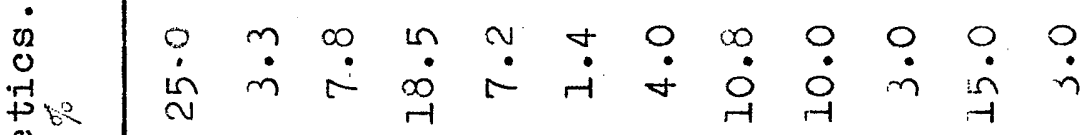

(1)

A-

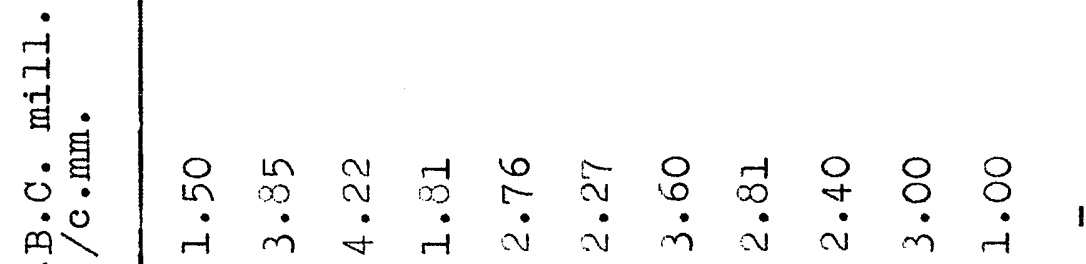



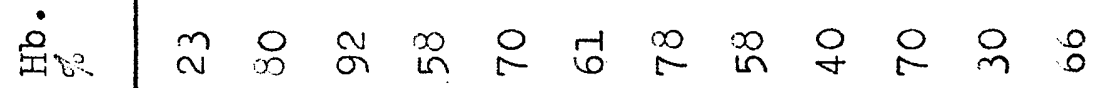

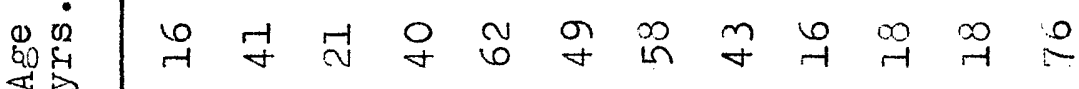

4.

()

O

$\frac{4}{\infty}$

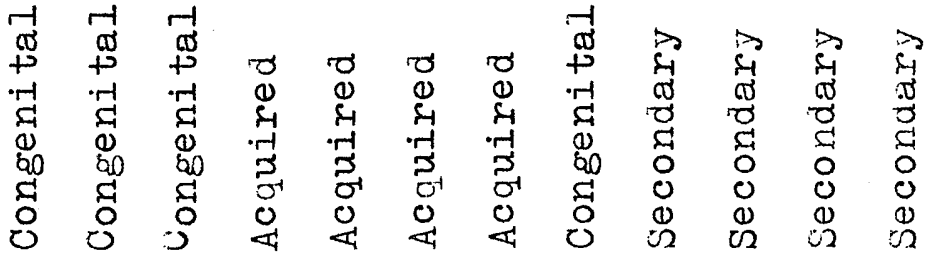


cell production cause a smaller increase in the transport iron. In Cases 9 \& 10, a subnormal serum iron level was recorded in spite of the fact that very transitony rises in the red cell count following blood transfusions indicated that destruction of red cells must have been rapid. From clinical investigations performed, the haemolysis was regarded as probably symptomatic in $\operatorname{Cas} \theta$ 9, although the existence of a primary disease was never established, and secondary to Iymphosar come in Case 10. It is possible therefore that some factor in addition to haemolysis was affecting the transport iron. In case 12 haemolysis was attributable to the presence of a high titre of cola agglutinins in the blood. Although there was persistent anaemia over the two years during which the patient was observed, the haemolysis was not at any time acute. The maintained high serum iron might therefore have been associated with some disturbance of the protein balance connected with the presence of the cold agglutinins. An increase in globulins might well be the responsible factor. An exact fractionation of the plasma proteins was unfortunately not performed, but it is well known that an increase in $\beta$-globulins can be associated with a high titre of cold agglutination, and, as discussed earlier, it is one of the $\beta-g l o b u l i n s$ which is responsible for binding iron in the serum. 
Infective, neoplastic \& toxic states:

AlI workers are agreed that infection is associated with a reduction in serum iron. Heilmeyer (1937) thought that until more was learned regarding the nature of anaemia in infection, and the anaemia of neoplastic disease, the two should be regarded as of similar aetiology. Fourteen years later, satisfactory discrimination has still not been made. In the present work infective, neoplastic and toxic states have been dealt with as one group and the distribution of serum iron levels obtained in 68 cases is represented in Fig.14. The pattern indicates that al though hypoferraemia predominates it is not so severe as in iron deficiency anaemia. The reduction in serum iron bore no direct relationship to the severity of the anaemia, and only in isolated cases was it associated with haemoglobin deficiency. (Patients known to have haemorrhage as a complicating factor were all excluded from the series). It was shown by Holmberg \& Iaurell.(1945), Laurell (1947), and Cartwright \& Wintrobe (1948) that the reduced serum iron in such conditions was associated with a reduction in the iron-binding capacity of the serum, but this could not be regarded as the limiting factor in determining the iron concentration because the reduction in serum iron was proportionately greater. Diversion of iron from the plasma 


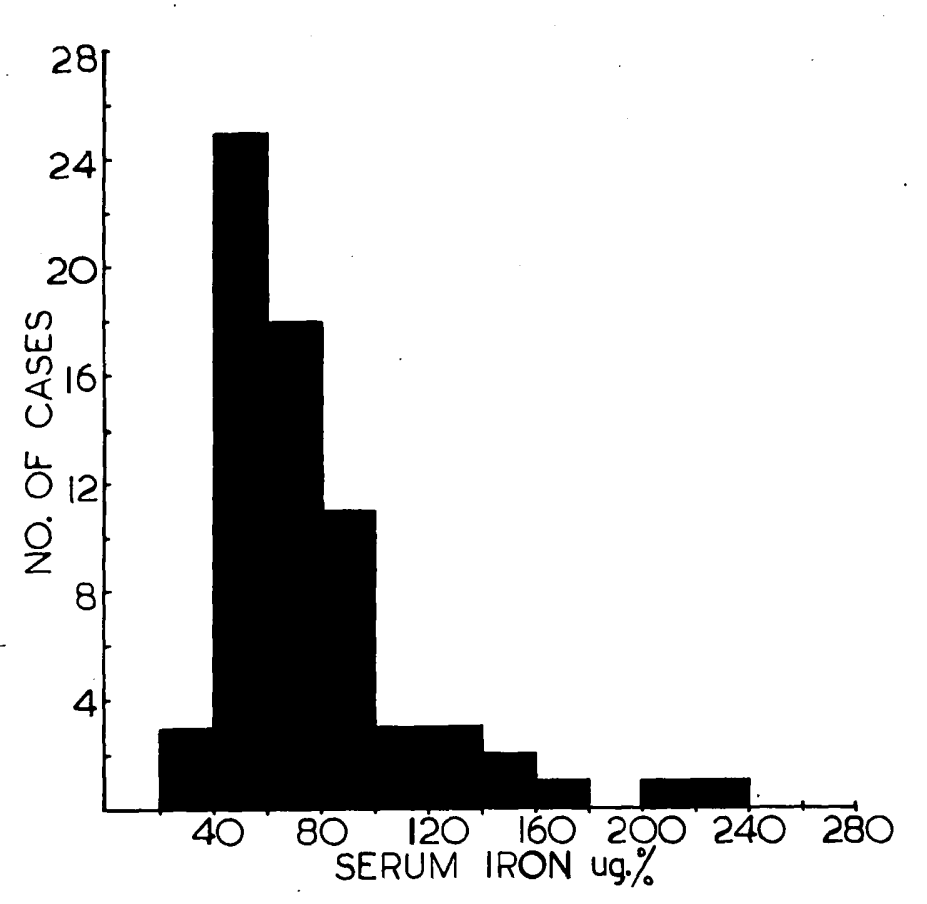

Fig. I4. Distibution of serum iron levels in anaemia associated with infective, toxic and neoplastic disease. 
to normal storage depots was demonstrated by Cartwright (1946), and in the present work, features of interest in relation to such diversion were revealed by intravenous iron disappearance curves and staining of marrow smears for iron. These will be discussed later. There is no evidence to indicate that iron loss by excess excretion can account for a reduction in transport iron in such conditions (Schaefer, 1940).

Infective hepatitis and other Iiver disorders:

The contrasting behaviour of the serum iron in infective hepatitis makes it advisable to consider this infection separately. In 6 cases the values recorded were $83,159,261,200,112$, and $140 \mathrm{ug} \%$. During the first week of illness high normal, or even greater values have been recorded (Hemmeler,(1946) ; Valquist, 1941; BrychnerMortensen, 1943; Laurell, 1947). Hemreler interpreted the finding as being indicative of defective iron excretion, but this seems a somewhat fallacious argument in the face of the many convincing experiments to show the very limited excretion of iron by any route at any time, excretion via the biliary tract being no exception. (Hawkins \& Hahn, 1944). Vannotti and Delachaux (1946) pointed out that deposition of iron in the liver was dependent upon the functioning of the hepatic parenchyma and reticulo-endothial cells. If the 
Iiver cells were damaged by disease they could not be expected to deal adequately with iron liberated from normal red cell breakdown, and this iron might therefore accumulate in the serum. In support of such a theory is their finding of normal serum iron values in patients with obstructive jaundice without evidence of intrinsic damage to liver cells. Iaurell (1947) favoured the theory that the regulatory function of the liver is put out of action, and that iron stored in liver cells in the form of ferritin is released into the serum when these cells are damaged during the acute phase of hepatitis. The serum ironbinding capacity is reduced during the initial phase, but is raised during regression of the infective process, at which time the serum iron begins to fall.

Hepatic cirrhosis is associated with low values for serum iron and a reduction in iron-binding capacity. This has been postulated as due to a defect in protein metabolism (Laurell, 1947).

Nephritis and Uraemia:

The results obtained in 9 cases of nephritis (included in the main series of refractory anaemias) can be considered separately in respect of certain features (Table (13.). In these patients the problem immediately arises regarding the relationship between serum iron, plasma 


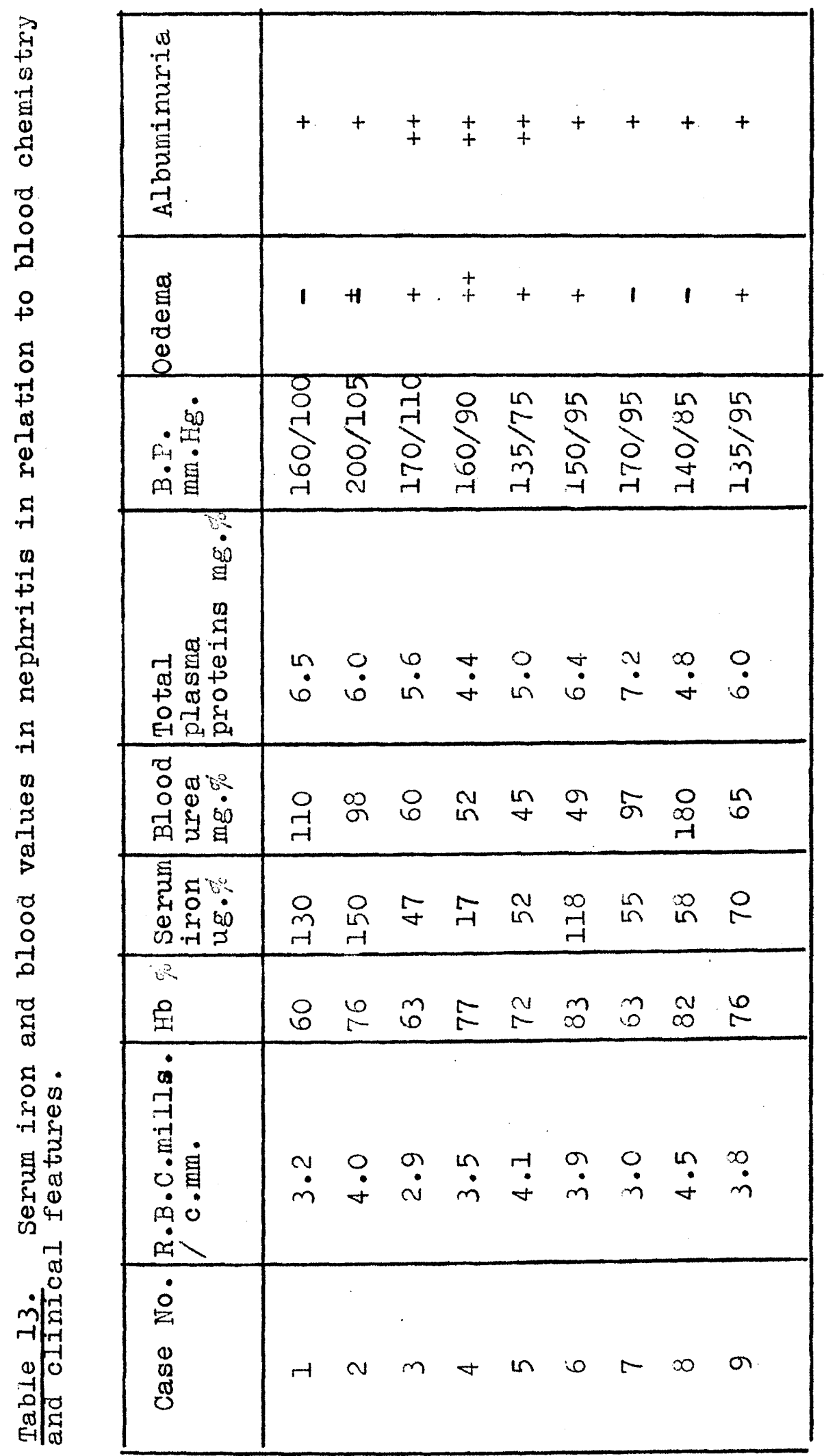


volume, plasma proteins, infection and metabolite retention, In all these cases, the bone marrow was examined by sternal marrow puncture and showed reasonable cellularity, although, in some instances, not quite such great activity as would normally have been expected to counteract the degree of anaemia present. Because any tendency to hypoplasia results as a rule in normal or increased semm iron values, owing to the transport iron not being removed for use, the low concentration in these patients is all the more significant. In the acute cases, the serum iron could well be reduced owing to infection and hydraemia. In subacute cases, hydraemia might again have an effect, but some alteration in the balance of plasma proteins might easily upset intermediary metabolism. Laurell (1947) showed a reduction in the plasma iron-combining power in nephritis, which he regarded as possibly due to loss of proteins of all forms in the urine. When oedema has disappeared and protein loss has diminished, the serum iron might be expected to come up to, or even to rise above, normal, if the marrow were at the same time becoming hypocellular. The two cases recorded with levels of 130 and 150 ug\% were patients with chronic renal disease and urea retention in whom plasma proteins were normal and there was no oedema, but two others with similar clinical and biochemical findings had relatively 
Low levels (Cases $7 \& 8$ ). The present numbers are insufficient from which to draw definite conclusions, but in a paper presented at the Association of Physicians Meetings in 1950 evidence was produced that the anaemia of nephritis was attributable to toxaemia in the acute stage, hypoproteinaemia in the subacute, and hypoplasia of the marrow latterly. The changes in serum iron in this short series could be explained on a similar basis. There is no apparent relationship to urea retention. Conclusions:

The most striking feature is the consistent and marked reduction of serum iron concentration encountered in iron deficiency anaemia. This is unfortunately not a specific characteriatic of iron deficiency alone, but is an early finding, although to a lesser degree, in most infective conditions, and is also present in toxic and neoplastic diseases such as uraemia, leukaemia, lymphadenma and carcinoma. In the presence of severe haemolysis, and in many cases of pernicious anaemia, the serum iron is unusually high. A low level in pernicious anaemia probably indicates the presence of associated iron deficiency. In parenchymatous liver disease, the serum iron is raised, while in obstructive jaundice it is normal. In the case of nephritis and uraemia, available evidence indicates that 
the disturbed iron metabolism is more intimately connected with protein imbalance than with nitrogen retention.

\section{SERIAL OBSBRVATIONS OF SERUM IRON CONCENTRATION}

\section{DURING COURSE OF ILINESS.}

Previous reports regarding the behaviour of the serum iron during the course of illness have been based on very small numbers of cases observed by numerous different investigators. Vannotti and Delachaux (1946) in reviewing such findings in relation to hypochromic anaemia stated that the serum iron fluctuates during the recovery period, but does not return to normal until the haemoglobin concentration has been restored. In pernicious anaemia, liver induced remission was found to be followed by an early and sudden fall in semum iron (Powell, 1944; Houghton \& Doan, 1941) this being maintained until red cell and haemoglobin levels approached normal. The terminal phases of chronic leukaemia and most cases of acute leukaemia were observed by Heilmeyer \& Plytner (1937) to be associated with lower serum iron values than during more favourable phases of these illnesses. The relative lack of systematic follow-up over long periods in any group suggested that routine check in a series of cases might be informative. In a number of patients the serum iron was therefore estimated weekly during the course 
of treatment.

Iron deficiency anaemia:

Eighteen cases of chronic iron deficiency hypochromic anaemia were followed in this manner. Eight of these were of idiopathic hypochromic type and showed no evidence of pathological blood loss at any time. The remaining ten had evidence of chronic haemorrhage, the result of bleeding piles, menorrhagia, or occult bleeding from peptic ulcer. One of the latter group was ultimately found to have carcinoma of the colon in addition, but faecal occult blood had never given more than a weak reaction with benzidine. In 16 patients, observations were continued for ten to twelve weeks, and in the other two, for eight weeks. All patients reached normal haemoglobin and red cell levels after treatment. In the case of patients on intravenous iron, injections were given at 3-4 day intervals, and specimens of blood for serum iron estimations taken immediately before injections were given. Patients on oral iron had had nore during the 18 hours prior to taking the blood samples. The immediate effects of injection or absorption of iron on serum iron levels were therefore eliminated, and the readings could be regarded as representative of the basic state of transport iron at the time.

The patterns of serum iron response were variable, but seemed to divide themselves into 3 groups (Figs. 15a,b,c). 


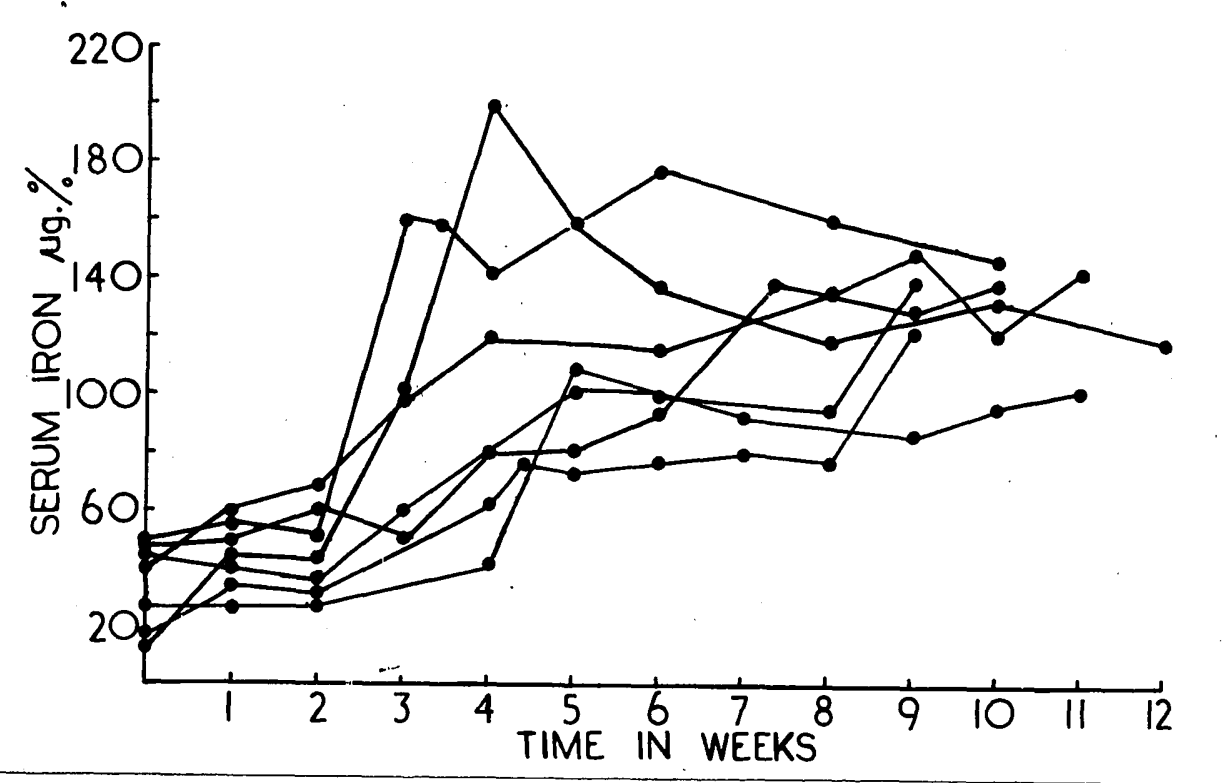

Fig. $15 \mathrm{a}$

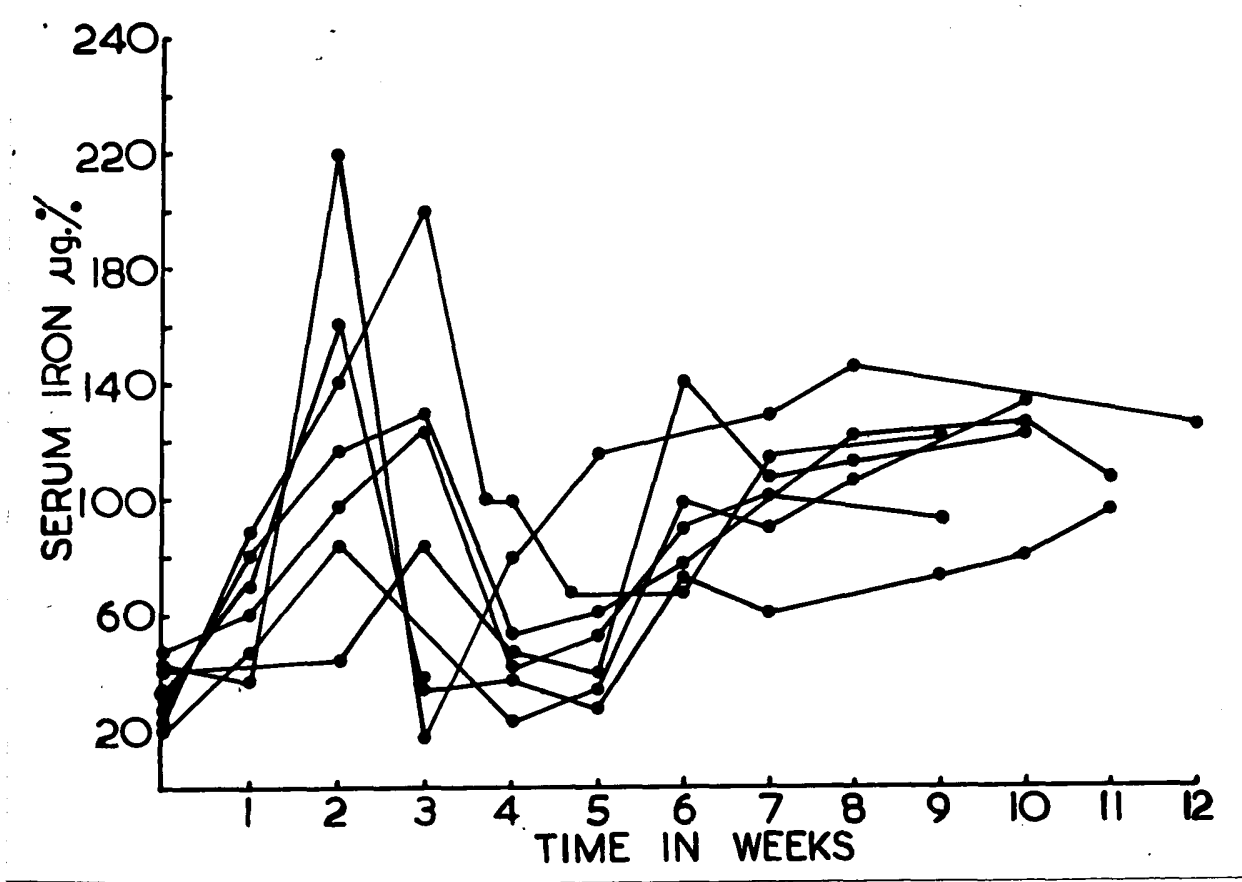

Fig. $15 \mathrm{~b}$

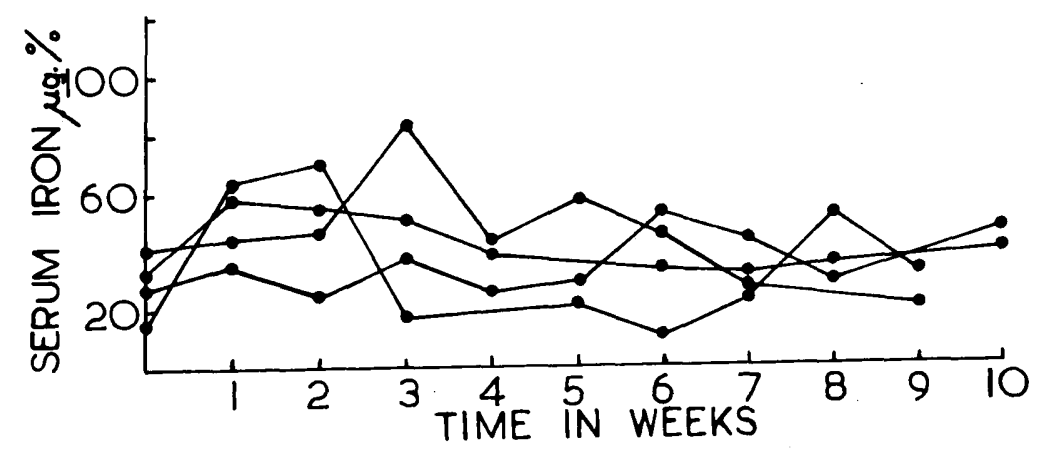

Fig. $15 \mathrm{c}$ 
Lable 14. Blood levels in relation to serum iron response inchronic iron deficiency anaemia.

\begin{tabular}{|c|c|c|c|c|c|}
\hline $\begin{array}{l}\text { Case } \\
\text { Mo. }\end{array}$ & $\underset{\%}{\mathrm{Hb}}$ & $\underset{R \cdot \mathrm{B} \cdot \mathrm{C} \cdot \mathrm{mm} \cdot \mathrm{mill}}{\mathrm{C}}$ & $\begin{array}{l}\text { Rate of } \mathrm{Hb} \text {. } \\
\text { rise } 8 \text { daily }\end{array}$ & $\begin{array}{l}\text { Type of seruh } \\
\text { iron response* }\end{array}$ & $\begin{array}{l}\text { Liethod } \\
\text { of treat } \\
\text { ment }+\end{array}$ \\
\hline 1 & 51 & 4.2 & 1.7 & a & $I . V$. \\
\hline 2 & 53 & 3.2 & 1.82 & a & $I \cdot V \cdot$ \\
\hline 3 & 40 & 2.5 & 0.54 & $b$ & oral \\
\hline 4 & 68 & 5.0 & 0.50 & a. & oral \\
\hline 5 & 60 & 3.6 & 0.83 & $b$ & orel \\
\hline 6 & 72 & $4 \cdot 5$ & 0.80 & a & oral \\
\hline 7 & 49 & 2.9 & 0.63 & c & oral \\
\hline 8 & 59 & $3 \cdot 3$ & 0.59 & $b$ & oral \\
\hline 9 & 65 & 3.9 & 1.20 & a & $I \cdot V \cdot$ \\
\hline 10 & 58 & 4.0 & 1.00 & a & oral \\
\hline 11 & 52 & 3.1 & .1 .10 & $c$ & oral \\
\hline 12 & 44 & 3.0 & 1.0 & $c$ & $I \cdot V \cdot$ \\
\hline 13 & 63 & 5.2 & 0.76 & $b$ & $I \cdot V \cdot$ \\
\hline 14 & 70 & $4 \cdot 3$ & 1.42 & a & $I \cdot V \cdot$ \\
\hline 15 & 61 & $3 \cdot 9$ & 0.83 & c & oral \\
\hline 16 & 42 & 3.1 & 2.00 & $b$ & $I \cdot V \cdot$ \\
\hline 17 & 40 & $2 \cdot 9$ & 1.71 & $\mathrm{~b}$ & $I \cdot V \cdot$ \\
\hline 18 & 38 & 3.2 & 0.92 & $\mathrm{~b}$ & oral \\
\hline
\end{tabular}

* a = remittent rise in serum iron during recovery.

$\mathrm{b}=$ steady rise of serum iron to normal during recovery.

$c=$ persistence of a subrormal serum iron after recovery.

$+\mathrm{I} \cdot \mathrm{V}$. = intravenous treatment with $200 \mathrm{mgm}$. iron as saccharated iron oxide twice weekly.

oral = administration of Fersolate tab. 1 t.i.a. 
(a) Seven showed a rise as haemoglobin and red cells approached normal, and the level afterwards remained within normal limits.

(b) Seven showed a rise at 14-2l days, a fall in the subsequent $2-3$ weeks, and then a rise to normal levels.

(c) Four showed persistence of a low serum iron concentration after recovery of a normal blood level.

These variable patterns were unexpected and occurred irrespective of the route used for iron medication. There is no apparent connection between the serum iron concentration and the rate of rise of the haemoglobin level.(Table 14). It appears however, that it is the patients with relatively high initial red cell counts who tend to have the early remittent rise in serum iron before it finally attains normal levels. In trying to account for these differences, reference might be made to certain personal observations on absolute values which indicate that iron administration can stimulate production of normally sized red cells before making good the deficient mean corpuscular haemoglobin concentration. Absolute values were estimated twice weekly in 6 patients during response to routine oral iron therapy (Table 15). An increase in the average size of the red cells precedes an 
Table 15.. Absolute values during treatment of chronic hypochromic anaemia with oral iron.

\begin{tabular}{|c|c|c|c|c|c|c|}
\hline fase no. & $\begin{array}{l}\text { Day of } \\
\text { treatment }\end{array}$ & $\vec{H}^{\mathrm{Hb}}$ & $\begin{array}{l}\text { R.B.c.mill. } \\
\text { /c.mm. }\end{array}$ & $\mathrm{P} \cdot \mathrm{C} \cdot \mathrm{V} \cdot \mathrm{g}$ & ${ }_{0} \cdot C_{0} \cdot \mathrm{C}$ & $\begin{array}{l}\text { तu. } \\
\text { cu. }\end{array}$ \\
\hline$I$ & $\begin{array}{r}1 \\
3 \\
7 \\
14 \\
21 \\
28 \\
35 \\
42\end{array}$ & $\begin{array}{r}7.5 \\
7.5 \\
8.3 \\
9.0 \\
10.6 \\
11.3 \\
12.0 \\
13.2\end{array}$ & $\begin{array}{l}3.80 \\
3.71 \\
4.16 \\
4.50 \\
4.70 \\
4.52 \\
4.63 \\
4.61\end{array}$ & $\begin{array}{l}30 \\
31 \\
35 \\
40 \\
42 \\
42 \\
43 \\
42\end{array}$ & $\begin{array}{l}25.0 \\
24.2 \\
23.4 \\
22.5 \\
25.0 \\
29.8 \\
27.9 \\
31.4\end{array}$ & $\begin{array}{l}78.9 \\
33.5 \\
34.1 \\
38.0 \\
89.0 \\
95.0 \\
90.9 \\
91.1\end{array}$ \\
\hline 2 & $\begin{array}{r}1 \\
3 \\
7 \\
10 \\
14 \\
21 \\
28 \\
31 \\
35 \\
42\end{array}$ & $\begin{array}{r}6.0 \\
6.2 \\
6.9 \\
7.2 \\
8.2 \\
9.0 \\
10.2 \\
10.9 \\
11.6 \\
12.8\end{array}$ & $\begin{array}{l}3.20 \\
3.22 \\
3.21 \\
3.89 \\
3.98 \\
4.50 \\
4.55 \\
4.50 \\
4.65 \\
4.72\end{array}$ & $\begin{array}{l}24 \\
24 \\
26 \\
30 \\
32 \\
37 \\
40 \\
42 \\
42 \\
43\end{array}$ & $\begin{array}{l}25.0 \\
26.0 \\
26.1 \\
26.5 \\
25.6 \\
24.3 \\
25.5 \\
26.9 \\
27.5 \\
29.1\end{array}$ & $\begin{array}{r}75.0 \\
74.5 \\
31.2 \\
77.1 \\
90.4 \\
82.2 \\
87.0 \\
91.0 \\
90.2 \\
91.1\end{array}$ \\
\hline 3 & $\begin{array}{r}1 \\
3 \\
7 \\
10 \\
14 \\
17 \\
21 \\
24 \\
30 \\
35 \\
38 \\
42\end{array}$ & $\begin{array}{r}6.4 \\
6.0 \\
6.4 \\
7.6 \\
8.2 \\
9.0 \\
9.7 \\
10.6 \\
11.9 \\
12.7 \\
13.2 \\
13.4\end{array}$ & $\begin{array}{l}3.30 \\
3.24 \\
3.36 \\
3.70 \\
4.20 \\
4.44 \\
4.50 \\
4.62 \\
4.85 \\
5.00 \\
4.90 \\
5.08\end{array}$ & $\begin{array}{l}22 \\
20 \\
24 \\
27 \\
28 \\
34 \\
37 \\
38 \\
42 \\
43 \\
43 \\
43\end{array}$ & $\begin{array}{l}29.1 \\
30.0 \\
26.6 \\
26.1 \\
28.2 \\
26.3 \\
26.2 \\
27.9 \\
23.3 \\
29.5 \\
30.7 \\
31.1\end{array}$ & $\begin{array}{l}66.6 \\
61.1 \\
73.8 \\
72.9 \\
69.0 \\
78.7 \\
82.2 \\
34.4 \\
86.0 \\
85.0 \\
34.9 \\
34.6\end{array}$ \\
\hline 4 & $\begin{array}{r}1 \\
3 \\
7 \\
10 \\
13 \\
17 \\
20 \\
27\end{array}$ & $\begin{array}{r}7.7 \\
7.9 \\
8.4 \\
9.1 \\
9.5 \\
10.4 \\
11.5 \\
13.0\end{array}$ & $\begin{array}{l}3.60 \\
4.02 \\
4.20 \\
4.46 \\
4.50 \\
4.63 \\
4.52 \\
4.60\end{array}$ & $\begin{array}{l}28 \\
29 \\
32 \\
36 \\
36 \\
40 \\
42 \\
43\end{array}$ & $\begin{array}{l}27 \cdot 5 \\
27.2 \\
26.2 \\
25 \cdot 3 \\
26.4 \\
26.0 \\
28.6 \\
30.0\end{array}$ & $\begin{array}{l}77.7 \\
72.0 \\
76.1 \\
30.0 \\
80.0 \\
87.0 \\
93.0 \\
93.7\end{array}$ \\
\hline
\end{tabular}


Table 15. (cont)

\begin{tabular}{|c|c|c|c|c|c|c|}
\hline $\begin{array}{l}\text { Case } \\
\text { no. }\end{array}$ & $\begin{array}{l}\text { Day of } \\
\text { treatment }\end{array}$ & $\underset{\%}{\mathrm{Hb}}$ & $\begin{array}{l}\text { R.B.c. mill. } \\
\text { /c.mm. }\end{array}$ & $\mathrm{P} \cdot \mathrm{C} \cdot \mathrm{V} \cdot$ & $\mathrm{M} \cdot \underset{q_{i}^{\prime}}{\mathrm{C}} \cdot \mathrm{H} \cdot \mathrm{C} \cdot$ & $\begin{array}{l}\text { M.C.V. } \\
\text { cu. }\end{array}$ \\
\hline 5 & $\begin{array}{r}1 \\
3 \\
7 \\
11 \\
14 \\
17 \\
21 \\
24 \\
27\end{array}$ & $\begin{array}{r}6.7 \\
6.6 \\
7.4 \\
8.2 \\
9.1 \\
9.8 \\
10.7 \\
11.3 \\
12.2\end{array}$ & $\begin{array}{l}3 \cdot 20 \\
3 \cdot 32 \\
3 \cdot 90 \\
4 \cdot 14 \\
4 \cdot 26 \\
4 \cdot 30 \\
4 \cdot 40 \\
4 \cdot 42 \\
4 \cdot 36\end{array}$ & $\begin{array}{l}26 \\
26 \\
31 \\
32 \\
35 \\
36 \\
38 \\
40 \\
41\end{array}$ & $\begin{array}{l}25 \cdot 9 \\
25 \cdot 4 \\
23.8 \\
25 \cdot 0 \\
26.0 \\
27 \cdot 2 \\
28.1 \\
26.2 \\
29.7\end{array}$ & $\begin{array}{r}81.2 \\
80.0 \\
79.5 \\
79.7 \\
82.1 \\
83.7 \\
86.3 \\
90.5 \\
94.3\end{array}$ \\
\hline 6 & $\begin{array}{r}1 \\
4 \\
7 \\
10 \\
14 \\
18 \\
21 \\
28 \\
31 \\
38\end{array}$ & $\begin{array}{r}8.80 \\
8.4 \\
9.0 \\
9.5 \\
10.2 \\
11.0 \\
12.0 \\
13.2 \\
13.5 \\
14.0\end{array}$ & $\begin{array}{l}4.00 \\
4.20 \\
4.50 \\
4.72 \\
4.81 \\
4.70 \\
5.0 \\
5.0 \\
5.2 \\
5.0\end{array}$ & $\begin{array}{l}33 \\
33 \\
35 \\
38 \\
38 \\
40 \\
41 \\
42 \\
41 \\
43\end{array}$ & $\begin{array}{l}26.7 \\
25.4 \\
25.7 \\
25.0 \\
27.0 \\
27.5 \\
29.1 \\
31.4 \\
30.4 \\
32.5\end{array}$ & $\begin{array}{l}81.5 \\
78.5 \\
77.8 \\
80.5 \\
79.0 \\
85.1 \\
82.0 \\
85.0 \\
78.7 \\
86.0\end{array}$ \\
\hline
\end{tabular}


improvement in the mean corpuscular haemoglobin concentration in several cases and in some instances the production of larger red cells is associated initially with an actual reduction in mean corpuscular haenoglobin concentration although the total haemoglobin increases. The fact that administered iron can have its greatest effect at first on the red cell bodies and not on the haemoglobin may explain the tendency for serum iron concentration to vary in relation to the red cell count.

Of the four patients who showed final subnormal serum iron concentrations in spite of normal haemoglobin and red cell counts, one had a chronic mild conjunctivitis and corneal ulceration; one was the patient found later to have carcinoma of the colon, and one had liver and spleen just palpable throughout the period of observation. The number of cases is small, but the findings suggest that the persistence of a subnormal serum iron in a patient thought to have a simple haemoglobin deficiency probably indicates the presence of some other abnormality.

Repeat estimations of serum iron were made on all these patients and on 40 others after the haemoglobin deficiency had been corrected and maintenance iron treatment continued for 6-8 weeks. The repeat estimation was made 10-14 days after iron had been stopped. The 4 males in the group were discounted, and the average value for the females 


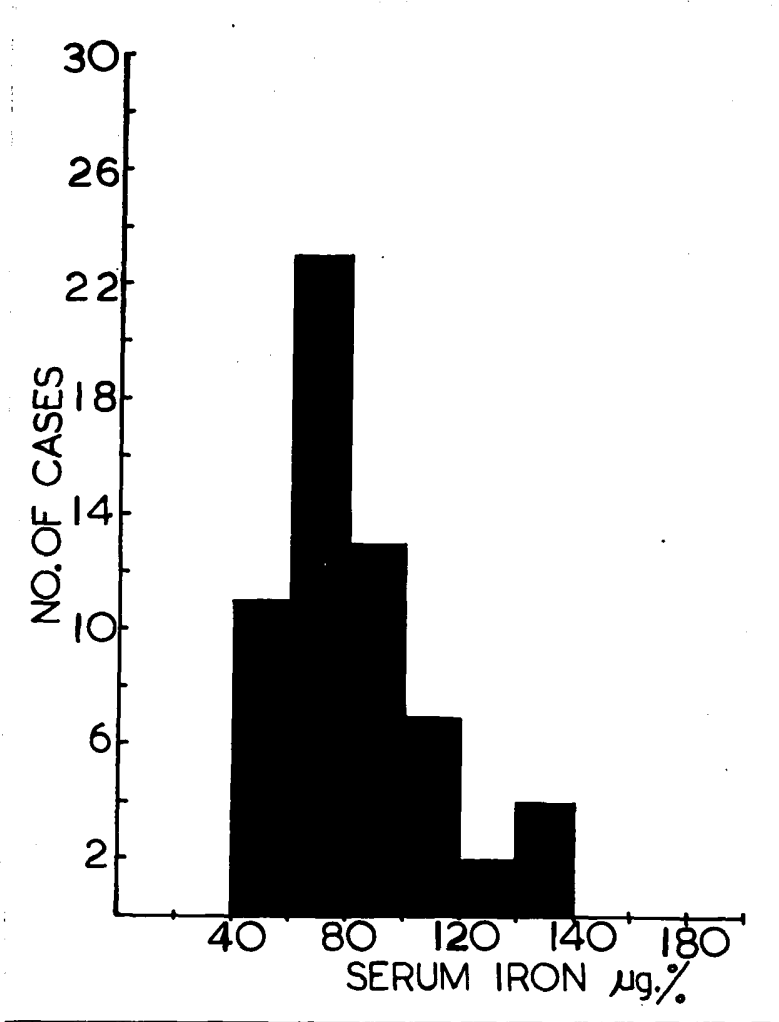

Fig. 16. Distribution of serum iron values in treated iron deficiency anaemia. 
was found to be $101 \mathrm{ug} . \%$ as compared with $113 \mathrm{ug} . \%$ for normal women. The difference is not statistically significant but is bordering on significance (Fig. 16). At this stage, haemorrhage could not be regarded as playing any major part in reducing iron stores, as any source of abnormal bleeding had now been controlled. Neither did it seem possible that hyperactivity of the marrow could still be present, leading to a drain on serum iron by increasing the requirements of iron. It therefore seemed that some fundamental disturbance of iron metabolism might be persisting in at least a proportion of cases. Fontes and Thivolle (1936) found that in haemoglobin-deficient dogs accelerated absorption of iron ceased once the bone marrow demands had been met, and that supplementary iron given for 6-12 months afterwards was not sufficient to replete the iron stores. If this slow accumulation of stores exists also in humans, it might well explain the tendency to a low normal serum iron after only 6-8 weeks maintenance iron therapy. The existence of a primary defect in alimentary iron assimilation in "idiopathic" cases might be postulated and be regarded as accounting for a relatively low serum iron. Further investigations in relation to this aspect will be discussed later in connection with oral iron absorption tests. 


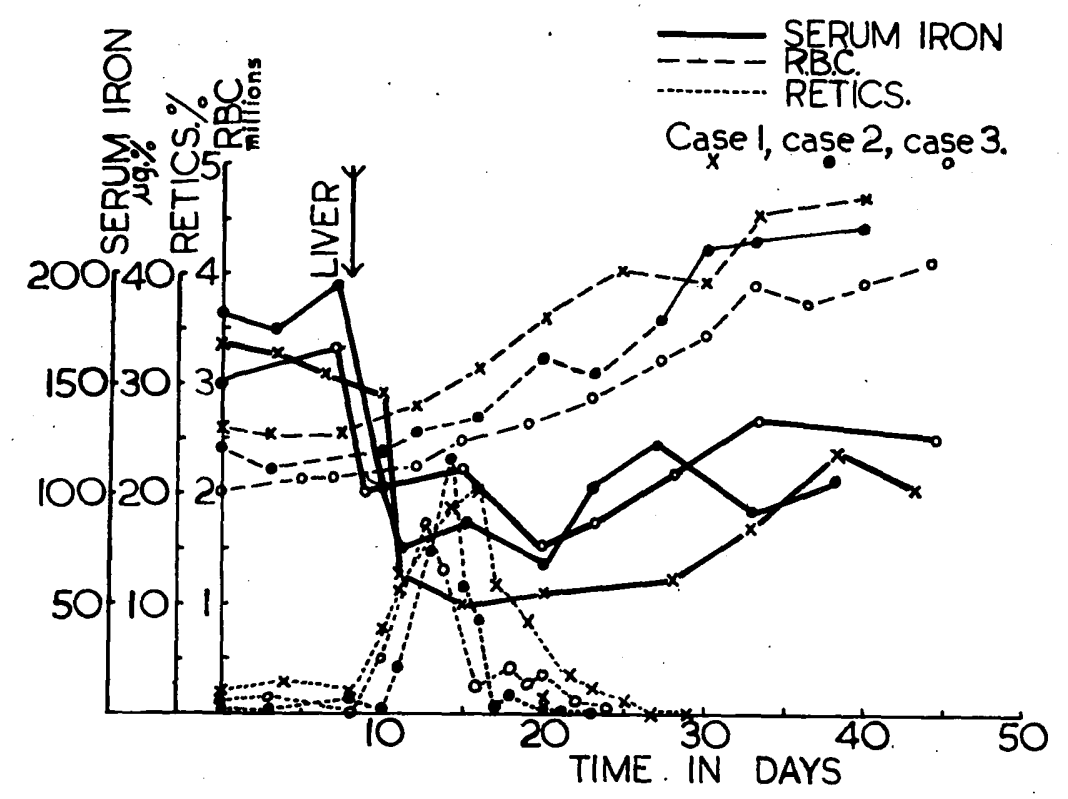

Fig. 17. Serum iron levels during response to treatment in pernicious anaemia ( 3 cases).

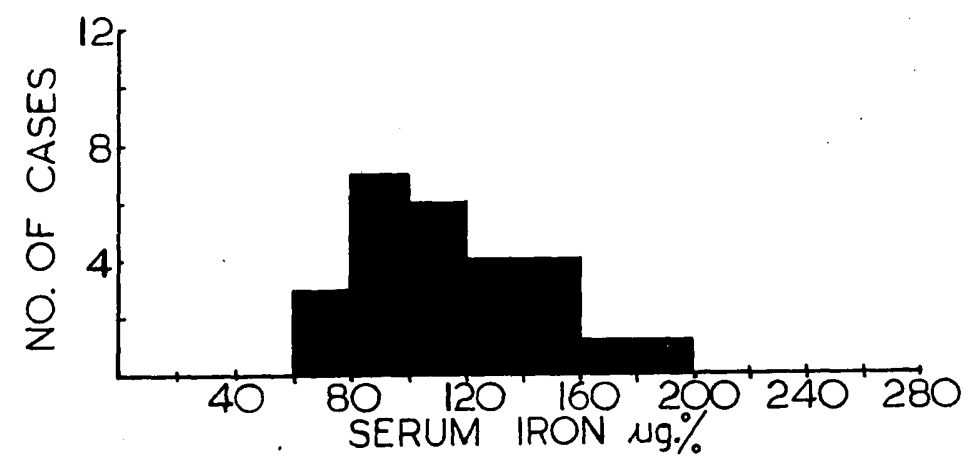

Fig. 18. Distribution of serum iron levels in treated pernicious anaemia. 
Pernicious anaemia:

The serum iron level was followed weekly in 3 patients with pernicious anaemia in whom the initial levels were relatively high. There was a sudden sharp fall in serum iron concentration within a day or two of giving liver. The concentration then remained low until the blood values were approaching normal, at which time the serum iron concentration also rose (Fig. 17). The fall was presumably accounted for by the sudden demand for iron for haemopoiesis once the haemopoietic principle had been supplied. It occurred before the reticulocyte crisis was demonstrable and was probably co-incident with the very early change of the marrow from megaloblastic to normoblastic erythropoiesis. Powell (1944), also observing this early fall in serum iron, considered it a useful sign of response to treatment, and Houghton and Doan (1941) regarded it as a reliable indication of effective treatment and one which might demonstrate active principle in test liver extracts when an adequate reticulocyte response was absent.

In 20 female patients, the serum iron was estimated 3-6 months after normal counts had been maintained (Fig.18). The group is small but the distribution of values agreed closely with the distribution for normal women, suggesting that iron balance was again normal. 


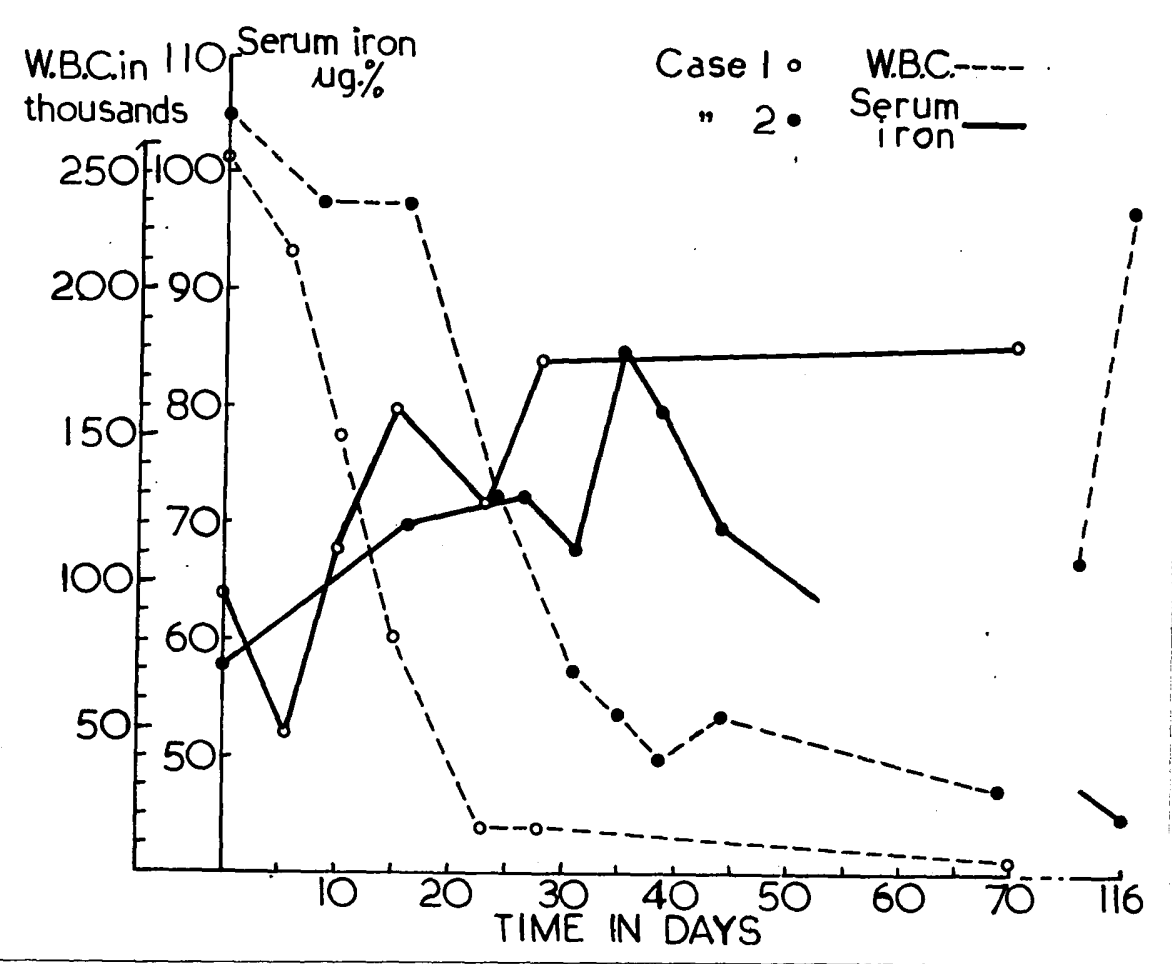

Fig. I9. Serum iron concentration during the course of chronic myeloid leukaemia.

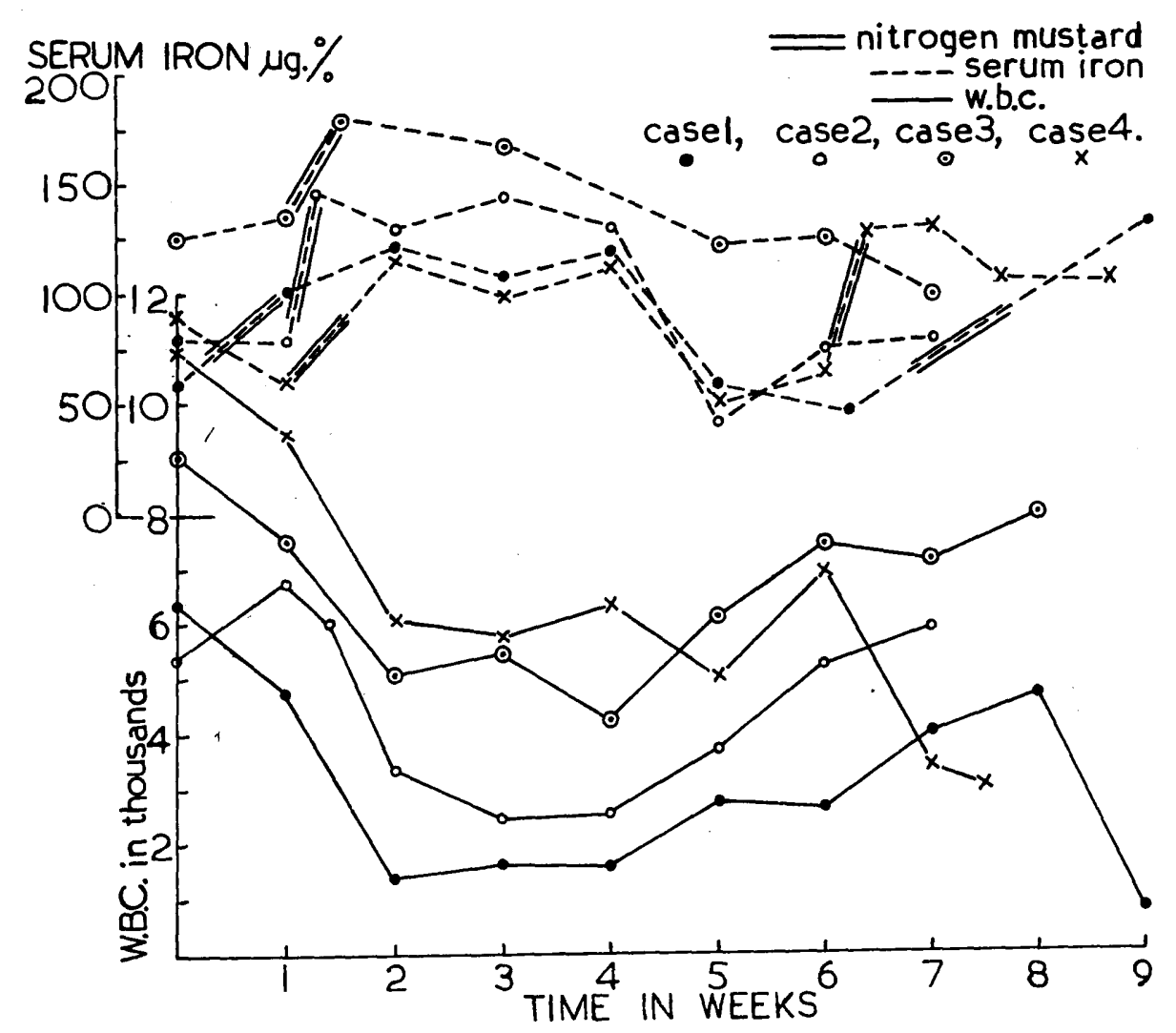

Fig. 20. Serum iron level in relation to white cell count during nitrogen mustard treatment of lymphadenoma and bronchial carcinoma. 
Myeloid Leukaemia:

In 2 cases of chronic myeloid leukaemia followed during treatment with urethane, the serum iron tended to rise as the white cell count fell and the haemoglobin concentration mounted. In one of these cases seen in a terminal acute phase, during which the white cell count suddenly increased and the haemoglobin concentration and red cell count fell, the serum iron showed a sharp drop (Fig.19). Cartwright and Wintrobe (1948) found that in chronic leukaemia, the serum iron level was usually a low normal, but there was often a terminal fall, while in acute leukaemia, the serum iron was often low throughout the course of the illness. Heilmeyer \& Plotner (1937) had made similar observations and maintained that serum iron estimation in leukaemia could therefore be of prognostic value. Iymphadenoma and carcinoma:

In 2 patients with Iymphadenoma and two with bronchial carcinoma, the serum iron was estimated weekly during and after nitrogen mustard therapy (Fig. 20). Initial semum iron levels were, in all instances, slightly subnormal, but during and immediately after treatment, the levels showed a definite rise. Brown and Davis (1950) observed marked depression of the marrow produced by nitrogen mustard, this hypoplasia being reversible, and most clearly reflected in the blood by a fall and subsequent rise in the total white 
cell count. If the white count is used as the index of marrow activity in the present cases, it is seen that depression of marrow function was associated with a rise in serum iron, and that regeneration coincided with a fall. Several previous reports have attributed normal or slightly raised iron levels in hypoplastic anaemia to lack of utilisation of iron in the marrow. The present observation confirms that this view is justifiable by demonstrating that induction of hypoplasia by therapeutic means results in an increase in serum iron, while recovery of marrow activity is accompanied by a fall.

Uraemia, myxoedema and carcinoma:

Two patients with uraemia; two with myxoedema and one with widespread metases of carcinoma in the skin from an undiagnosed primary site, all had a variable degree of slightly hypochromic anaemia. Oral iron was ineffective in producing any alteration in the haemoglobin and caused no sustained rise in the semum iron concentration. Intravenous iron produced a slight rise in serum iron levels as long as it was being given, but was equally ineffective in raising the haemoglobin. In four of these patients, the marrow smears after iron injection showed a considerable amount of iron present, thus further demonstrating that iron lack was not a significant factor in production of the anamia. Even once in the marrow, the body was apparently incapable of using the iron to increase 
haemoglobin production.

\section{Conclusions:}

The serum iron concentration is apparently directly influenced by the degree of marrow activity. It shows a sharp reduction when erythropoiesis is suddenly stimulated, as at the commencenent of liver treatment in pernicious anaemia, while a rise follows induced depression of marrow activity, such as by nitrogen mustard administration. The latter change in serum iron concentration is immediately reversed when the marrow again resumes its function. In leukaemia the serum iron concentration is lowest when leukaemic activity is greatest but one can only theorise as to whether this means a depression of iron metabolism on account of the leukaemia or a arain on transport iron as a result of the leukaemic hyperplasia. Whatever the mechanism for producing a low serum iron in the chronic toxic and neoplastic states it is extremely difficult to counteract as is indicated by the very temporary increase in serum iron concentration obtained after intravenous iron administration, and the fact that the concentration remains low even after storage iron is demonstrable histologically in the marrow. The different behaviour of the serum iron concentration during recovery in patients with relatively high and relatively 
Iow initial red cell counts may be connected with the fact that after iron administration the production of new and normally sized red cells takes precedence in some instances over the production of adequately haemoglobinated red cells. The clinical usefulness of serial observations is small. In hypochromic anaemia, the persistence of a low level may be an indicator that some other disease is present. In pernicious anaemia, the fall after liver administration is undoubtedly an early sign of response, but estimation of the serum iron is a cumbersome means of obtaining the same information, as becomes obvious with the reticulocyte response in the vast majority of cases only a few days later. Fall in serum iron as an indication of activity of a liver preparation seems an unreasonably indirect method of assay. In the case of iron deficiency anaemia the occurrence of serum iron levels in the lower limits of normal 6-8 weeks after normal counts have been attained raises the possibility of an abnormality in iron balance still existing. The present serial observations give no information as to whether this is a defect in absorption or in storage. The finding emphasises the necessity for continuance of iron therapy for a prolonged time after the haemoglobin level has returned to normal. 


\section{PART VI. \\ INTRAVENOUS IRON DISAPPEARANCE TESTS.}

Such results as are recorded from the use of intravenous iron disappearance tests are variable (Heilmeyer \& Pl8tner, 1937; Skouge, 1939; Vanotti \& Delachaux, 1942; Bröchner-Mortensen,1943 a \& b; Waldenstrom, 1944; Tytterman, 1949; Thedering,1949). In these reports, the observations were mostly incidental in the course of other investigations, although in the later papers they formed the main subject of study. Tutternan applied them in investigating the role of iron and vitamin $C$ in infection, and demonstrated an increased rate of iron elimination from the blood in infection. Thedering used them in an attempt to assess the function of the autonomic nervous system in controlling serum iron levels. He concluded that daily fluctuations in serum iron concentration were attributable to cholinergic and adrenergic control, and that the intensity of autonomic activity at the moment of initiating any experimental observation determined the degree of response which would be obtained, and whether this response would be of positive or negative type. This control influenced the course of intravenous and oral iron curves. In a later 
paper (1950) he combined the use of oral and intravenous iron curves in the investigation of anaemia, and claimed to demonstrate a group of idiopathic hypochromic iron deficiency anaemias in which impaired alimentary absorption of iron was the primary defect.

Suitability of Substances available for Intravenous Iron

Tests: Three groups of substances may be considered in regard to their properties as test agents for investigating the rate of disappearance of iron from the peripheral blood stream; namely, electrolyte iron preparations, radioactive isotopes of iron, and saccharated iron oxides. In considering their usefulness in relation to the investigation of patho-physiological processes, it is necessary to appreciate the chemical state of the normally-occurring non-haemoglobin iron of the blood, and the manner in which iron may be expected to leave the blood stream. The earlier views that non-haemoglobin iron was all in ferric form were questioned by Laurell (1947). Starkenstein \& Weden (1928) had shown that when ferrous iron was added to whole blood it was rapidly oxidised to the ferric form. The amount of iron nomally occurring in the serum was too small to allow of differential analysis as to valency, but they considered that as added ferrous iron became oxidised, it was justifiable to assume that the native serum iron-protein complex was a ferrous 
compound. Barkan's results (1933) agreed so closely with these that he subscribed to their view. Iintgel (1931) and Tompsett (1934 and 1940) had demonstrated that ferric iron but not ferrous iron formed complexes with biological materials and that such combined iron could be liberated with pyrophosphate. Iaurell, however, observed that the claims of Starkenstein \& Weden and of Barkan could not be accepted, as the physical state of iron added in excess to blood may be different from that of the naturally occurring iron. His own experiments showed that only about half the native iron could be demonstrated directly as ferric, the rewainder being demonstrable after oxidation with hydrogen peroxide. Tompsett, he considered, had simply shown that iron in serum could be liberated with a reducing substance, but the amount of reducing agents (hydrosulphate and thiolactic acid) employed had made the reaction of the solution slightly acid, and Laurell showed that an acid reaction in itself caused some dissociation of the serum iron complex to occur. He also demonstrated that cautious acidification of fresh serum in the presence of phenanthroline to $\mathrm{pH} 5$ resulted in about $90 \%$ of the iron reacting even without addition of any reducing substance. This could be interpreted as indicating that serum iron complexes were of ferrous form. Tompsett, however, had shown that ferric 
iron was reduced to ferrous on cautious addition of acid in the presence of protein. There is therefore no proof that all of the serum iron is present in any one form, and experimental evidence indicates that it may occur in the ferrous as well as in the ferric state.

Iron normally circulating in the serum is in complex combination with a $\beta$-globulin, and the ability of the serum to carry iron is limited by the amount of this protein present, a phenomenon which will be discussed later. Barkan (1927) and Valquist (1941) studied the dialyzability of iron in this complex and found it was negligible at physiological pH. Valquist found that even when serum was enriched with iron (valency unspecified), the metal was still in an undialyzable form. Tompsett (1940) reported that excess ferrous iron dialyzed easily, but ferric hardly at all. All this work was done with physiological saline as the outer medium. In vivo, the media on both sides of the capillary membrane contain protein, and Laurell (1947) showed that this significantly altered the passage of iron across a membrane. Using serum as his outer medium, he demonstrated that when serum is enriched with iron under the saturation limit, all the iron is bound in an undissociated and undialyzable form. Added iron in excess of the saturation limit is, however, loosely bound, dissociated, 
and easily dialyzable. Excess ferrous salts dialyzed more readily than ferric salts. From these experiments it may be concluded that excess ionizable iron may leave the plasma by dialysis through the capillary walls. There is no reason to believe that it enters mature red cells directly. Iron enriched semum that has been incubated with red cells and separated again retains its total complement of iron as determined by chemical estination (Cartwright \& Wintrobe 1946 , Tytterman 1949), and radio-active iron added to serum in vitro does not become transferred to the red cells even on permitting long contact (Dubach et al. 1948). The recent work of Walsh et al.(1950) suggests that direct entry into reticulocytes may occur. Bven if this does happen the amount of plasma iron thus diverted must be negligible unless the reticulocyte count is high. The site where iron is normally deposited out of the blood is dependent upon the form and the amount of iron which reaches the plasma. Studies with radioactive iron are all agreed that alimentary iron is largely taken up by the parenchymal cells of the liver and spleen, as soon as the immediate needs of the bone marrow have been satisfied. In the liver, iron is chiefly periportal in distribution. A similar distribution is found with ionizable iron given intravenously, and is therefore apparently due to an intrinsic property of portal cells to take up iron, and not to the 
manner in wich the metal has entered the blood. Along with these parenchymal deposits, the reticulo-endothelial tissue of the liver and spleen and macrophages throughout the body also show small deposits of iron. Eventually it is demonstrable in other parenchymal tissues, incluaing the duodenal mucosa, Brunner's glands, outer zone of adrenals, proximal tubules of the kidney, and acinar tissues of the pancreas (Finch et al, 1950). Poorly dissociable iron preparations given intravenously are taken up in reverse manner. They appear primarily in the reticuloendothelial cells of the body, and although redistribution into parenchymatous tissue ultimately occurs, large amounts remain in the reticulo-endothelial system for at least as long as two years if the haemoglobin has been normal at the time of injection (Polson,1928; Cappell, 1930; Finch,1950) Iron salts ich have been used for experimental purposes by intravenous injection include ferrous lactate, ferrous chloride, ferric amnonium citrate and iron ascorbate $\left(\mathrm{Fe}^{2}\right)$. From the point of view of valency, it would appear that reduced and oxidised salts are equally suitable, as both forms of iron may exist naturally in plasina, and, as the previous discussion shows, moderate amounts given intravenously are dealt with in similar manner to iron absorbed from the alimentary tract. The toxic effects liable to be produced 
by their administration constitute a serious arawback to their use and for chemical estimation to demonstrate significant changes, it is unfortunately necessary to work with relatively large amounts. An intravenous dose of more than 6-10 mg. is usually followed by symptoms of flushing, upper respiratory irritation, constriction in the chest, nausea and vomiting, shock, central nervous system depression, and even corra. Milder reactions often occur even with considerably smaller dosage. These reactions have been attributed to dialysis of unbound iron salt from the capillaries into the tissues leading to flocculation and local irritation, and have proved a considerable handicap to investigators who have used these preparations. It would certainly preclude their use in any routine clinical test which might be established.

Radio-active isotopes have the great advantage that they can be given intravenously in small enough amounts to be comparable to the normally occurring concentrations of iron in the body. After administration it is, however, only practicable to estimate them in the red cell mass where they mostly appear quantitatively in the haemoglobin. This is a measure of utilisation and not of rate of disappearance of iron from the blood. Dubach et al.(1948) pointed out that 
under certain circumstances, all the iron may not even appear in the haemoglobin. Isotopes cannot therefore be used as a direct means of determining the immediate rate of disappearance of iron from the blood stream. There remain the colloidal preparations such as iron ascorbate gelatin and saccharated iron oxide. The latter was perfected for routine intravenous administration by Nissim in 1948 and trials have shown that large arnounts can be given without serious untoward effects in the vast majority of cases. The proprietory preparations "Ferrivenin" and "Iviron" can be tolerated in doses of up to 200-300 mgm. at a single injection. As experimental substances, they have the disadvantage of not being in a form comparable to the naturally occurring serum iron. Being colloidal preparations, they are primarily taken up by the reticuloendothelial cells and not the parenchymal cells as is the case with ionizable iron. Nevertheless, a small amount of the latter does also appear in reticulo-endothelial cells, immediately after administration, and the behaviour of colloidal iron may therefore be expected to bear some relationship to the physiological metabolism of iron. In selecting a substance for the present tests, 
colloidal iron has the great advantage that anounts suitable for chemical estimation can easily be administered without toxic effects. Saccharated iron oxide was therefore chosen as the test substance, and "Iviron" was used in the greater part of this work.

Method of investigation \& variables affecting method:

The aim was to learn something of the rate of disappearance of iron from the blood stream. The method adopted was to give a known quantity of iron intravenously to a fasting subject, and follow the serum iron concentration during the subsequent few hours.

Tests were begun between 9 and 9-30 a.m. on fasting subjects, and fasting continued until the test was completed. A dose of 5 c.c. of saccharated iron oxide (100 mg. elemental iron) was given intravenously over a period of 5 minutes. Blood for serum iron estimation was taken from the same arm immediately before iron administration, and from the opposite arm at $5 \mathrm{~min}, 0.5 \mathrm{hr}$, 1.5 hr., $4.5 \mathrm{hr}$. and $7.5 \mathrm{hr}$. after the iron had been given. On performing such a test on 13 normal people between the ages of 18 and 62 years, the 5 minute level was found to be unexpectedly low, and was not significantly different when repeated in 3 persons using a $200 \mathrm{mgm}$. 
$=$

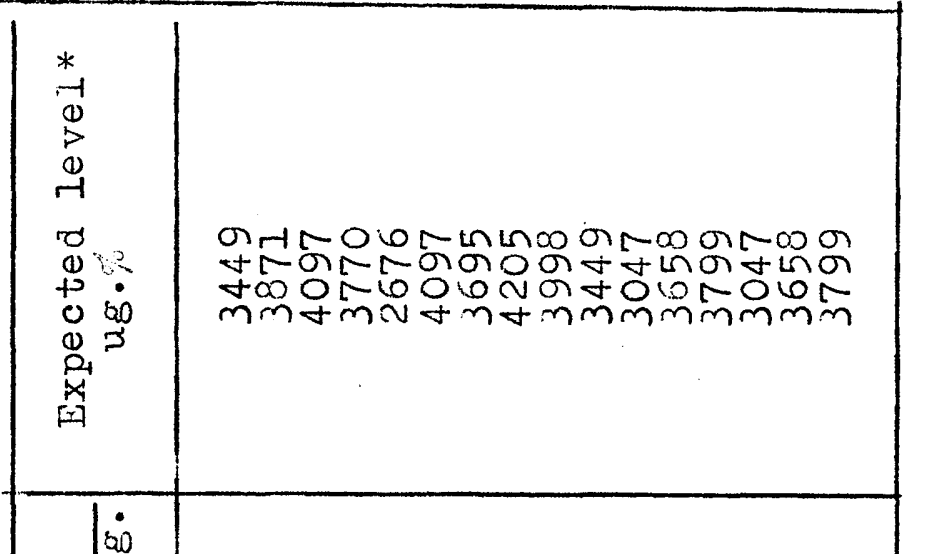

bio

80

ह

$\overbrace{0}^{0}$

4

o

5

도

.

0 .

๑)

\&

तO

$4 \mathrm{~N}$

(1)

+

w $\cdot+1$

C

O

H

\$

\&ै

도 (1)

(1) \&

0

ro

0 क

\&

it

- 40

悬离

monoomooninomooon

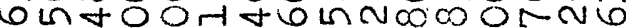

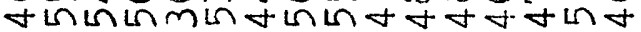

$+\infty 0 m 0 m+0$ m

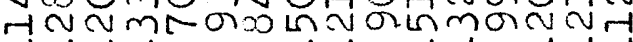

$\mathrm{HH}-1$

तम नाम त्मत्म

(1)

(1)

$\begin{array}{ll}+ & 0 \\ \text { si } & 0 \\ 00 & 0 \\ +1 & -1 \\ 0 & -1\end{array}$

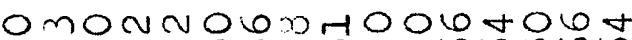
T.6

of

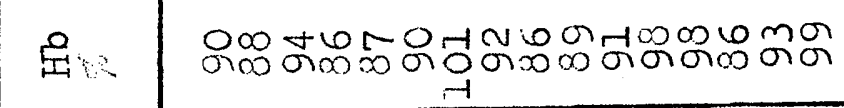

ortanomonomona

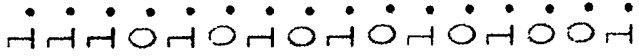$$
\text { rif }
$$

it

$\stackrel{\text { ㄱ- }}{\text { 年 }}$

i目

$\ddot{\dot{m}} \dot{0}$

MOHNNOOHNTNHOHZ

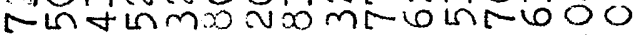

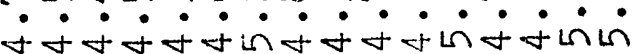

مI

0
02
0

0

Hom the - W O

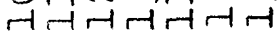


injection (Table 16). Factors which require special consideration as possibly affecting this result are the accuracy of recovery of iron from "Iviron", and the properties of colloidal iron in relation to plasma ironcombining capacity, adsorption, dialysis and excretion. Recovery of iron from "Iviron":

In previous work serum iron estimations have been performed following intravenous loading with simple iron salts. These are recovered quantitatively from serum, as has been confirmed in the present work, and it is consequently justifiable to conclude that any iron not estimated in a serum sample taken after giving such a preparation intravenously must have been eliminated from the blood stream. Saccharated iron oxide is colloidal, and it was therefore indicated to assess the efficacy with which its iron content could be recovered from serum using the methods chosen for serum iron estimation.

Dilutions were made of "Iviron" in water and of "Iviron" in serum, so that $100 \mathrm{ml}$. of the mixture contained known amounts of iron. The amount recovered is shown in Table 17. Recovery of the total iron is obviously inadequate but is apparently directly proportional to the 
Table 17. Recovery of iron after adaition of a known quantity of "Iviron" to water or serum.

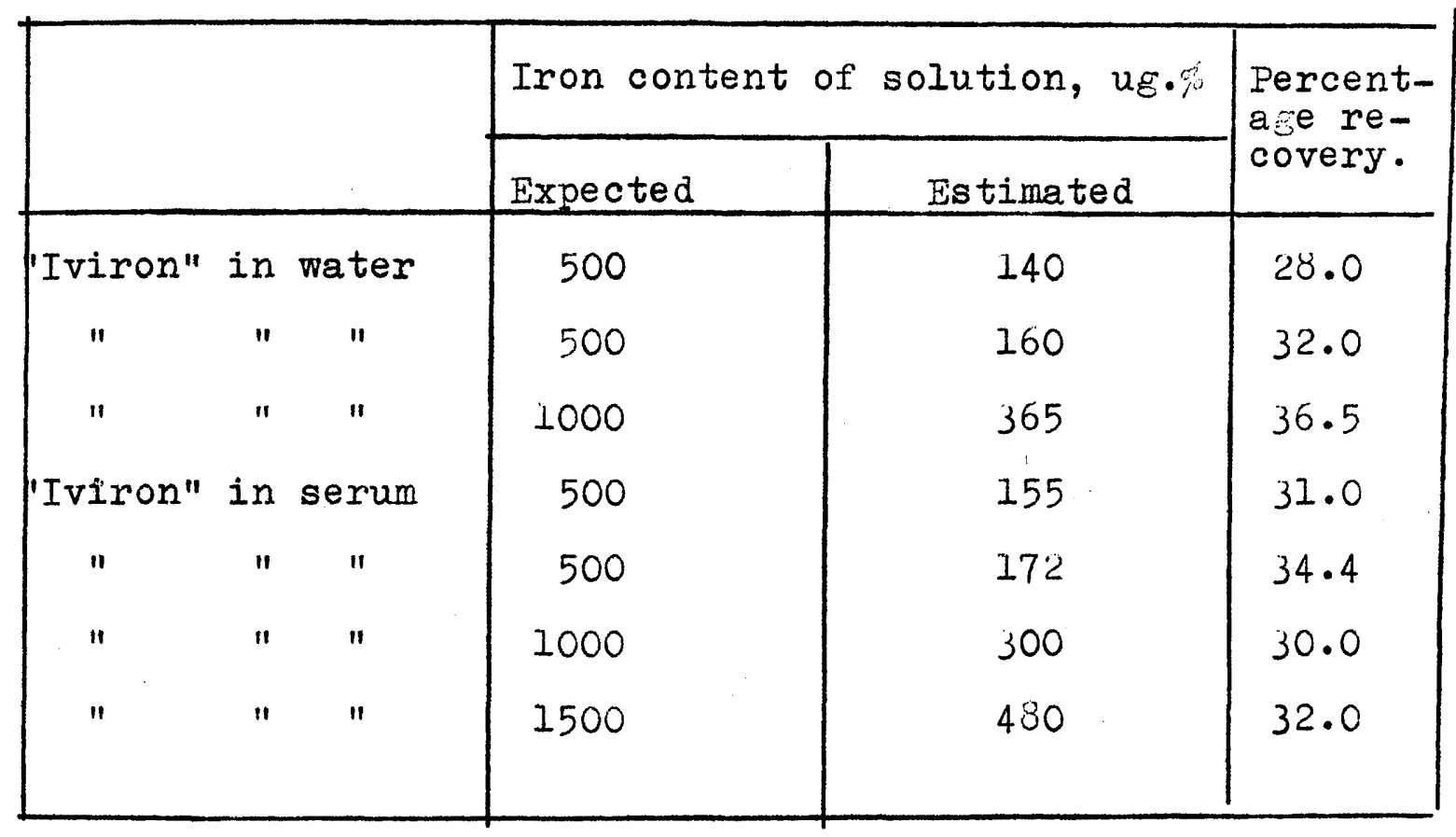

Table 18. Recovery of iron from iron-enriched serum before and after its incubation for I hour with washed red cells, iron being added as "Iviron" and estimated by the ashing technique.

\begin{tabular}{|l|l|l|l|}
\hline $\begin{array}{l}\text { Sample } \\
\text { No. }\end{array}$ & $\begin{array}{l}\text { Iron content of } \\
\text { serum used, } \\
\text { ug. \% }\end{array}$ & $\begin{array}{l}\text { Iron content of } \\
\text { serum + "Iviron" } \\
\text { ug. \% }\end{array}$ & $\begin{array}{l}\text { Iron content of } \\
\text { serum +Iviron" } \\
\text { after incubation } \\
\text { with red cells } \\
\text { ug.\% }\end{array}$ \\
\hline 1 & 950 & 4400 & 3500 \\
2 & 700 & 3450 & 4500 \\
3 & 250 & 3005 & 3505 \\
5 & 210 & 3300 & 3000 \\
\hline
\end{tabular}


strength of the iron dilution being estimated, an average of $32 \%$ being accounted for in each specimen. By ashing, the iron content of "Iviron" was found to be accurate to within 3\%. This constant experimental error explains only partially the relatively low concentration of serum iron 5 minutes after a large injection. Iron binding capacity of serum in relation to "Iviron" WaIdenstrom (1944) observed that five minutes after intravenous injection of $10 \mathrm{mg}$. of iron as a simple salt, the serum iron value was lower than was to be expected if aII the iron had been distributed in the plasma volume of the organism. Repeat injections at a short interval resulted in only small rises, and toxic symptoms of flushing, nausea, sneezing and headache appeared. He was therefore able to postulate that there was something which controlled the maximum serum iron level attainable at an average of $291 \mathrm{ug} . \%$ in normal subjects, and that iron in excess of this was rapidly eliminated from the blood causing toxic symptoms. Holmberg (194I) had previously advanced the hypothesis that iron was bound to the serum proteins in complex manner up to a certain saturation Iimit, and any excess was Ioosely bound and easily split, a hypothesis which was later proved tenable by in 
vivo experiments. The saturation limit in his findings had an average value of $312 \mathrm{ug} . \%$ in normal people (Holmberg \& Iaurell, 1947). The experiments of Schade \& Caroline (1946) established that the iron-binding component is Cohn's Fraction IV-3.4 which is rich in $\beta$-globuline. They determined the iron-binding capacity at an average of $260 \mathrm{ug} . \%$ in health. Normally, this ironbinding component is saturated to approximately one-third of its capacity. Cartwright \& Wintrobe (1949) found that the capacity of this protein to bind iron was so specific that estimation of the iron-binding capacity of the serum could probably be made by estimation of the serum iron concentration after injection of an excess of iron intravenously. Again, these findings are based on experiments made with simple iron salts. In this work, even making allowance for the experimental error in estimation of iron in "Iviron" a proportion of the saccharated iron oxide is unaccounted for at a very short interval after its injection (Table 16). It seems justifiable to attribute this deficit to the influence of the serum iron binding protein. Such iron as is "bound" presumably remains for a longer time in the circulation while the excess is almost immediately eliminated. 
Adsorption and dialyzing properties of "Iviron" and excretion:

In accounting for this initial rapid disappearance of "Iviron" from the circulation it is necessary to consider the possibility of adsorption on the cellular elements of the blood, of penetration through the capillary vessel walls, of excretion from the body.

Adsorption and dialysis:

The equivalent of $3 \mathrm{mg}$. elemental iron per $100 \mathrm{ml}$. serum was added as "Iviron" to serum, and $10 \mathrm{ml}$. of the mixture allowed to stand for 1 hour at $37^{\circ} \mathrm{C}$. In contact with $10 \mathrm{ml}$. of packed red cells which had been washed in normal saline. The serum was then separated again and its iron content estimated. The ashing technique was used (Table 18). The variation in results can be attributed to inaccuracy encountered with the less delicate ashing method of estimating iron concentration and to slight haemolysis which is liable to occur in using packed red cells and subsequently re-separating them. It is, however, evident that significant adsorption of iron does not occur. As far as is known there is no question of this colloidal preparation dialysing through the capillary walls. Excretion:

The question of iron excretion in health and after oral iron ingestion, haemolysis and blood transfusion has already been discussed and published work indicates that it is minimal. The excretion of iron after intravenous 
administration of saccharated iron oxide is greater but is still relatively slight. Scott \& Govan (195l) in a limited investigation found that $5 \%$ might appear in the urine after giving moderate amounts. Crawley (personal communication, 1951) demonstrated negligible excretion from the bowel and limited excretion from the kidneys. The latter ranged from $2.9-4.4 \%$ of the dose given and was unrelated to the haemoglobin level at the time of administration. Although the most of this amount was excreted in the first 24 hours the total was that for a 3 day period. Bxcretion during the tine of an intravenous iron disappearance test must therefore be negligible and certainly cannot account for the speed at which the iron leaves the blood stream.

Neither adsorption, dialysis nor excretion can be held responsible for the rapid disappearance of injected "Iviron". The evidence suggests that the serun is capable of holding the preparation only up to a certain maximum level, probably aependant upon the iron-binding capacity, and that the excess disappears extraordinarily rapidly from the circulation but is nevertheless retained within the body. Since it is unaccounted for by dialysis or adsorption it nay all be transferred to the reticulo-endothelial system. 
Interpretation of intravenous iron disappearance tests:

The curves obtained by the test described have two phases. There is an initial rapid disappearance of injected iron to a level probably dependant upon the iron combining capacity of the serum, and a secondary slower disappearance of iron which has presumably been protein-bound. The rate of this secondary disappearance in different subjects can best be compared by expressing serial estimations as percentages of the 5 minute concentration. In thel 3 norral people this disappearance rate is very similar (Fig.2l). Since the iron does not appear to leave the plasma by excretion, dialysis or adsorption, its rate of disappearance below the saturation linit can be expected to be affected by the body's requirement for iron. The curves may therefore be used for comparison of the iron-binding capacity of the serum as represented by the levels 5 minutes after injection of excess saccharated iron, and to indicate the rate at which iron subsequently disappears from the plasma. Application of rethod to patients with Anaemia:

From the immediately preceding discussion it is evident that an intravenous iron disappearance test using "Iviron" is practicable. The curves obtained in 13 normal subjects 


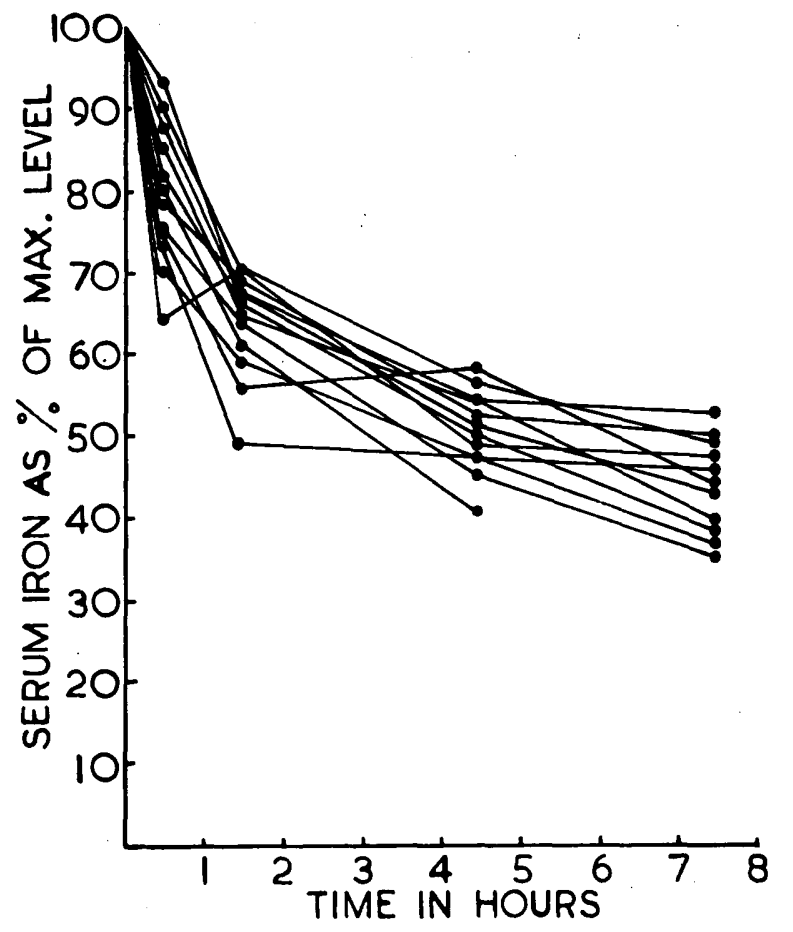

Fig. 21. Disappearance rate of "Iviron" injected intravenously in normal subjects. 
Table 19. Material on which intravenous iron disappearance tests were performed.

\begin{tabular}{|c|c|}
\hline Nature of illness. & No. of cases. \\
\hline Chronic hypochromic anaemia & 15 \\
Anaemia from recent massive \\
haemorrhage. \\
Refractory normoblastic anaemia \\
- in toxic states \\
- in infections \\
- in neoplastic disorders \\
Pernicious anaemia
\end{tabular}


(Fig.21), are comparable, and when repeated in three of the group, the form remained similar. There is therefore a characteristic pattern for intravenous iron disappearance curves in healthy people which is suitable as a standard of comparison for curves obtained in disease. Application of the test was consequently extended to patients suffering from various forms of anaemia.

Haterial: The accompanying table indicates the cases investigated by means of intravenous iron disappearance tests (Table 19). All patients with chronic hypochromic anaemia had a haemoglobin deficiency (as indicated by a colour index of less than 0.9) and active normoblastic erythropoiesis. The patients with toxic, infective or neoplastic diseases had colour indices between 0.9 and 1.1 , except two, who had hypochroraic anaemia. The narrow reaction in this group was active and normoblastic. The cases of pernicious anaemia were of classic type, with raised colour index, megaloblastic marrow and histamine-fast achlorhydria. Results:

Figures and curves obtained are shown in Table 20 and Figs. 22 to 27. As previously explained the curves are obtained by expressing the serial readings as percentages of 
Table 20. Serum iron concentration after injection of 100 mg. Iron as "Iviron" in various types of anaenia.

\begin{tabular}{|c|c|c|c|c|c|c|}
\hline $\begin{array}{l}\text { Nature of } \\
\text { anaemia. }\end{array}$ & $\begin{array}{l}\text { Case } \\
\text { No. }\end{array}$ & $\mathrm{Hb}$ & $\begin{array}{l}\text { K.B.C. mili. } \\
/ \text { c.mm }\end{array}$ & C.I. & $\frac{\text { serum is }}{\text { Initiai }}$ & 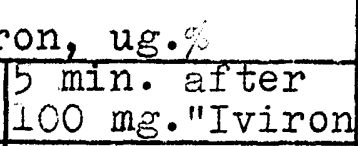 \\
\hline $\begin{array}{l}\text { Chronic } \\
\text { hypo- } \\
\text { chromic } \\
\text { - post } \\
\text { haemorr- } \\
\text { hagic }\end{array}$ & $\begin{array}{r}1 \\
2 \\
3 \\
4 \\
5 \\
6 \\
7 \\
8 \\
9 \\
10\end{array}$ & $\begin{array}{l}60 \\
42 \\
51 \\
46 \\
70 \\
45 \\
57 \\
39 \\
63 \\
55\end{array}$ & $\begin{array}{l}4.3 \\
3.6 \\
3.9 \\
3.4 \\
4.5 \\
3.9 \\
4.2 \\
3.3 \\
4.5 \\
3.8\end{array}$ & $\begin{array}{l}0.7 \\
0.6 \\
0.7 \\
0.7 \\
0.8 \\
0.6 \\
0.7 \\
0.5 \\
0.7 \\
0.7\end{array}$ & $\begin{array}{l}35 \\
58 \\
40 \\
48 \\
42 \\
30 \\
20 \\
15 \\
47 \\
39\end{array}$ & $\begin{array}{l}452 \\
590 \\
600 \\
651 \\
700 \\
623 \\
562 \\
452 \\
682 \\
640\end{array}$ \\
\hline $\begin{array}{l}\text { iüio- } \\
\text { pathic }\end{array}$ & $\begin{array}{l}11 \\
12 \\
13 \\
14 \\
15\end{array}$ & $\begin{array}{l}64 \\
59 \\
46 \\
40 \\
46\end{array}$ & $\begin{array}{l}4.0 \\
4.2 \\
3.0 \\
4.1 \\
5.0\end{array}$ & $\begin{array}{l}0.8 \\
0.7 \\
0.7 \\
0.5 \\
0.5\end{array}$ & $\begin{array}{l}15 \\
31 \\
30 \\
46 \\
35\end{array}$ & $\begin{array}{l}600 \\
502 \\
573 \\
570 \\
550\end{array}$ \\
\hline $\begin{array}{l}\text { Recent } \\
\text { massive } \\
\text { haemorr- } \\
\text { hage }\end{array}$ & $\begin{array}{l}- \\
1 \\
2 \\
3 \\
4 \\
5 \\
6 \\
7\end{array}$ & $\begin{array}{l}- \\
10 \\
63 \\
72 \\
58 \\
60 \\
75 \\
63\end{array}$ & $\begin{array}{c}--5-- \\
3.6 \\
3.4 \\
3.8 \\
3.3 \\
3.1 \\
4.0 \\
3.5\end{array}$ & $\begin{array}{l}\overline{1} \cdot \overline{0} \\
\overline{1} \cdot \overline{1} \\
\overline{1} \cdot 0 \\
0.9 \\
1.0 \\
0.9 \\
0.9\end{array}$ & $\begin{array}{l}-1 \overline{-}- \\
106 \\
120 \\
189 \\
100 \\
98 \\
133 \\
90\end{array}$ & $\begin{array}{r}-700 \\
500 \\
530 \\
421 \\
412 \\
488 \\
545 \\
440\end{array}$ \\
\hline $\begin{array}{l}\overline{\text { Pernic- }}- \\
\text { ious } \\
\text { anaemia }\end{array}$ & $\begin{array}{l}- \\
1 \\
2 \\
3 \\
4 \\
5 \\
6 \\
7 \\
8\end{array}$ & $\begin{array}{l}-7- \\
50 \\
40 \\
61 \\
38 \\
72 \\
52 \\
63 \\
61\end{array}$ & $\begin{array}{c}------ \\
2.2 \\
1.4 \\
2.5 \\
1.5 \\
3.2 \\
2.0 \\
2.7 \\
2.5\end{array}$ & $\begin{array}{l}-\overline{1} \cdot \overline{12} \\
1 \cdot 40 \\
1 \cdot 22 \\
1 \cdot 26 \\
1 \cdot 12 \\
1 \cdot 30 \\
1 \cdot 16 \\
1 \cdot 25\end{array}$ & $\begin{array}{l}-1 \overline{1}-- \\
150 \\
130 \\
126 \\
148 \\
118 \\
102 \\
63 \\
50\end{array}$ & $\begin{array}{r}-\overline{506} \\
493 \\
450 \\
430 \\
350 \\
412 \\
500 \\
371\end{array}$ \\
\hline
\end{tabular}


Table 20. (continued)

\begin{tabular}{|c|c|c|c|c|c|c|}
\hline \multirow{2}{*}{$\begin{array}{l}\text { Nature of } \\
\text { anaemia }\end{array}$} & \multirow{2}{*}{$\begin{array}{l}\text { Case } \\
\text { No. }\end{array}$} & \multirow{2}{*}{$\underset{\% b}{H b}$} & \multirow{2}{*}{$\begin{array}{l}\mathrm{K} \cdot \mathrm{B} \cdot \mathrm{C} \cdot \mathrm{mill} \\
/ \mathrm{c} \cdot \mathrm{mm} \cdot\end{array}$} & \multirow[t]{2}{*}{ C.I. } & \multicolumn{2}{|c|}{ Serum iron, ug.s } \\
\hline & & & & & Initial & $\begin{array}{r}5 \text { min after } \\
100 \text { mE: "Iv } \\
\text { iron" }\end{array}$ \\
\hline Toxic & $\begin{array}{l}1 \\
2 \\
3 \\
4 \\
5\end{array}$ & $\begin{array}{l}41 \\
73 \\
60 \\
68 \\
50\end{array}$ & $\begin{array}{l}2.4 \\
3.5 \\
3.4 \\
3.2 \\
2.5\end{array}$ & $\begin{array}{l}0.9 \\
1.0 \\
0.9 \\
1.0 \\
1.0\end{array}$ & $\begin{array}{l}38 \\
59 \\
78 \\
60 \\
70\end{array}$ & $\begin{array}{l}400 \\
427 \\
400 \\
437 \\
505\end{array}$ \\
\hline $\begin{array}{l}\text { Intect- } \\
\text { ive }\end{array}$ & $\begin{array}{r}1 \\
2 \\
3 \\
4 \\
5 \\
6 \\
7 \\
8 \\
9 \\
10 \\
11 \\
12 \\
13\end{array}$ & $\begin{array}{l}69 \\
63 \\
74 \\
76 \\
60 \\
60 \\
54 \\
73 \\
70 \\
63 \\
78 \\
68 \\
57\end{array}$ & $\begin{array}{l}3.4 \\
3.4 \\
3.6 \\
3.2 \\
3.0 \\
3.5 \\
2.8 \\
3.6 \\
3.3 \\
3.6 \\
4.1 \\
3.4 \\
3.1\end{array}$ & $\begin{array}{l}1.0 \\
0.9 \\
1.0 \\
0.9 \\
1.0 \\
0.9 \\
1.0 \\
1.0 \\
0.9 \\
0.9 \\
0.9 \\
1.0 \\
0.9\end{array}$ & $\begin{array}{r}135 \\
50 \\
45 \\
45 \\
53 \\
40 \\
62 \\
55 \\
74 \\
55 \\
72 \\
61 \\
75\end{array}$ & $\begin{array}{l}3 y 0 \\
403 \\
400 \\
430 \\
512 \\
330 \\
408 \\
450 \\
370 \\
390 \\
480 \\
461 \\
351\end{array}$ \\
\hline $\begin{array}{l}\text { Neo- } \\
\text { plastic }\end{array}$ & $\begin{array}{r}1 \\
2 \\
3 \\
4 \\
5 \\
6 \\
7 \\
8 \\
9 \\
10 \\
11 \\
12 \\
13 \\
14 \\
15\end{array}$ & $\begin{array}{l}64 \\
70 \\
74 \\
50 \\
75 \\
54 \\
52 \\
61 \\
52 \\
56 \\
77 \\
68 \\
67 \\
67 \\
59\end{array}$ & $\begin{array}{l}4.4 \\
3.5 \\
3.8 \\
2.8 \\
3.6 \\
3.9 \\
2.6 \\
2.9 \\
2.9 \\
3.0 \\
4.0 \\
3.2 \\
3.5 \\
3.8 \\
2.7\end{array}$ & $\begin{array}{l}0.8 \\
1.0 \\
1.0 \\
0.9 \\
1.0 \\
0.0 \\
1.0 \\
1.0 \\
0.9 \\
1.0 \\
1.0 \\
1.1 \\
1.0 \\
0.9 \\
0.9\end{array}$ & $\begin{array}{r}40 \\
38 \\
54 \\
63 \\
42 \\
61 \\
60 \\
113 \\
81 \\
71 \\
49 \\
45 \\
65 \\
50 \\
44\end{array}$ & $\begin{array}{l}400 \\
201 \\
340 \\
300 \\
310 \\
432 \\
300 \\
452 \\
350 \\
422 \\
342 \\
420 \\
427 \\
411 \\
379\end{array}$ \\
\hline
\end{tabular}




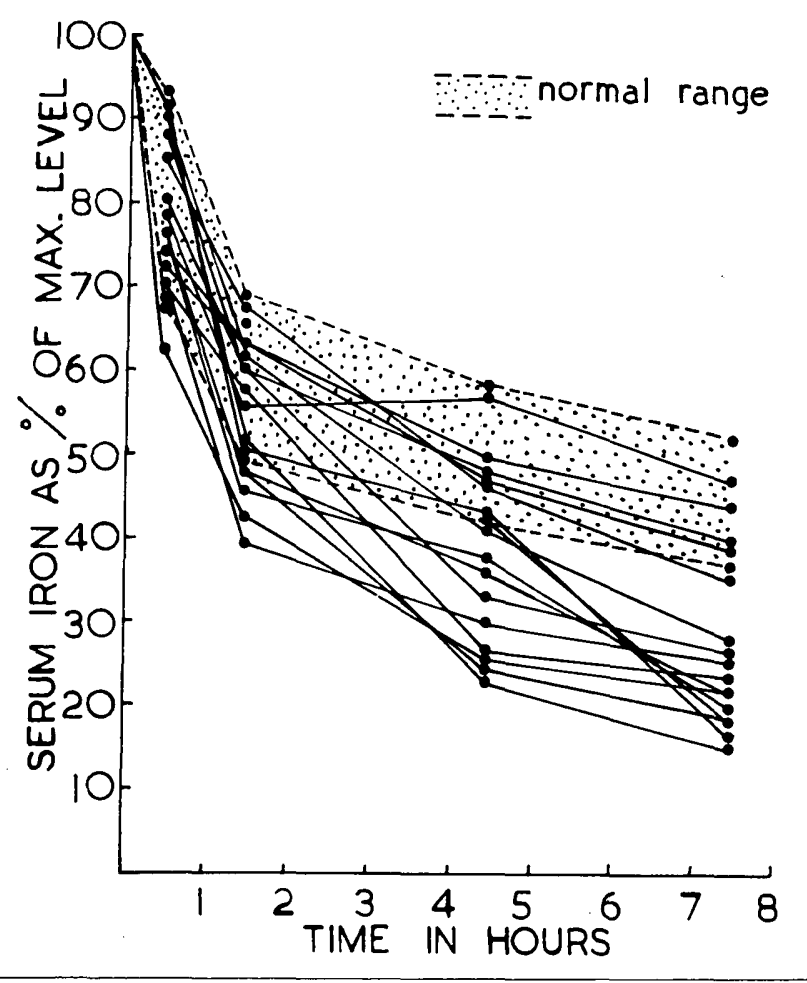

Fig. 22. Chronic hypochromic anaemia - rate of disappearance of iron after intravenous injection of $100 \mathrm{mg}$. "Iviron".

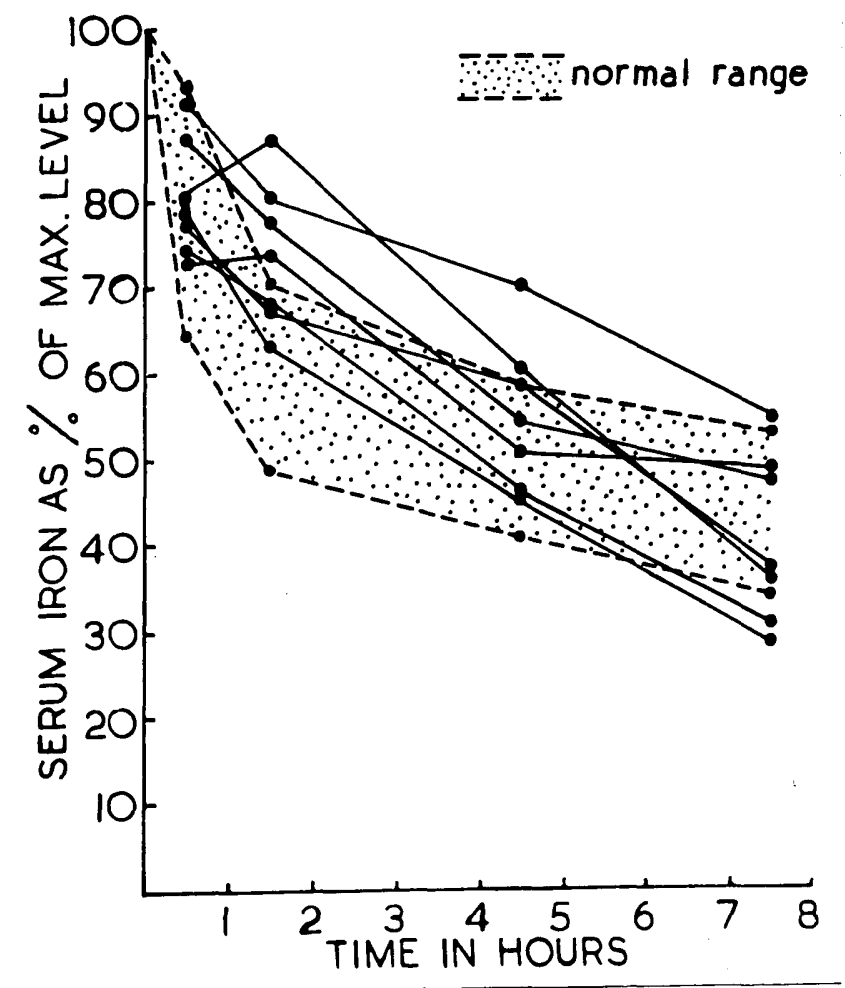

Fig. 23. Recent massive haemorrhage - rate of disappearance of iron after intravenous injection of $100 \mathrm{mg}$. "Iviron". 


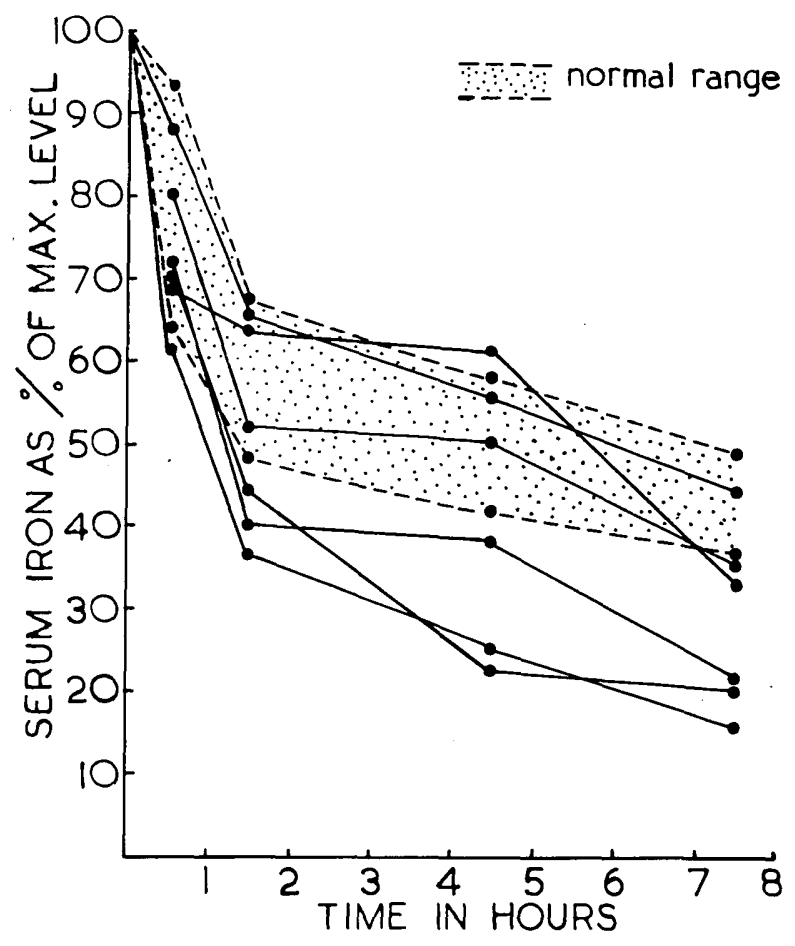

Fig. 24 Anaemia of toxic states - Rate of disappearance of iron after intravenous injection of I00 mg. "Iviron"

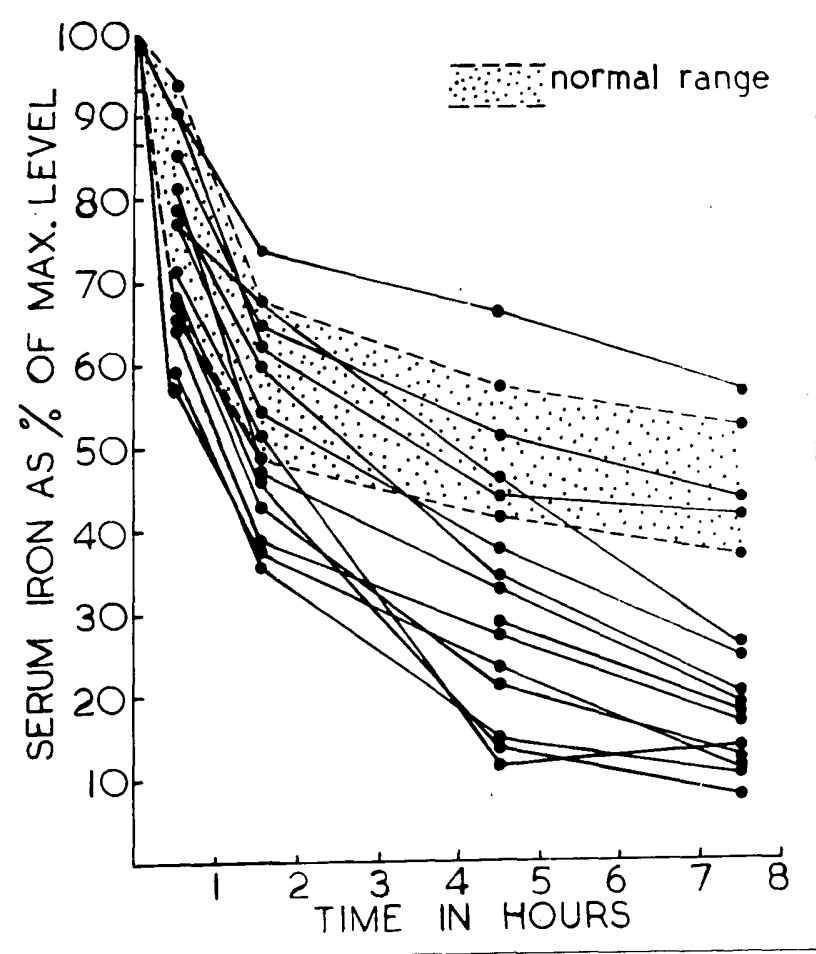

Fig. 25. Anaemia of infection - rate of disappearance of iron after intravenous injection of $100 \mathrm{mg}$. 


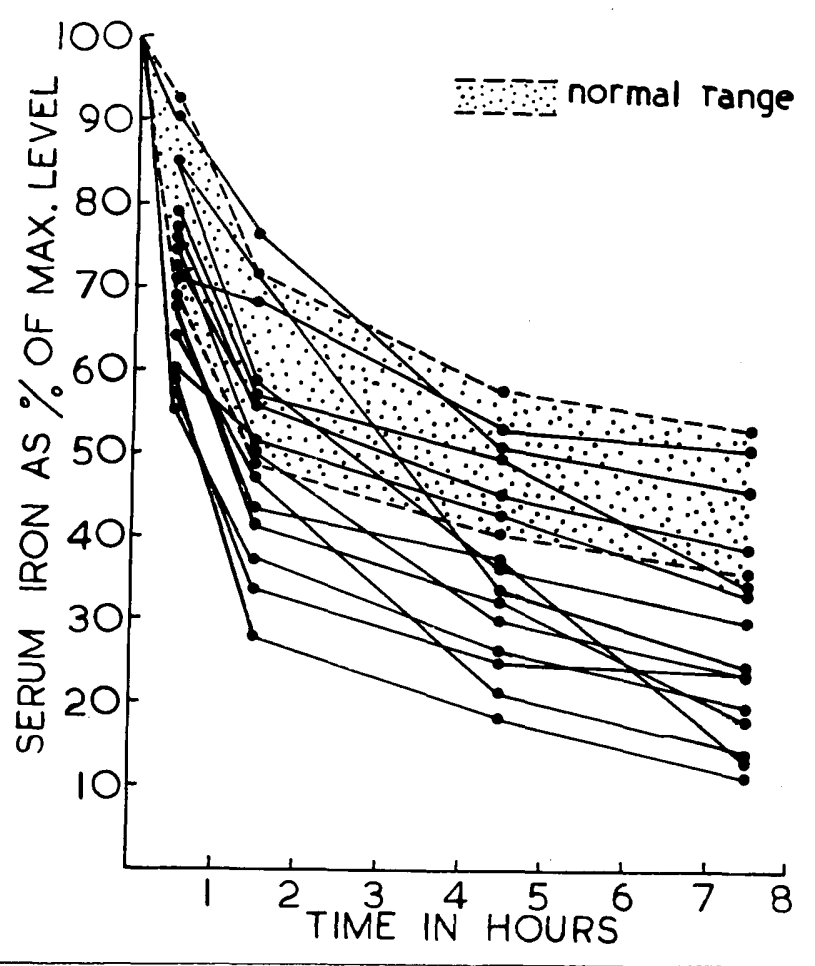

Fig. 26. Anaemia of neoplastic disease - rate of disappearance of iron after intravenous injection of $100 \mathrm{mg}$. "Iviron".

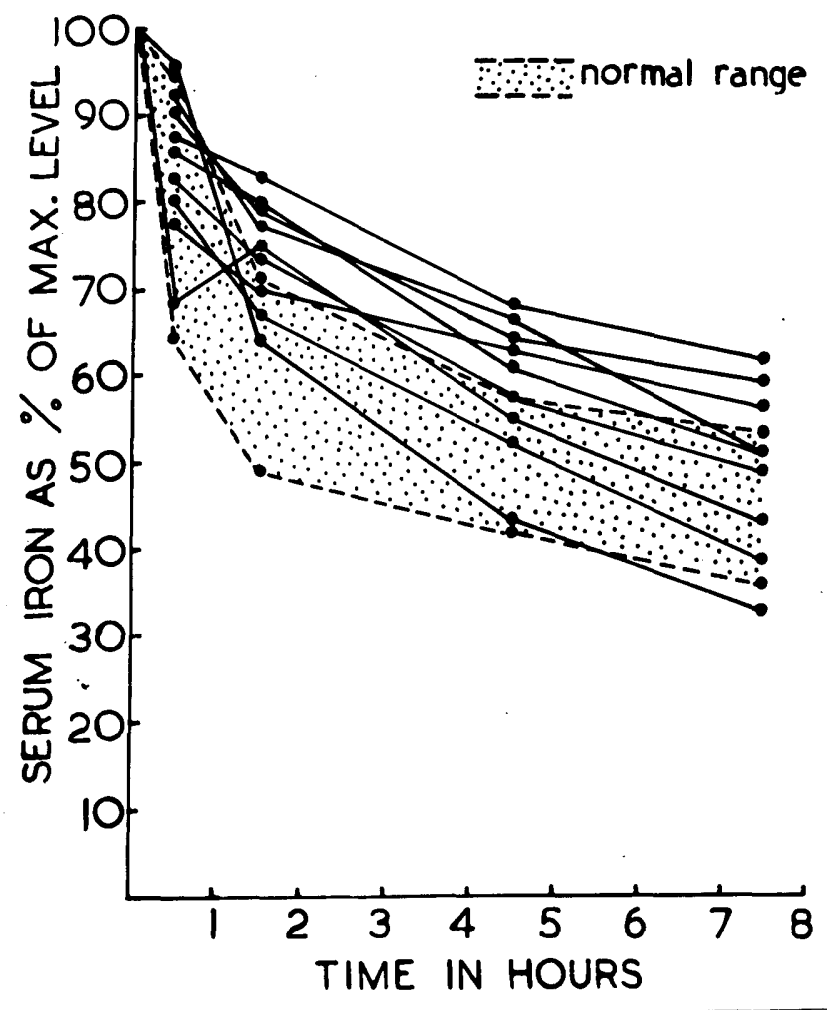

Fig. 27. Pernicious anaemia - rate of disappearance of iron after intravenous injection of $100 \mathrm{mg}$. "Iviron". 
the 5 min. level (the maximum level produced) in order to demstrate the rate of disappearance.

The two phases of the curves obtained will be considered separately:

(a) Level produced after injection of iron considered in relation to plasma iron-binding capacity;

(b) Subsequent rate of fall in relation to body requirements for iron.

Results in relation to iron binding capacity:

The various groups showed characteristic levels in the concentration of serum iron recorded 5 minutes after the injection of "Iviron" (Table 21). If the findings of Cartwright \& introbe (1948) are applicable to colloidal iron, these figures can be regarded as representative of the iron-binding capacity of the serum. They would indicate that when compared with normal this is raised in chronic iron deficiency both of idiopathic and post-haemorrhagic type, and lowered in the refractory toxic, infective and neoplastic anaemias and in pernicious anaemia. Shortly after massive haemovrhage there is no significant change. Comparison with the findings of Laurell (1947) in similar diseases after direct estimation of the iron-binding capacity of the serum shows close similarity in the manner in 
Table 21. Average serum iron levels after injection of $100 \mathrm{mg}$. of "Iviron" intravenously.

\begin{tabular}{|c|c|c|}
\hline $\begin{array}{l}\text { Type of } \\
\text { cases }\end{array}$ & $\begin{array}{l}\text { Av. serum iron level } \\
5 \text { min. after } 100 \mathrm{mg} \text {. } \\
\text { "Iviron", ug.\% }\end{array}$ & $\begin{array}{l}\text { Av. initial serum } \\
\text { iron level, ug. } \\
\text { (figs. from part } \bar{V} \text { ) }\end{array}$ \\
\hline Normals & 480 & 122 \\
\hline $\begin{array}{l}\text { Hypo- } \\
\text { chromic }\end{array}$ & 583 & 37 \\
\hline Toxic & 434 & 72 \\
\hline $\begin{array}{l}\text { Infect- } \\
\text { ive }\end{array}$ & 406 & 65 \\
\hline $\begin{array}{l}\text { Neo- } \\
\text { plastic }\end{array}$ & 380 & 65 \\
\hline $\begin{array}{l}\text { Pernic- } \\
\text { ious } \\
\text { anaemia }\end{array}$ & 439 & 152 \\
\hline $\begin{array}{l}\text { Massive } \\
\text { haemorr- } \\
\text { hage }\end{array}$ & 478 & 105 \\
\hline
\end{tabular}


which the level varies in the different groups of diseases, thus supporting the view that the level attained after injection of "Iviron" is under the control of the serum iron-binding capacity. Iaurell draws attention to the fact that the serum iron-binding capacity does not vary in proportion to the resting serum iron concentration, and from his findings concludes that when iron is being stored in the organs, as after haemolysis, the quotient of the manifest iron-binding capacity (indicated by resting serum iron concentration) to the latent iron-binding capacity (the portion of the iron-bindins protein which is not saturated) is higher than normal, whereas when iron is having to be mobilized from the depots, this quotient is greatly increased. Such a conception is supported by the present figures.

Rate of disappearance:

In previous work published, the rate of fall of the serurn iron after the naximum level has been reached has received comparatively little attention. From the present findings, it appears that in chronic hypochromic anaemia there is an increased rapidity in the rate of disappearance of the protein-bound iron. In refractory normochromic anaemia associated with toxic, infective and neoplastic 
disease, there is also a tendency to an increased rate of disappearance, in spite of the fact that there is no evidence of hypochromia and the anaemia is refractory to iron. In pernicious anaemia there is delay in disappearance. In chronic iron deficiency, an increased demand for iron by the body is undoubted, and provides a rational explanation for the rapid disappearance of iron from the blood. In pernicious anaenia there is waturation arrest of the narrow presumably resulting in much smaller iron sequirements. Flatter disappearance curves are therefore not surprising. If the findings in these two groups can be regarded as indicating that demand for iron determines the rate of its disappearance from the blood, then in the refractory toxic, infective and neoplastic anaemias, there may be a need on the part of the tissues for iron for some purpose other than haemoglobin fornation. Cartwright et al. (1946) and Tötterman (1949) have already demonstrated an increased rate of intravenous iron disappearance in infective diseases. It is of interest that the toxic and neoplastic groups here show similar patterns, as Heilmeyer (1937) assumed that an important aetiological factor in all these anaemias was deviation of iron from the bone 
marrow: Deviation in infection has not been accounted for by abnormal excretion of iron in the urine or bile, even when iron is given intravenously (Hahn et al.1939) and Schäfer's iron balance studies on children with sepsis (1940) also showed no increase in iron excretion. The findings presented later are contrary to Heilmeyer's idea that there is in fact deviation of iron from the marrow. The marrow certainly seems incapable of using iron normally in these refractory states but it appears that this may actually result in accumulation of iron there.

The rate of disappearance of iron from the plasma is not related in these experiments to the serum iron binding capacity. The serum iron binding capacity is high in iron deficiency anaemias and low in chronic refractory anaemias, yet the rate of iron aisappearance from the blood is rapid in each. Cartwright and Wintrobe (1949) restored the serum iron-binding capacity to normal in two patients with infection by intravenous injection of metal-combining globulin but were unable in this way to affect the rate of disappearance of subsequently injected iron. SUNMARY:

The suitability of saccharated iron oxide as a 
test substance for studying the rate of disappearance of iron from the blood has been discussed and the possibility of dialysis, adsorption and excretion considered. In spite of considerable experimental error in recovery of the iron content of such a preparation by the techniques chosen, the substance has been found useful for demonstrating relative differences in serum iron-binding capacity in different groups of anaemia and for perfoming intravenous iron diseppearance tests. Simpe iron deficiency anaemia appears to be associated with an increase in plasma iron-combining capacity, while refractory normoblastic anaemia and pernicious anamia are associated with a reduction. This reduction is greatest in pernicious anaemia. A differential rate of disappearance of iron from the plasma is demonstrable but is unrelated to the iron-combining capacity. The fact that the rate of disappearance is increased in chronic iron deficiency and decreased in pernicious anaemia suggests that it may be affected by iron requirement. An increased rate of disappearance is evident in the refractory anaemias associated with chronic toxic, infective, and neoplastic diseases. This selective rate of disappearance must be the result of differences in internal iron metabolism since all available evidence is in agreement that excretion, even of intravenously administered iron, is minimal. 
The findings obtained by intravenous disappearance tests will now be related to the results obtained with oral iron absorption tests. 
PART VII.

ORAL IRON ABSORPTION TESTS.

From a series of experiments performed by McCance and Widdowson. (1938) and Whipple. (1939), it can be concluded that the organism maintains its iron balance princlpally through control of absorption, and that iron excretion is a function of secondary interest lacking major physlological significance. The investigations of Mitchell and Hamilton (1949) suggested that significant amounts of iron are excreted in the sweat. Their findings, however, are difficult to accept, as they claim an excretion of 6.5 gms. of iron dally in this manner, an amount which exceeds the average daily intake. This relatively one-sided control of the body's iron content makes possible the study of Iron absorption by oral iron loading tests. Shortly after the establishment of various methods for estimating serum 1ron, numerous workers found that the serum iron level rose after oral ingestion of 1ron. Moore et al. (1939) recognised that this offered for the first time a means of making a direct comparison of the degree of iron absorption under different local conditions in the allmentary tract. Previous workers in investigating the amount of Iron absorption had had to rely on such indirect methods as 
measurement of the deficit in allmentary excretion of iron after ingestion of a known quantity. (Fowler and Barer, 1935; Widdowson and MCCance, 1937); estimation of the amount of iron removed from isolated segments of intestine under experimental conditions. (Abbott and Miller, 1936); or determination of the total increase in clrculating haemoglobin resulting from medication with a given amount of iron (Whipple and Robbins, 1936; Heath, 1933; Hahn, 1937). The Iron balance type of investigation offered great technical difficulties in that the amount of iron absorbed was so small compared with the amount ingested and excreted. In the isolated inteatinal loop there was the possibility that ab. sorption on the mucosa accounted for the disappearance of some iron presumed at the time to have been absorbed. Measurement of the hamoglobin increase incurred assumption that all absorbed iron was ut1lised for haemoglobin formation and none was diverted elsewhere. Moore and his associates were limited in the interpretation of their oral absorption curves by lack of knowledge regarding the rate of iron disappearance from the plasma. They were, however, able to show that soluble iron salts are absorbed exclusively into the blood stream, and not at all into the lymph, and, contrary to the experience of several other workers, that closely parallel curves could be obtained in the same subjects under 
standard conditions. Insolubie iron salts, they found, were not absorbed at all, while ferrous preparations were somewhat bettax absorbed tian ferric. Reducing substances aided absorption of the latter, but also often increased the uptake of ferrous iron. With the information available from the present work regarding the rate of diseppearance of iron from the blood stream, it was decided to explore further the value of oral absorption tests in the investigation of various forms of angemia.

Method: In selecting a substance for performance of oral iron absorption tests, the alm was to use a preparation which was readily procurable, reasonably palatable, and in liquid form. The amount of iron given was, of necessity, going to be far in excess of the average physiological iron intake, but it was none the less desirable to use the smallest quantity with which consistent results could be obtained. A dose of $45 \mathrm{gr}$. ferric ammonium citrate was found to fulfil these requirements. This dose was given in the morning to fasting subjects, and samples of blood were taken for serum iron estination immediately before giving the iron and at 2,4 , and 7 hours afterwards. In a few instances, samples were taken at $I$ and 3 hours afterwards as well, but as the maximum level was found to occur almost invariably in the 2 -hour specimen, the internediary estima- 
Table 22. Cases investigated by oral iron absorption tests.

Nature of cases No. investigate $\bar{\alpha}$

Chronic hypochromic anaemia

- post-haemorrhagic

- "idiopathic"

Gastro-enterostomy with

hypochromic anaemia

Pernicious anaemia

10

12

12

5

Refractory normoblastic anaemia

- in toxic states

8

- in infections

I 6

- in neoplastic diseases 
tions were discontinued. Intolerance to this dose of iron was minimal and only once resulted in vomiting.

In order to compare the degree of iron absorption in individual cases, the resting serum iron concentration was subtracted from subsequent values. The curves therefore represent the actual increase produced by oral iron loading. Changes in plasma volume in anaemia must influence the concentration of Iron recorded, but as the difference in various forms of anaemia appeared significant without making such al lowance, plasma volumes were not calculated. Material: The accompanying table, (Table 22), indicates the material investigated by oral iron absorption tests. Curves obtained in normal subjects: The results obtained in 10 normal subjocts are shown in Fig.28a. The group included both sexes, and the ages ranged from 18 to 65 years. All persons had a normal blood level and normal blood sedimentation rate, and physical examination of each was entirely negative. The maximum increase in serum iron concentration produced is seen to range from 18 to $83 \mathrm{u}$ g. per cent. Individual curves were reproducible (Fig.28b), indicating that this variation must be due to intrinsic characteristics in the subjects, and not to inaccuracies arising from the method. The criticlsm may be ralsed that the smaller changes produced are within the limits of spontaneous diurnal varlation. 


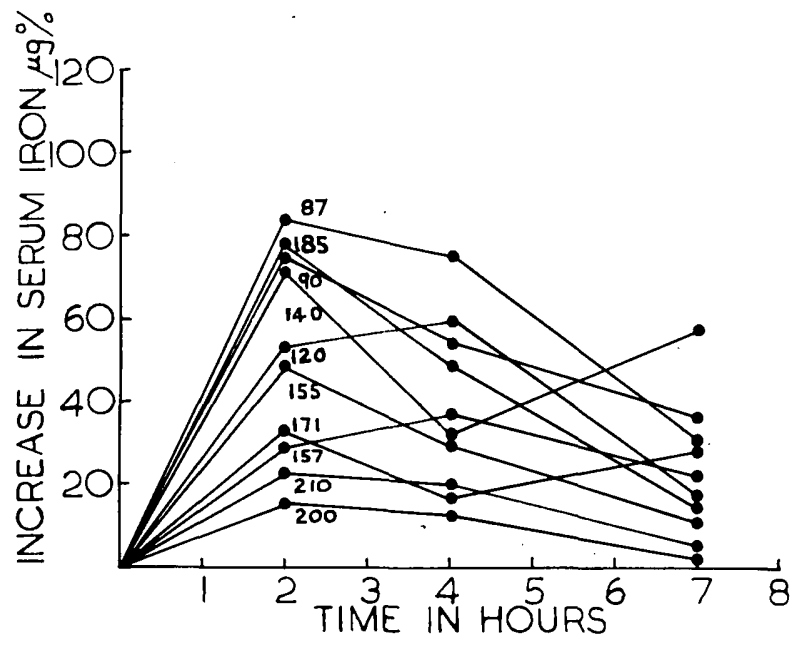

Fig. 28a. Oral iron absorption curves in normal subjects.

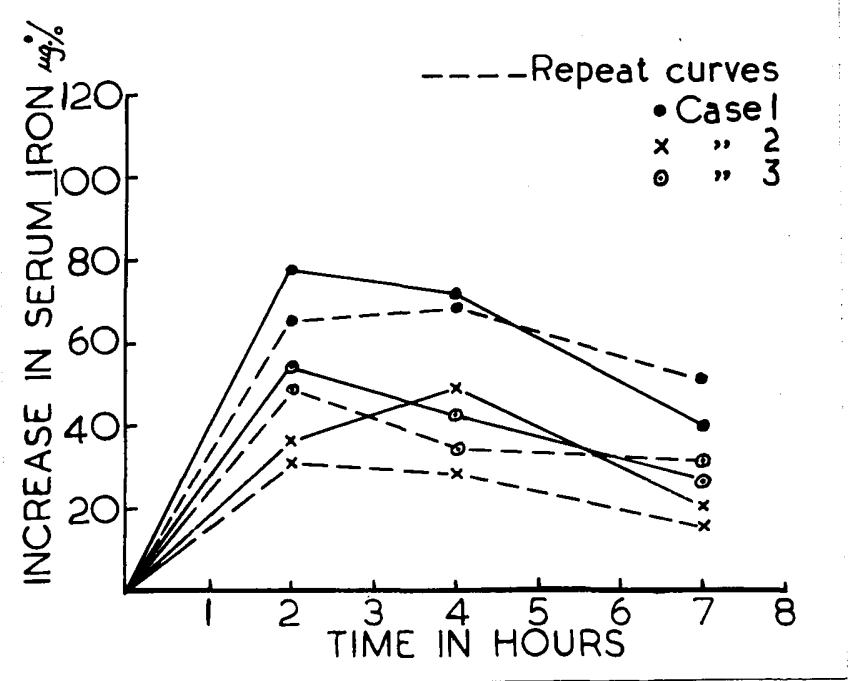

Fig. 28b. Repeat oral iron absorption curves in normal subjects. 
Nevertheless, since the changes were consistently positive and occurred shortly after iron administration, it seems reasonable to assume that they represent alimentary iron absorption.

The fasting serum iron concentrations are indicated as figures on their respective curves. Superficial examination suggests that the height of the curve after loading bears an inverse relationship to the fasting concentration. The numbers are too few for this to be anything further than an observation, but this tendency was observed by Thedering (1948). From analysis of 314 curves of his own and 27 collected from the literature, he showed that this relationship was statistically significant and used it to support his view that control of serum iron, like that of other physicomchemical systems in the body, is under autonomic influence. According to Wilder's Law, (WIlder, 1931), the fasting levels, ("starting values"), are dependent upon the state of equilibrium in the autonomic nervous system, and when autonomic stimulation happens to be present at the moment of the experimental observation being made, weak or even paradoxical responses may be expected. The level of the resting serum iron concentration, he concluded, affects the type of absorption curve obtained. On the other hand, using a radioactive technique, Dubach et al. (1948) produced results Indicating that the serum iron level did not affect 
absorption directly. Iron introduced intravenously to raise the serum concentration to $500 \mathrm{ug} . \%$ did not alter the amount of an oral dose absorbed. Analysis of oral iron curves in chronic hypochromic anaemia. Twentytwo cases of chronic hypochromic anaemla were investigated. These are divided into two sub-groups according to whether or not haemorrhage could be demonstrated. In neither group could dietary deficiency or multiple pregnancy be considered as contributing to the anaemia. Twelve cases were regarded as examples of essential idiopathic hypow chromic anaemia, and in these, thorough investigation, including $X$-ray of the alimentary tract and examination for occult blood in the stools, revealed no evidence of abnormal blood loss. In the other 10 cases, haemorrhage could definitely be regarded as an important causal factor in the anaemia. In these patients bleeding was manifested as menorrhagia, chronic haemorrhage from piles, or chronic bleeding from peptic ulcer. Patients in whom there was doubt regarding the possible role of blood loss in precipitating their anaemia were not included in the investigation. The curves obtained are shown in Figs.29. and 30. A striking feature in both groups is the wide variation in the serum iron levels recorded at 2 to 4 hours after iron administration. This spread is not wholly a chance occurrence, because repetition of the test in several subjects yielded similar 


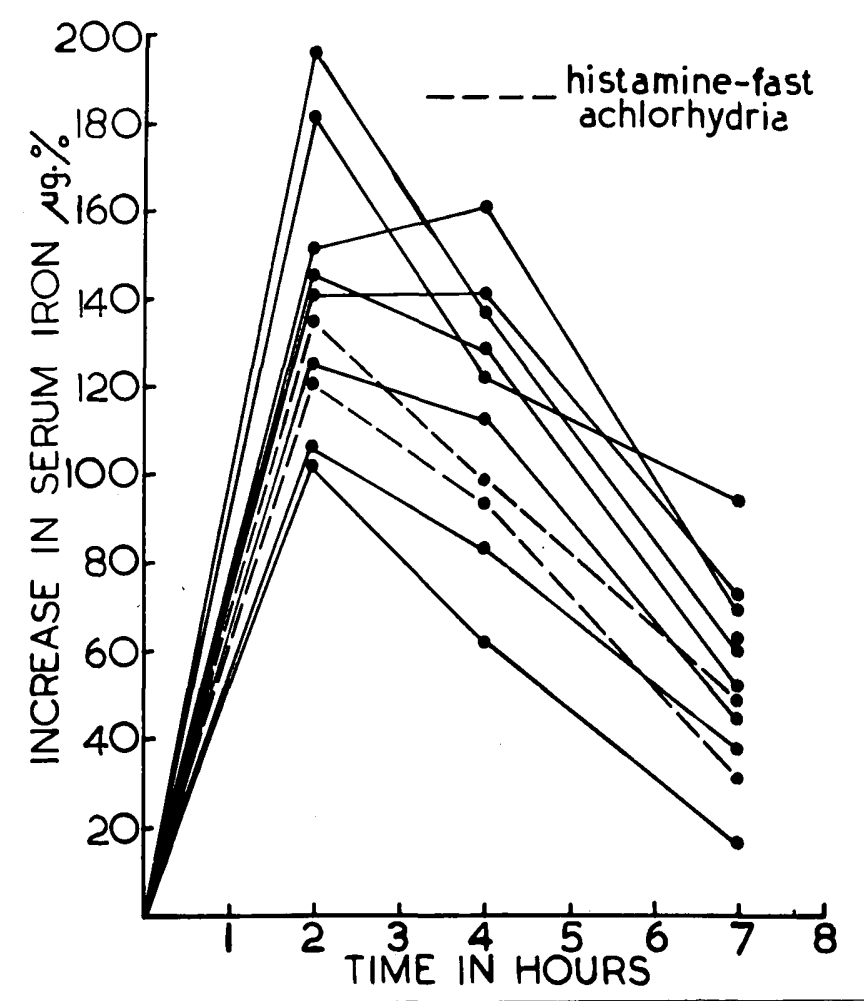

Pig. 29. Oral iron absorption curves in posthaemorrhagic iron deficiency anaemia.

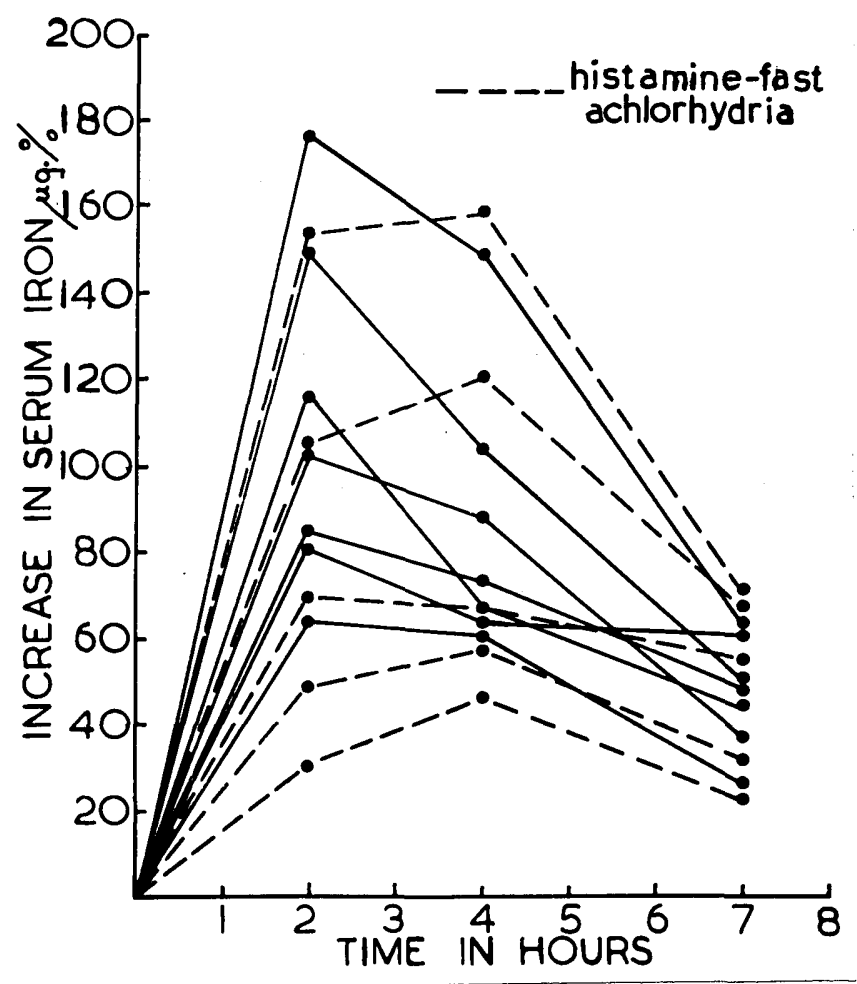

Fis. 30. Oral iron absorption curves in iaiopathic iron deficiency anaemia. 
results, thus indicating that the amount of iron absorbed is characteristic for each individual. The curves were therefore investigated in relation to the following factors which might possibly influence iron absorption: (1) Age and sex; (2) Gastric acidity. (3) Haemoglobin level - this represents to some extent the body iron reserve at the time as the haemoglobin level probably does not fall till avaliable tissue fron is exhausted, (Vannottil and Delachaux, 1949). (4) Body's ability to utilise iron given as indicated by the rate of haemoglobin regeneration. (5) Simultaneous rate of disappearance of iron from the serum. Age and $s e x$ as influencing iron absorption in hypochromic anaemia: Only 3 of the 24 cases were males so that sex is not a factor concerned. There is also no close relationship to age. One of the flat curves and one of the steep curves are both from patients aged 21 years. The ages of the remainder of the group likewise show no relation to the curves obtained, but the ages range only up to 48 years, - which is perhaps too limited on which to make any significant comparison.

Effect of gastric acidity on iron absorption in bypochromic anaemia: In all cases the fasting stomach contents were tested for the presence of free hydrochloric acid. Histamine 
(0.5 ml.) was given if there was no free acid present, and the juice tested again 15 mins., and if necessery, 45 mins.: later. Cases with histamine-fast achlorhydria are indicated in the charts and it is apparent that there is no relationship between the height of the serum iron curve and the occurrence of achlorhydria. This raises the problem regarding the role of hydrochloric acid in iron absorption and therefore in the production of anaemia. There is evidence that normal gastric acidity is probably required for optimal assimilation of food iron. (Barer and Fowler, 1937; Kellogg and Mettier, 1936; but there is doubt regarding the effect of gastric acidity on the absorption of metalif iron salts in therapeutic doses. Brock and Taylor (1934) showed that dialysis of soluble inorganic iron salts is hastened by the addition of small amounts of mineral acid and retarded if the solution is made alkaline. Halvorsen and Starkey (1927) had proviously shown that at a pH of over 5.0, only small concentrations of iron are present in solution. In therapeutic triels Mettier and Minot (1931) obtained a higher reticulocyte response when they gave iron and ammonium citrate in an acid-buffered medium than when they gave it in an alkali-buffered medium, a finding confirmed again in later work (Minot and Heath, 1932). On the other hand, Balrer and Fowler (1937) obtalned as much retention of 
iron after high dosage in subjects with an achlorhydria as in those with normal gastric acidity, and Moore et al. (1939), although observing lower absorption levels of ferric salts than ferrous salts given in massive dosage, found no significant relationship to the presence or absence of free hydrochloric acid in the gastric juice. Workers using reduced iron as their test agent, (Heilmeyer and Plotner, 1937), did find that hydrochloric acid aided absorption as it increased solution and ionization of the iron in the gastro-intestinal tract. When soluble ionized salts are given, hydrochloric acid may assist in preventing their change into insoluble and undissociated compounds (Tompsett, 1934 and 1935).

My own investigations show not only that iron may be very well absorbed in the presence of achlorhydria, but also that it may be relatively poorly absorbed when gastric acidity is normal. In 3 cases showing poor absorption and achlorhydria, a similar dose of iron was given along with 20 minims dilute hydrochloric acid. No alteration in the absorption curve resulted (Fig. 30a). In interpreting these results, it must be remembered that the iron preparation used was in itself acid and was given in massive dosage. Its own acidity might counteract any necessity for the presence of hydrochloric acid to maintain a suitable medium for absorption, and the high dosage might overcome any mucosal barrier. 


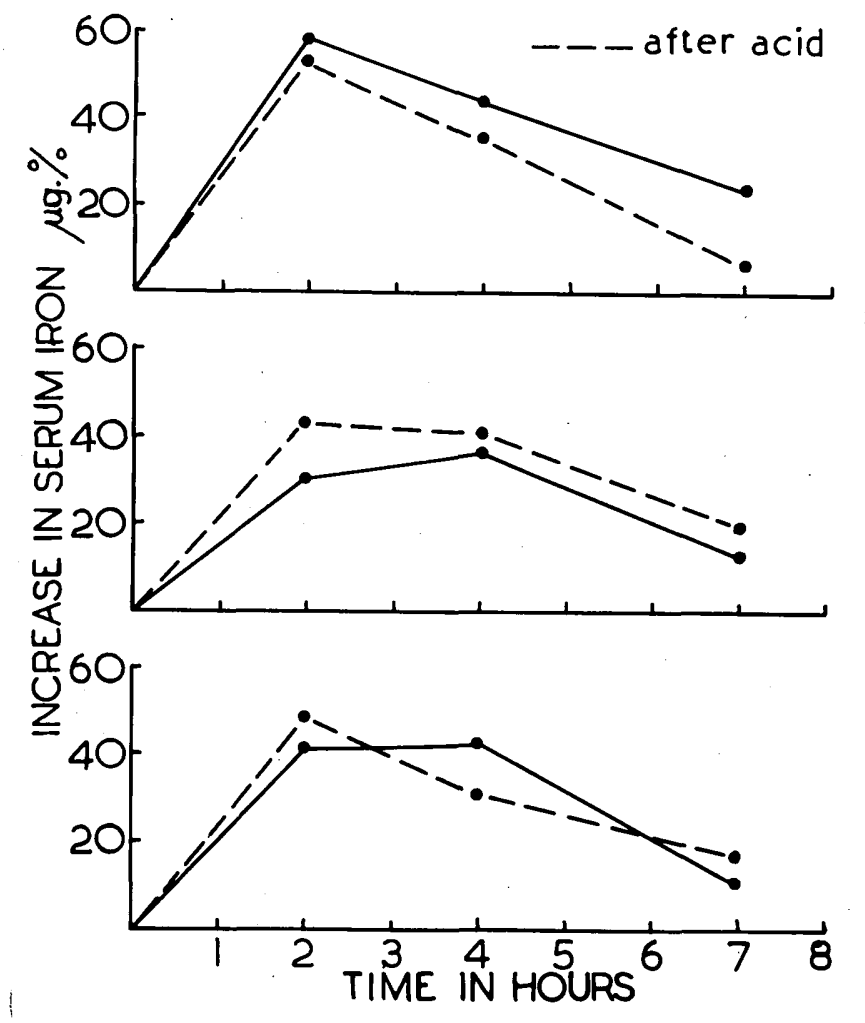

Fig. 30a. The effect of 20 minims dilute hydrochloric acid on iron absorption curves in achlorhydric patients.

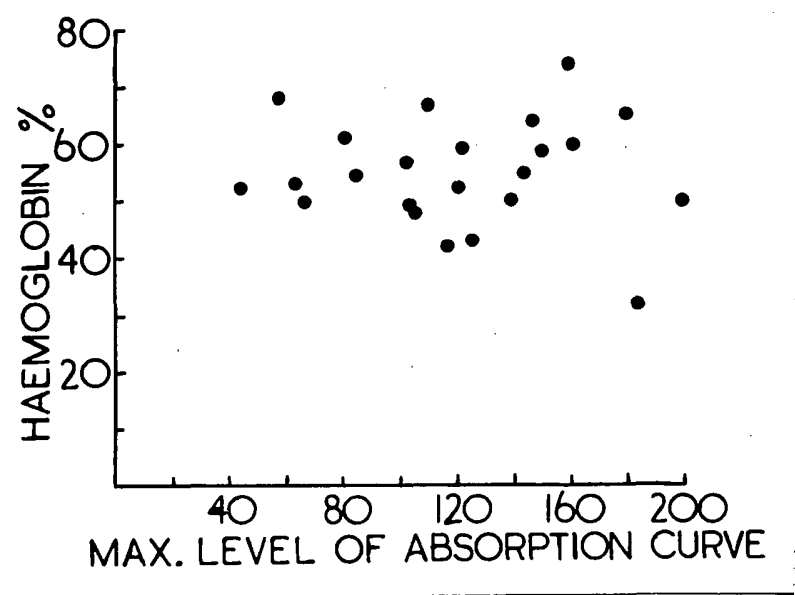

Pig. 31. liaximum absomption levels in relation to haemoglobin levels in iron deficiency anaemia. 
The technique is therefore probably not suitable for analysing the role of hydrochloric acid in the absorption of iron under physiological circumstances. It does however indicate that when iron is given in therapeutic dosage, the addition of hydrochloric acid is of no further benefit. Absorption of iron in relation to haemoglobin level and utilisation: When absorption levels are related to haemoglobin levels, no correlation is seen. (Fig.31). This is perhaps to be expected. The circulating haemoglobin iron is intracellular, and therefore unlikely to influence intestinal absorption of iron directly. An idea of efficlency of utilisation of iron can be obtained only from compaing the relative rates of haemoglobin regeneration. This is obviously unsatisfactory, as any such comparison must presuppose a uniform rate of utilisation of absorbed iron. In the present work it is also unfortunately not possible, as patients received varied forms of treatment after the initial investigations were performed. The use of radioactive iron would provide the most satisfactory answer. Dubach et al. (1946) showed that radioactive iron given intravenousiy appeared more rapidly in the peripheral blood in patients with chronic haemoglobin deficlency due to blood loss than in normal subjects. They make no comparison of rates of utilisation in different patients with iron deficiency. An extension of their work to cover this aspect 


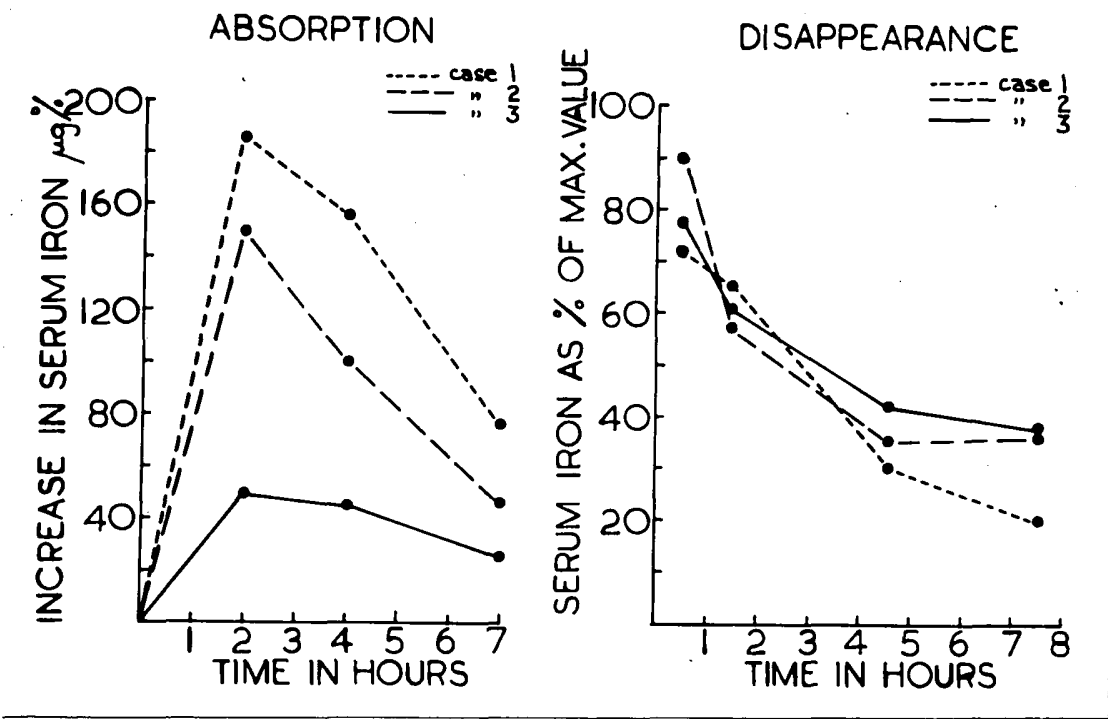

Fig. 32. Comparison of oral iron absorption curves and intravenous iron disappearance curves in the same individuals. 
woulà seem desirable.

Oral absorption curves in relation to the rate of disappearance of iron from the serum: Local conditions in the alimentary tract may impede iron absorption, and result in flat curves after oral iron loading, but such curves could also be due to unusually rapid disappearance of iron from the serum. It has already been shown that the rate of disapporance of intravenously injected iron is raised in iron deficiency anamia as a group (Fig.22). To compare individual results both oral and intravenous iron tests were performed on three patients before treatment (Fig.32). On these results the relative rate of iron disappearance from the serum does not account for the differences in oral curves. Comparison of oral curves in essential and post-haemorrhaglc chronic iron deficiency: From these investigations no obvious feature emerges to account for the variable curves obtained. Age, sex, gastric acidity and rate of disappearance of iron from the serum have no significant demonstrable influence. If the cases are considered in their two groups, however, one observation seems justified. In the idiopathic group, 6 out of 12 curves show a rise of less than 100 u.g.\%. at any point in their course, while in the post-haemorrhagic group, all of 10 curves rise more than $100 \mathrm{u} . \%$. The poss $1-$ bility of differences in alimentary absorption should be considered further. The flatter curves in idiopathic 
hypochromic anaemia might indicate an impalred ability to absorb iron. The fact that there is no clear-cut difference in the curves of the two groups is not necessarily disconcerting. The idiopethic group is elmost certainly a heterogeneous one, since cases are classed as such simply because no cause has been found for the anaemia at the time of examination, and the post-haemorrhagic group could quite well include cases in whom defective absorption of iron had hastened the development of anaemia. Presumably if these groups show differences in their ability to absorb medicinal iron when the need is similar, there may also be differences in their ability. to absorb food iron under normal circumstances. If such a primary defect in iron absorption is postulated, it means adding yet another factor to the already long list of possible aetlological factors in iron deficiency. The cases classed here as essential idlopathic hypochromic anaemia do, however, seem to indicate that such an abnormality is deserving of consideration. All were apperently taking a balanced and adequate diet, none showed anything to suggest an increased demand for iron, none had any signs of abnormal blood loss, (several of the females had even passed the menopause), and many had normal gastric acidity.

The conception of a possible primary defect in the 
mechanism of iron absorption in essential hypochromic anaemia is not a new one. Lederer (1939 and 1940) performed a series of experiments from which he concluded that liberation of complex food iron in normal subjects is effected by means of an enzyme acting in the presence of free hydrochloric acid. His findings demonstrated that in idiopathic hypochromic anaemia this enzyme is absent, while in pernicious anaemia it is present but inactive, owing to achlorhydria. In this way he accounted for otherwise unexplained cases of hypochromic anaemia. I have been unable to find any work either confirming or disproving Lederer's theory. If such an enzyme does, in fact, exist, but requires hydrochloric acid in order to function, it is difficult to understand why there is not a much greater incidence of iron deficiency accompanying perniclous anaemia. Thedering (1949) found poorer alimentary absorption of iron during recovery in "idiopathic" iron deficiency patients than in patients with chronic post-haemorrhagic anaemia, and concluded that malabsorption of iron was a basic factor in the production of unexplained iron deficiency anaemia.

Surprisingly little attention has in fact been paid to the subject of fron absorption in the fasting individual. Dietary factors under such conditions are eliminated, and the iron uptake can be as sumed to depend purely upon demand by the organism for iron and upon local conditions in the 
alimentary tract. There is no doubt from published work and from the present curves that great need for iron, such as occurs in post-haemorrhagic anaemia, leads to a great increase in the amount of iron absorbed (Hahn et al. 1939.a; Custom \& Greenberg, 1940; Balfour, 1942). In regard to local conditions, hydrochlorlc acld has already been discussed and regarded as of little significance in connection with absorption of iron in therapeutic doses, but possibly of significance in maintaining a suitable medium for liberation of iron from food complexes. Apart from this, the on Iy studies on local conditions appear to have been by laylor et al. (1931 and 1935), and Gillman and Gillman. (1945). Taylor and his colleagues observed that ligature of the pancreatic duct or removal of the pancreas resulted in excessive accumulation of iron in the body, particularly in the peripheral parenchymal cells of the liver lobules. They claimed that this was accompanied by atrophic changes in the epithelial cells lining the gut. These findings were confirmed by Gillman and Gillman. (1945). There is evidence, therefore, that change in composition of the upper alimentary tract secretions other than alteration in acidity may affect the assimilation of iron. The present findings suggest that such may play a part in production of idiopathic iron deficiency anaemia. If such a defect does exist, it must be 
readily overcome in the majority of cases by massive oral iron intake, as is evident from the fact that all patients responded satisfactorily to routine oral iron medication. No examples of simple iron deficiency fefractory to oral iron were encountered during the treatment of 189 cases of uncomplicated chronic hypochromic anaemia, only five of which required admission to hospital for adequate supervision of treatment. The opportunity was not therefore obtained for performing absorption tests in a selected group in which malabsorption could be suspected. Oral absorption curves in gastro-enterostomy: Accumulated data on the problem of anaemia in patients who have undergone gastric operations indicate that there is a definitely higher incidence of anaemia in this group than in the general population. Whitby and Britton (1950) state that "there can be little doubt that anaemia after gastric operation is the result of the surgery". In the vast majority of cases it is hypochromic in type (Taylor et al. 1929; Morley \& Roberts,1928 Hartfall, 1934; Lublin, 1931,), but Vaughan (1932) showed tnat there may in fact be a dyshaemopoietic element in addition to the iron deficiency in a considerable proportion of cases. Two xtiological factors are commonly suggested. Firstly, regurgitation of alkaline intestinal juices may make the stornach contents alkaline, and therefore hinder liberation 


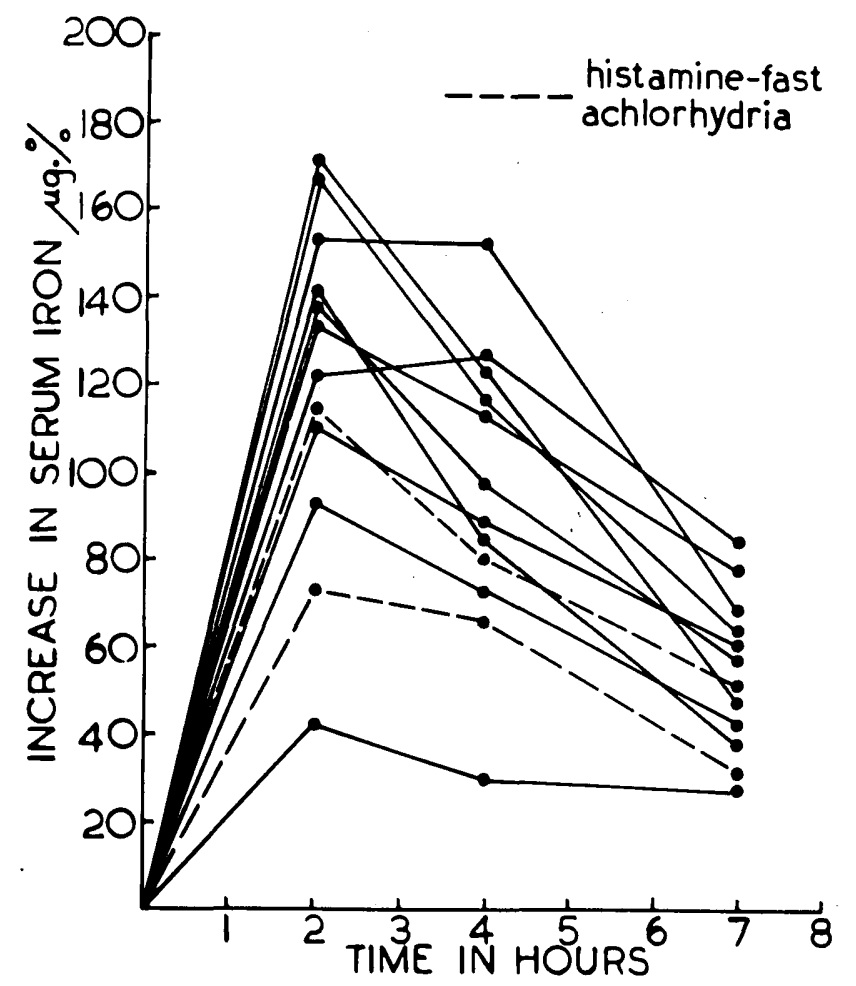

Fis. 33. Cral iron absorption curves in gastroenterostomy associated with iron deficiency anaemia.
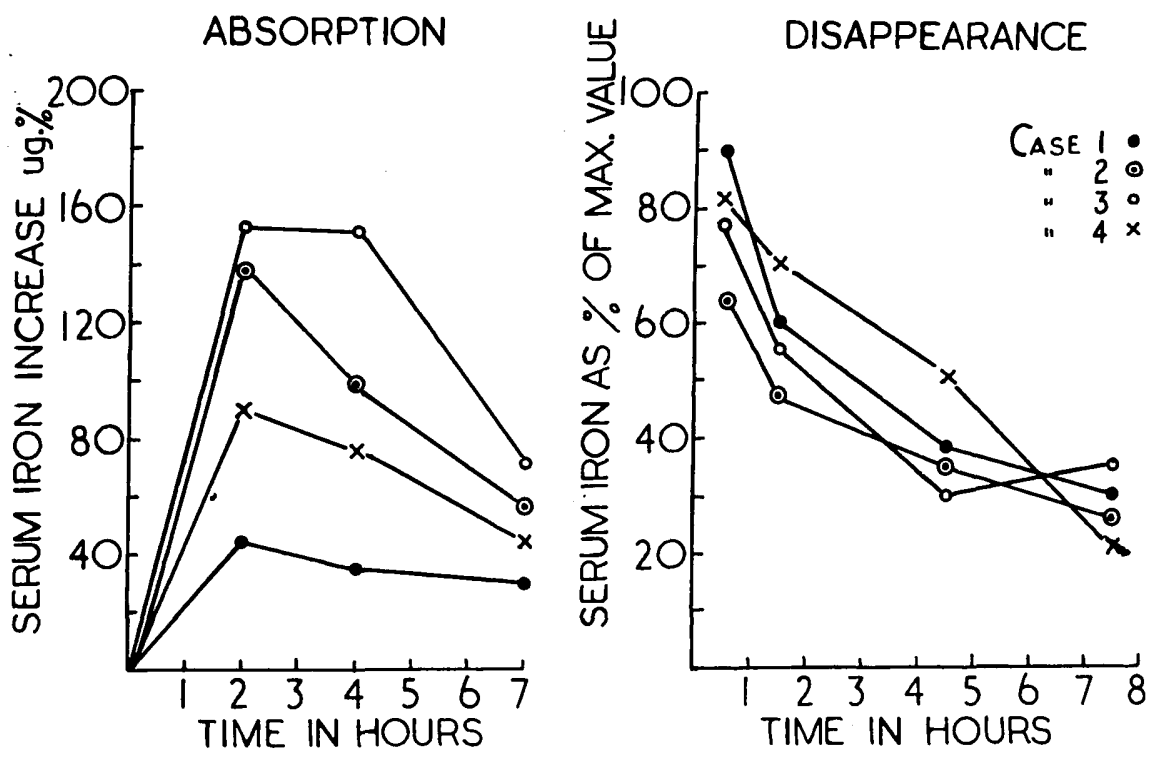

Hig. 34. Intravenous iron disappearance in relation to oral iron absorption in gas iro-enterostomy. 
of iron from the food. Secondly, unduly rapid transit of food through the upper alimentary tract may not allow time for the iron to be separated and assimilated. Iublin (1931) studied the acidity of the stomach after gastroenterostomy, and found normal or hyperacidity present. It therefore appears that local changes in acidity can have little significant role in production of the anaemia. Mechanical changes resulting from such operation may well be such as to predispose to anaemia from malabsorption due to intestinal hurry. Such malabsorption might be revealed by oral iron absorption curves.

Oral iron absorption tests were performed in 12 consecutive cases of gastro-enterostomy presenting on account of symptoms of anaemia. Six of these were males. Operation had been performed one to thirty years previously because of peptic ulcer. The anaemia was of moderately severe hypochromic type in all instances, and the bone marrow, examined in each, was active and normoblastic. In 9 cases the iron absorption curves were high, and in 3 they were normal (Fig.33) In two of the patients with Iow curves and in two with high curves intravenous iron disappearance tests were performed (Fig.34). A consistent relationship between alimentary absorption of iron and rate of disappearance from the serum 
was not established, and it would appear that differences in absorption curve levels have to be attributed to differences in the amount of iron absorbed from the alimentary tract. The proportion of cases showing low curves ( 3 out of 12 ) is surprisingly small if malabsorption is the main aetiological factor in producing the anaemia. Nevertheless, two of the patients with low curves had been taking supplementary iron orally in considerable amounts for several months without effect. Another patient on whom an absorption test was not performed had been treated on two previous occasions for hypochromic anaemia. During the eighteen months prior to being seen she had taken Colliron and Vitamin C. daily, but the haemoglobin remained around $40 \%$ and the red cell count at just over $4 \mathrm{million} / \mathrm{c} . \mathrm{mm}$. Iron was then given intravenous ly (200 mgm. twice a week to a total of $2,600 \mathrm{mgm.)}$ An immediate response resulted, and the haemoglobin rose steadily to $96 \%$. Malabsorption of iron cannot therefore be discounted as possibly being of importance, but in considering the whole group of cases, there are other factors which seem to deserve more attention than is often given to them.

The high curves obtained in the majorlty of the gastro-enterostomy patients are of the type already demonstrated in chronic post-haemorrhagic anaemia. In patients with 
a gastro-onterostomy, there is the possibility that healing of the original ulcer in a proportion of cases is incomplete. Moreover, a stomal ulcer may develop and this does not always produce symptoms. It might consequently be said that patients with gastromenterostomy form a selected group in which to watch for the development of haemoglobin deficlency anaemia due to chronic haemorrhage. Only two of the present group showed a positive faecal occult blood, but a negative test when the patient is investigated does not eliminate the possibility that bleeding may proviously have been present. Many peptic ulcer patients have had impressed upon them the necessity of taking a "bland diet". Ieft to the patient, interpretation of this advice often results in a most inadequate dietary regime, In which deficiency of ixon is one of the features. Assessment of the dietary intake of patients at home is notorlously difficult, but there is no doubt that 5 of the present group were existing on a completely inadequate food intake in which satisfactory sources of iron were few.

The conception of malabsorption of iron as a caase of anamia after gastro-enterostomy should therefore prob$a b l y$ not be allowed to take precedence over the more common causes of iron deficiency anaemia such as chronic haemorrhage and deficient iron intake. In this series, as 
In the simple iron deflciency anaemias, even patients with flat curves responded to oral treatment under hospital supervision. (The one who recelved intravenous iron and on whom a test was not performed was not hospitalized.)

Oral absorption curves in perniclous anaemia.

Absorption curves were performed in 5 classic cases of untreated permicious anaemia in whom the initial serum Iron levels were hlgh. During the first two hours, a rise was demonstrable, (Fig.35), but this was the only group which later showed a fall to below the fasting serum iron concentration. It has already been shown that removal of iron once in the blood stream tends to be delayed in rate in pernicious an aemia. It is certainly not accelerated, so that the unusual fall in oral curves cannot be accounted for by the rate of disappearance of iron from the blood. The fall probably indicates that serum iron levels are not being sufficiently influenced by the iron absorbed to overcome the effect of the spontaneous daily fluctuation in serum iron which at high levels is sometimes associated with a drop towards evening. The initial rise indicates that some iron is being absorbed, even although maturation of erythrocytes is arrested and iron requirements for haemoglobin formation correspondingly small. It should be noted that the greatest height is not actually less than in some of the normal individuals, but it is not so long maintained. 


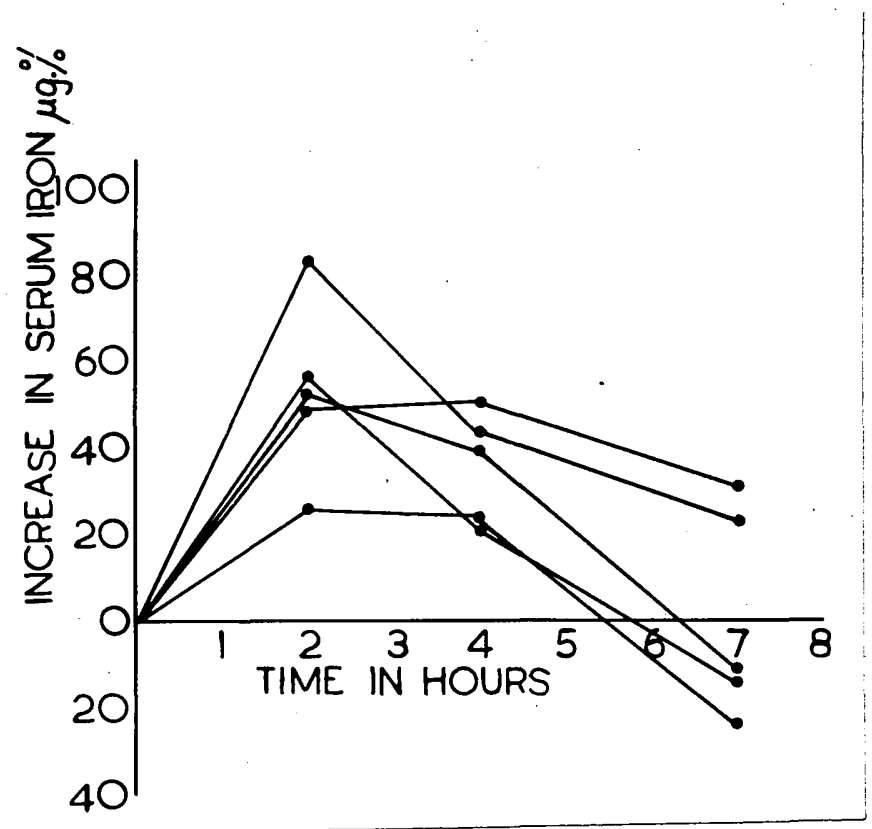

Fig. 35. Oral iron absorption curves in pernicious anaemia. 
Confirmation that some iron is absorbed in patients with untreated pernicious anaemia but not immediately made use of is found in the work of Dubach et al. (1946), who show that radioactive iron given orally appears only in very small amounts in the circulating red cells of untreated cases, but once remission is induced, radioactive iron rises to as much as $20 \%$ in the peripheral blood without any further oral dose being given. This indicates that even though the tissues probably contain an excess of stored iron, a proportion of orally adminlstered iron is still absorbed, and is used later in haemoglobin formation. Analysis of oral curves in an aemia associated with toxic, infective and neoplastic disease. Iron lack as an aetiological factor in the production of anaemia of infection and related refractory normochromic anaemias has been exhaustively investigated, and in spite of consistently negative findings, It is still often postulated. The fact that most such anaemias are now being proved refractory to parenteral as well as to oral iron is strengthen ing the ovidence against iron deficiency in itself being a cause of the anaemia. The fate of iron in such states remains imperfectly understood. Block to intestinal iron absorption or block to utilisation in the marrow are postulated. The small recovery of radio-active material in erythrocytes following administration of radio-active iron orally, as described by Finch et al. 
(1949) and Dubach et al. (1946) cannot be regarded as necessarily indicative of poor iron absorption in view of the fact that all absorbed iron is not always immedlately utilised. Dubach: et al.(1950), by radiomactive Iron balance experiments used in conjunction with estimations of iron utilisation, found absorption of $52 \%$ and $32 \%$ of orally administered iron in 2 cases of lymphadenoma and $20 \%$ in a patient with haemochromatosis. On the other hand, in animal experiments, Gubler et al.(1950), found that the total fron content of infected rats fed on iron-enriched diet was less than the iron content of normal rats fed the same diet for a similar period. Whether their experimental findings can be applied to humans is doubtful.

Oral iron absorption tests were applied to the problem in the present work. Cases investigated included patients with uraemia, rheurnatold arthritis, empyema, pyelitis, pneumonia, lymphadenoma, chronic leukaemia and bronchial carcinoma. No cases with any evidence of blood loss were included. The anaemla was of normochromic normoblastic type in all cases except two, in which it was slightly hypochromic. The curves obtained were of a pattern comparable to normal in each group (Figs.36,a, b, and c.) Since absorption of iron was not depressed, as compared with normal, there is no evidence that malabsorption 

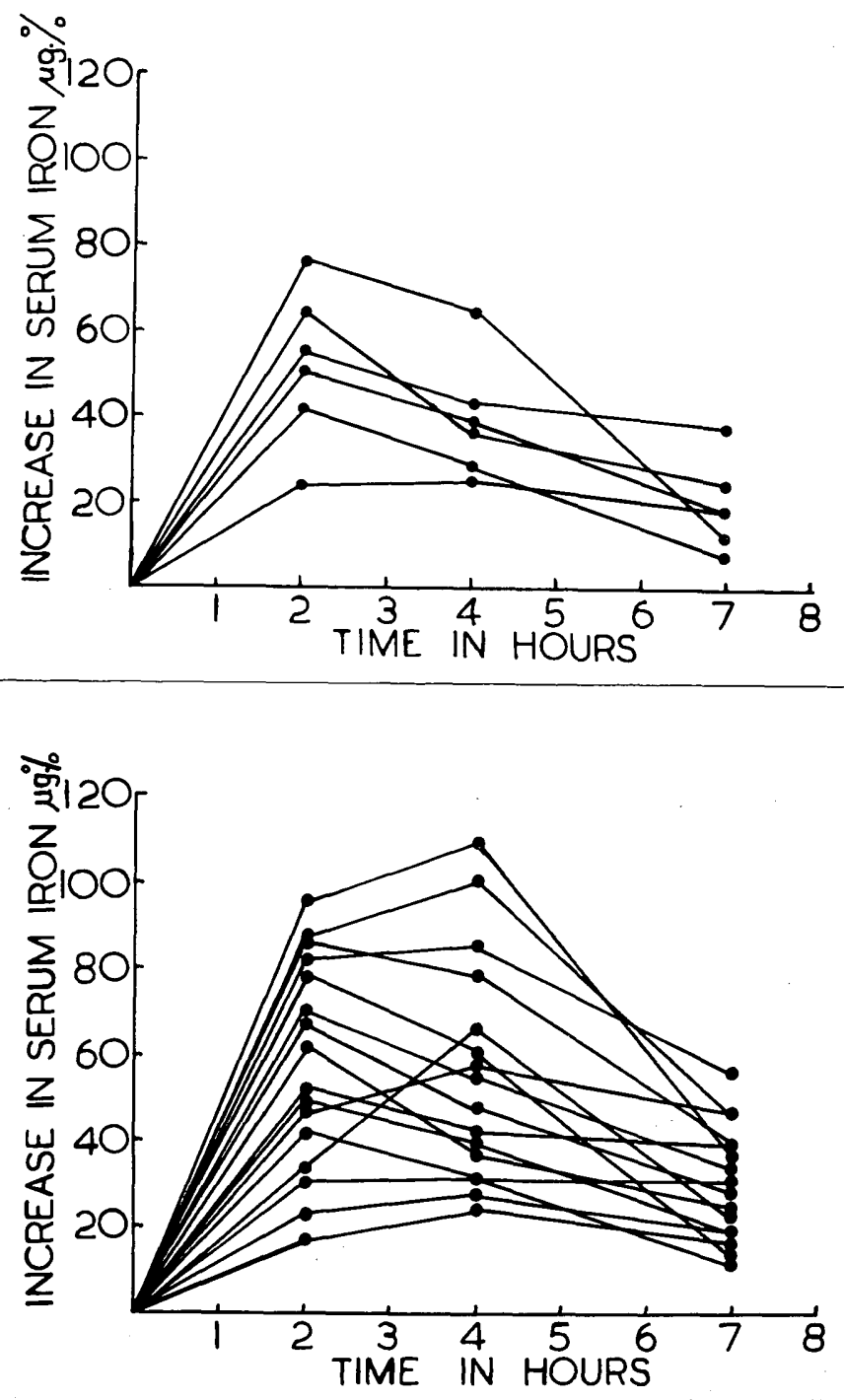

a

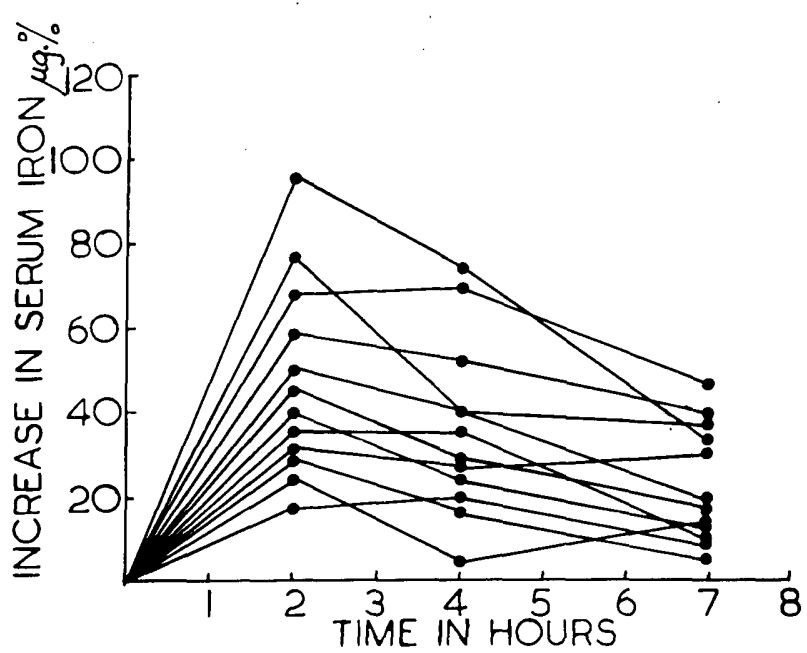

Pig. 36. Oral iron absorption curves in refractory normoblastic anaemia associated with -

a. toxic diseases. b. infectious. c. neoplastic diseases 
of Iron is a primary factor in production of the anaemia. The intravenous tests showed a rapid rate of disappearance of iron from the plasma, the iron being retalned within the body. It therefore appears that blockage in Iron utilization in these anaemias occurs at the site of blood formation and not at the level of intestinal absorption. Histological evidence of marrow iron accumulation w1ll be presented in the next section, and Pirrie, working in this Department, has found excessive iron stores in the organs of such patients on direct estimation of their iron content.

From a practical point of view, it is of importance to note that defective absorption of iron as compared with normal has not been demonstrated. Excessive absorption, such as was present in the majority of cases of simple iron deficiency, was not, however, encountered. The lower curves may therefore be regarded as indicative of potential refractoriness to oral iron therapy, but not pathognomic of such a state, because the few cases of simple iron deficiency with similar curves responded subsequently to routine therapy .

Summary: Absorption of iron from the alimentary tract has been studied by means of serial serum iron determinations after oral fron loading in cases of chronic iron deficiency anaemia, gastro-enterostomy associated with hypochromic 
anaemia, pernicious anaemia and refractory normoblastic anaemia associated with toxic, infective and neoplastic disease. The results have been discussed in relation to my investigations by means of intravenous iron disappearance tests. Greatly enhanced 1ron absorption is evident in most cases of chronic iron deficiency, but in a proportion of cases iron absorption is relatively poor. The flattest curves are recorded in cases of idopathic nature and since the degree of absorption could not be related to the rate of disappearance of iron from the blood, to age, sex, or utilisation, or to the occurrence of achlorhydria, the possibility must be considered that some other local abnormality accounts for the defective absorption. In patients with gastro-enterostomy, the curves obtained suggest that occult haemorrhage and deficient iron intake must be regarded as of no less importance than malabsorption in accounting for hypochromic anaemia. In pernicious anaemia and in refractory normoblastic anaemia, iron requirement for haemoglobination is minimal. Nevertheless, iron absorption remains equal to nornal. In the refractory group, this finding, in association with the rapid disappearance of iron from the blood stream previously demonstrated, suggests an active accumulation of iron within the body. Refractoriness to oral iron treatment of a normoblastic anaemia, cannot definitely be anticipated from the type of absorption 
curve obtained; flatter curves than normal were never encountered, and cases of ldiopathic anaemia with relatively low curves responded to oral treatment. Performance of an intravenous test is of no additional value because the disappearance rate in both these types of anaemia is rapid. 
PART VIII.

HISTOLOGICAL IRON IN STERNAL PUNCTURE MATERIAL.

There can be no doubt both from the foregoing and from other published work that the amount of iron absorbed from the alimentary tract varies in different forms of anaemia; that iron once in the blood is limited in its maximum concentration by the quantity of iron-combining protein present, and that the disappearance of Iron from the plasma is affected by the nature of the anaemia. The present conception of iron metabolism infers that the existing body stores of iron play an important role in the control of these processes. The significance of storage Iron and its influence on iron metabolism has not yet, however, been satisfactorily evaluated, probably largely because of difficulties in its measurement and uncertainty as to what it actually constitutes. In the present work a study was made of depot iron in relation to iron assimilation. Histological iron in marrow blopsy smears and sections was used as the index of iron storage. Interpretation of the findings obtained is dependent upon an understanding of the nature and relationship of the storage compounds haemosiderin and ferritin, and upon a knowledge of $t$ heir functions and of the mechanisms liable to affect the site or the extent of storage. 
Haemosiderin: The term haemosiderin does not denote a specific chemical substance; it is merely descriptive of a granular pigment seen in unstained histological preparations as golden granules and giving the histochemical reactions of iron when stained. It is an iron-protein complex of varying form, but whether all its forms are ava1lable to the organism for haemoglobin synthesis is doubtful. The pigment is probably chiefly formed as an intermediate product in the breakdown of haemoglobin and as such appears in the reticulo-endothelial cells where effete erythrocytes are ingested. It is possible that it also develops intracellularly in degenerating cells. Gillman and Giliman (1944 and 1945) in a study of liver blopsy specimens from 200 patients with pellagra observed the development and increase of haemosiderin in liver cells concurrent with the disintegration and disappearance of mitochondria. The knowledge that mitochondria contain: lipo-protein and iron, the constituents of haomosiderin, suggested that the haemosiderin became formed within the cells.

Ferritin: Ferritin is a well defined iron-protein complex which occurs as an iron storage compound particularly in liver, spleen and bone marrow. It cannot be demonstrated histologically but can be isolated in crystallized form, the crystals being specific for different species. It has 
never been synthesised in vitro. In vivo, its synthesis is probably catalyzed by specific substances, and it is possible that derangerient of the enzymatic mechanism responsible may account for some types of anaemia. (Laufberger, 1937; Granlck, 1946; Michaelis, 1947). Its storage function was established by Hahn: $(1943, b)$ when he showed that injected radio-active iron was recoverable shortly after its administration in molecules of ferritin isolated from liver and spleen. About $20 \%$ of the injected iron is converted into ferritin in two hours (Granick and Hahn, 1944). Storage ferritin is the same compound as is demonstrable In the gastro-intestinal mucosa in relation to iron gbsorption. Its absence from the serum indlcates that it is not a compound likely to be concerned in iron transport. (Granick, 1948). Its protein component, apoferritin, although crystallizable, has also never been isolated in vivo either from plasma or from storgge organs. Evidence indicates that it is formed only as required for ferritin synthesis and disappears again when iron has to be released for transport or for haemoglobin formation. Relationship and functions of ferritin and hoemosiderin: The chemical nature of the two compounds is similar. (Granick, 1946), and haemosiderin may actually represent a condensation or clustering of ferritin molecules. (Granick, 1949). Both 
are Iron-protein complexes and both occur intracellularly in similar sites in the body. That they are important factors in connection with iron storage is indicated by their occurrence in the recognised iron depots, (Ifver, spleen and bone marrow), and by the very high iron content of ferritin, $(23 \%)$. It is general opinion that there are at present no justifieble grounds for their functional differ. entiation from the standpoint of storage. According to Finch et 8.1. (1950) each increases in the tissues in the presence of excess iron, and each becomes depleted when iron is required for erythrogenesis. He quotes unpublished data of his own as supporting the observations of sandberg et al. (1942) that storage iron of both types becomes increased if there is reduction in the circulating red cell mass due to any other cause than haemorrhage or iron deficiency. That both forms are normally available for haemoglobin production is indicated by the complete disappearance of hoemosiderin from histological specimens and the reduction to minimal amounts of chemically-estimated iron in the livers of dogs which have been bled. It is possible that over filling of cells with iron may impair their function and consequently their ability to liberate stored iron. In this way, it may happen that iron is not avallable for erythropolesis even although stored in excess. The similarities between haemosiderin and ferritin have to be accepted 
meantime in an investigation of the function of storage iron but differences must not be forgotten; for instance, in aplestic anaemia, consistently less siderosis is produced than in haemolytic ansemia, even although the chemical iron content of depot organs may be similar. Site and extent of iron storage: Iron is widely distributed in the body, but for convenience may be considered as occurring in two main depots, the reticulo-endothellal system and the parenchymal cells, the liver far exceeding other parenchymal tissues in its storage capacity. The Iron of the retialo-endothelial system comprises chiefly iron liberated from extravascular destruction of red cells and any colloldal iron given introvenously, the former being mainly localised in the spleen and the latter in the Ifver and bone marrow. Parenchymal iron represents chiefly that which has been stored following allmentary assimilation, or deposited after intravenous administration of simple iron salts. Both reticulo-endothelial and parenchymal iron reach their greatest concentration in the liver. Significant amounts of iron are demonstrable in the cells of the renal tubules after intravascular haemolysis. This is explained by reabsorption of 1 ron liberated from local disintegration of haemoglobin which has exceeded the renal threshold and entered the tubules. Focal haemosiderosis 
can occur in any organ or tissue where blood is extravasated locally and decomposed; it occurs in the neighbouring macrophages and lymph glands.

The amount of iron stored may be influenced in two ways. Because the body is relatively unable to excrete iron, redistribution of the normal body iron content may become necessary if the red cell mass is reduced by anything other than haemorrhage or iron deficiency; the storage Iron compartment then increases proportionately to the decrease in blood iron (F'anger et al, Unpublished quoted by Finch et al. 1950). This is in contrast to the absolute increase in body iron which can follow excessive iron absorption or parenteral iron administration. If the "mucosal block" theory as described by Granick (1946) were full-proof, unwanted iron should not pass through the intestinal mucosa. Nevertheless, excessive storage does occur under certain circumstances. It has been demonstrated when pyridoxin is deficient, when phosphate intake is extremely low, after Ilgation of the pancreatic ducts, in haemochromam tosis, and probably in some refractory anamic states. The ultimate distribution of iron stored in the body is similar whatever its initial disposition, (Polson, 1933; Cappel1, 1930) and is localised mainly in the liver.

A blopsy sample of sternal marrow affords a very 
small glimpse of this enormous and complex storage system and represents only reticulo-endothelial iron. Nevertheless, examination of such specimens is the only means of gaining some direct insight into the state of storage during life. Biopsy of the liver, the most important storehouse, is feasible, but is too hazardous a procedure to be performed routinely for research purposes. Finch (1948) produced evidence that stainable marrow iron is actually roughly proportional to the expected total body stores. It is usually absent in iron deficiency, present in small amounts in health, and increased excessively in haemochromatosis, while in different forms of anaemia, varying intemediate amounts are seen. Consequently, provided the patient has not received blood transfusion or parenteral iron, histological marrow iron can be regarded as an index of the storage component of iron metabolism within the organism.

Material examined: Smears and sections were made from marrow granules obtained by sternal puncture. Demonstration of iron was carried out by staining the preparations for 30 minutes with a mixture of equal parts of freshly prepared $2 \%$ potassium ferrocyanide solution and $2 \%$ hydrochloric acid. After washing in distilled water, they were counterstained with $1 \%$ neutral red for 15 minutes. In 


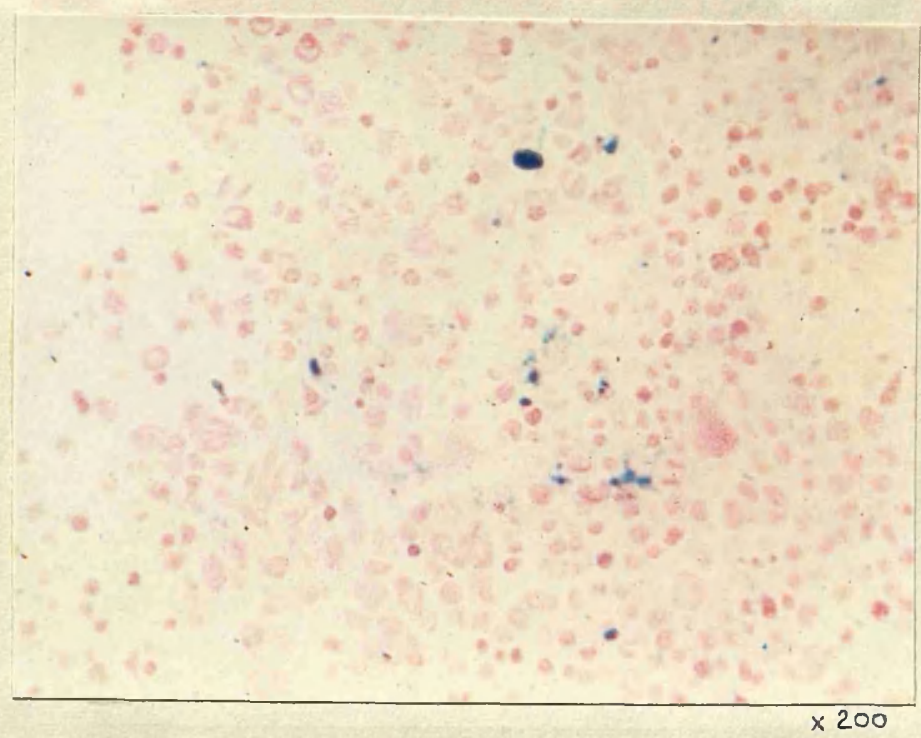

Fig. 37. Marrow section of sternal puncture material showing moderately light infiltration with iron.

Prussian blue reaction counter-stained with methyl red.

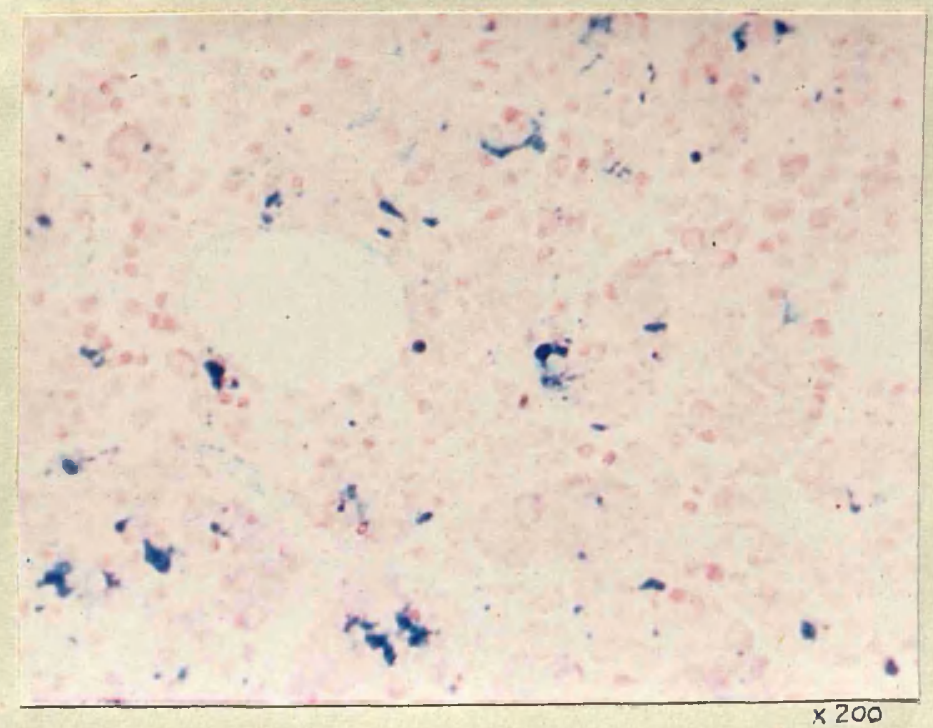

Fig. 38. Narrow section of sternal puncture material showing heavy infiltration with iron. Prussian blue reaction counter-stained with methyl red. 


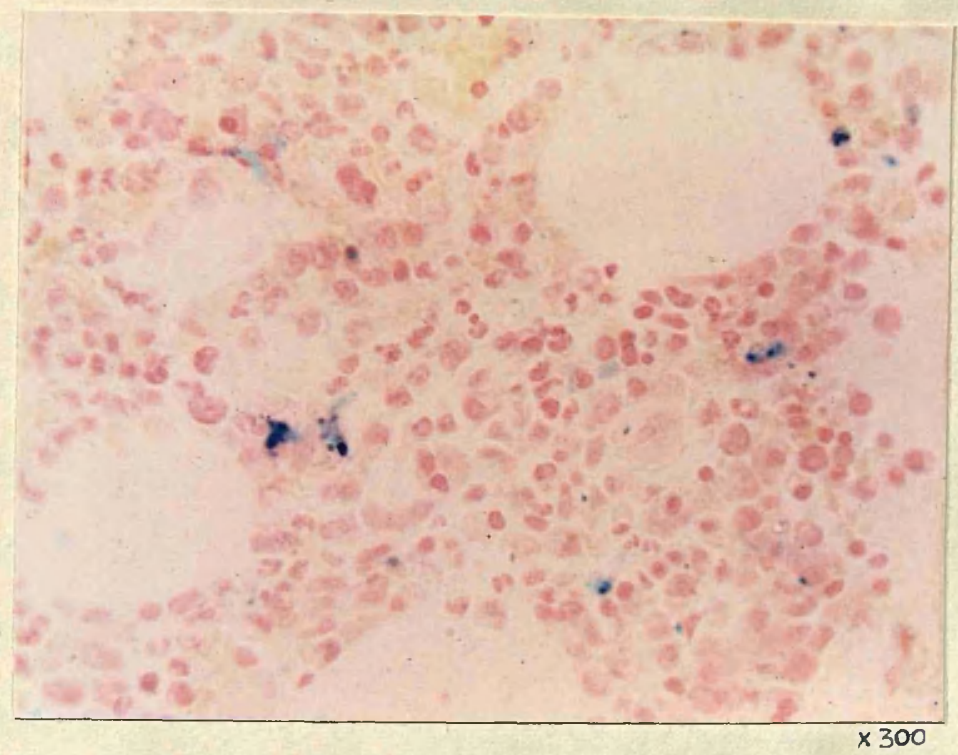

Fig. 39. Narrow section of sternal puncture material showing infiltration with iron. Prussian blue reaction counter-stained with methyl red.

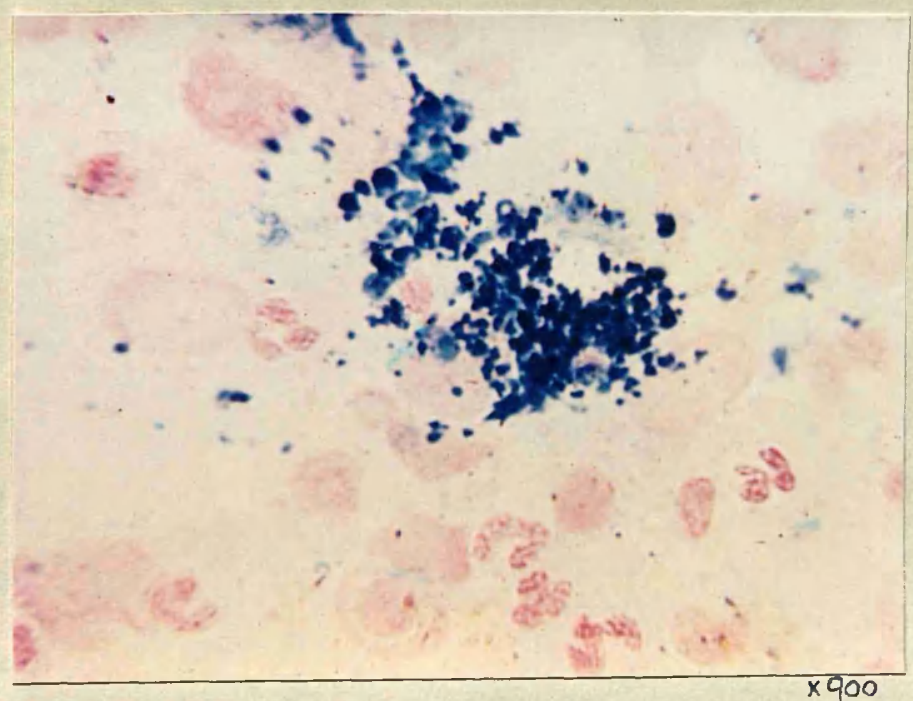

Fig.40. Group of iron-positive granules in a smear preparation of sternal puncture material. Prussian blue reaction counter-stained with methyl red. 
each instance 2 or 3 marrow smears and one section were examined for stained iron, so that any inaccuracies due to irregular dispersal of the iron might be minimised. The amount of iron present varied considerably from case to case, but there was satisfactory agreement between the amount demonstrable in marrow smears and the amount identified in the sections. The method of preparation did not lend itself to demonstration of histological detail but the iron itself was readily distinguishable as Prussian blue granules of variable coarseness. In the smears most of the iron was apparently lying free in the matrix, but here and there aggregations of granules round a nucleus indicated an intracellular origin.

The cases were classified arbitrarily into 5 grades according to the amount of iron seen, grade I representing absence of iron and grades 2 to 5 increasing amounts. Actual classification was made on an overall assessment of the amount of iron present but Figs. 37 and 38 show representative fields from heavily and lightly infiltrated preparations. The punctate nature of distribution is more easily distinguishable in Fig. 39. The granular nature of the deposit was most readily seen in the smears and an example of a collection/ 
of coarse iron positive granules is shown in Fig. 40. Preparations from 15 normal subjects and from 102 patients with anaemia were examined. The results obtained are presented in Table 23. Result's in relation to expected iron reserves:

The amount of iron demonstrable conforms to the proportions which could be expected in the various types of cases investigated. In normal people, only small amounts are found; in iron deficiency, there is consistent absence of iron; in pernicious anaemia and haemolytic anaemia, there is an increase in iron in a quarter and a third of the patients respectively. This is compatible with exhausted reserves in iron deficiency and with a redistribution of the body iron due to reduction in the red cell mass in pernicious anaemia and haemolytic anaemia. of the four patients with pernicious anaemia in whom negative results were obtained for marrow iron, 2 were among those previously presented as having an M.C.H.C. below normal and low serum iron concentrations. (Table 11 , INos. 5 and 10). The two others had low serum iron concentrations but a normal if.C.H.C. 
Table 23. Stainable marrow iron graded according to the amounts present.

\begin{tabular}{|c|c|c|c|c|c|c|}
\hline \multirow[t]{2}{*}{ Condition } & \multicolumn{5}{|c|}{ Grade * } & \multirow[t]{2}{*}{ Total no. } \\
\hline & ㄱ) & 2 & 3 & 4 & 5 & \\
\hline Normals & 3 & 5 & 7 & - & - & 15 \\
\hline $\begin{array}{l}\text { Anaemia of } \\
\text { toxic states }\end{array}$ & 2 & - & 3 & 2 & - & 7 \\
\hline $\begin{array}{l}\text { Anaemia of } \\
\text { infection }\end{array}$ & 2 & 3 & 2 & 2 & 3 & 12 \\
\hline $\begin{array}{l}\text { Anaemia of } \\
\text { neoplastic } \\
\text { disease }\end{array}$ & 5 & 3 & 7 & 5 & 2 & 22 \\
\hline $\begin{array}{l}\text { Iron } \\
\text { deficiency }\end{array}$ & 21 & - & - & - & - & 21 \\
\hline $\begin{array}{l}\text { Pernicious } \\
\text { anaemia }\end{array}$ & 4 & 3 & 5 & 3 & 1 & 16 \\
\hline $\begin{array}{l}\text { Aplastic } \\
\text { anaemia }\end{array}$ & - & - & 1 & - & - & 1 \\
\hline $\begin{array}{l}\text { Cirrhosis of } \\
\text { liver. }\end{array}$ & 1 & 1 & - & - & - & 2 \\
\hline $\begin{array}{l}\text { Haemolytic } \\
\text { anaemia }\end{array}$ & - & - & 2 & 2 & 2 & 6 \\
\hline
\end{tabular}

* Grade $I$ = absence of iron

Grades 2 to 5 = increasing amounts of iron 
The combined findings suggest concurrent existence of a moderate degreo of iron deficiency in these patients. In the refractory normoblastic anaemias, the marrow iron deposit was again in excess of normal, and in fact, often appeared greater than was to be expected from the degree of anaemia.

Marrow siderosis in relation to transport, a bsorption and assimilation of iron: The quantity of iron present in the depots does not appear to be entirely responsible for the concentration at which the circulating serum iron is maintained. Exhausted stores in iron deficiency are certainly associated with very low levels of transport iron, and inm creased stores in pernicious anaemia with relatively high levels, but in the refractory anaemia group, an increase in storage exists in conjunction with reduction in transport iron to about half normal levels.

Existing stores also cannot be wholly responsible for the amount of iron assimilated. In the case of iron deficiency anaemia, alimentary absorption of iron has been shown to be greatly enhanced in the great majority of cases and the rate of disappearance of iron from the blood always accelerated. In permicious anaemia, both these functions are depressed below normal. These findings might have been attributed purely to decreased and increased stores respect- 
ively, but in the refractory nomoblastic anaemias existence of excessive storage is accompanied by an alimentary absorption of iron equal to normal, and an increase in the rate of disappearance of iron from the blood. From a histological study alone one cannot be dogmatic that the siderosis recorded represents an absolute increase in the body iron but the work of Pirrie, (personal communication) indicates that the amount of depot iron in patients with infections or carcinoma is in fact significantly increased beyond that which can be accounted for by redistribution of iron already in the body. Accumulation of depot iron in these patients would therefore appear to be an active rather than a passive process as it continues even after the total iron has reached average normal limits.

Consideration of findings in relation to Granick's "mucosal block" theory: In its simplest form, Granick's theory states that iron is absorbed from the intestine only until the mucosal cells become saturated and is passed on to the serum when the iron concentration there is diminished, this concentration being largely determined by the body Iron requirement. The amount of iron absorbed is therefore ultimately dependent upon the quantity of iron stored, and is theoretically negligible when stores are replete. The 
present findings in iron deficiency anaemia and in pernicious anaemia are essentially in keeping with such a hypothesis, but there is accumulating evidence that the theory is not water-tight. In this investigation the continued iron absorption and the increase in the rate of disappearance of iron from the serum in spite of wellfilled stores in patients with refractory anaemia suggest that under certain circumstances the absorptive mechanism may be modified. The work of other investigators also indicates that the "mucosal block" must at times be overcome. Balfour et al. (1942) described a case of leukaemia in which orally- administered radio-active iron was never demonstrable in the haemoglobin but was isolated from the liver and spieen at autopsy a few months later. Dubach et al. (1948) after giving radio-active iron orally to a patient with pernicious anaemia recovered only minimal amounts in the haemoglobin before treatment, but after administration of Ilver accounted for $20 \%$ of it. In two patients with Hodgkin's disease and refractory anamia, they recorded absorption of $52 \%$ and $32 \%$ of orally administered doses. In animals, pyridoxin deficiency has lod to iron absorption of sufficlent degree to cause haemochromatosis (Cartwright ot al. 1949; Gubler et al. 1949), and reduction in the free phosphate content of the diet has caused similar changes (Day 
and Stein, 1938; Kinney, 1949; Hegsted et al. 1949). Excessive iron accumulation was recorded by Taylor et al. (1931 and 1935) after ligature of the pancreatic duct in cats, and Finch et al. (1950) confirmed this in dogs. In humans, Gillman and Gillman (1945) observed hepatic siderosis in African pellagrins, studied by liver biopsy. In normal men, prolonged administration of iron has been claimed to cause an increase in haemoglobin but of temporary duration (Fowler \& Barer, 1941), while iron accumulation in the organs of Bantu races has been shown attributable simply to a prolonged high dietary iron intake resulting from constant cooking of food in iron utensils (Walker and Arvidsson: 1950).

Stainable marrow iron as a guide to intravenous iron therapy:

It is inadvisable to give parenteral iron indiscriminately in view of the fact that the body has difficulty in getting rid of unwanted iron, and although never proved experimentally, the occurrence of fibrosis in the iron storage organs in haemochromatosis raises the possibility that iron accumulation can lead to fibrous tissue formation. In iron deficiency anaemia, iron was consistently absent from the marrow and iron was required as treatment; in pernicious anaemia, iron was mostly demonstrable in the marrow, and iron was not indicated for treatment. Consequently it seems worth while to review these refractory cases treated with parenteral iron 


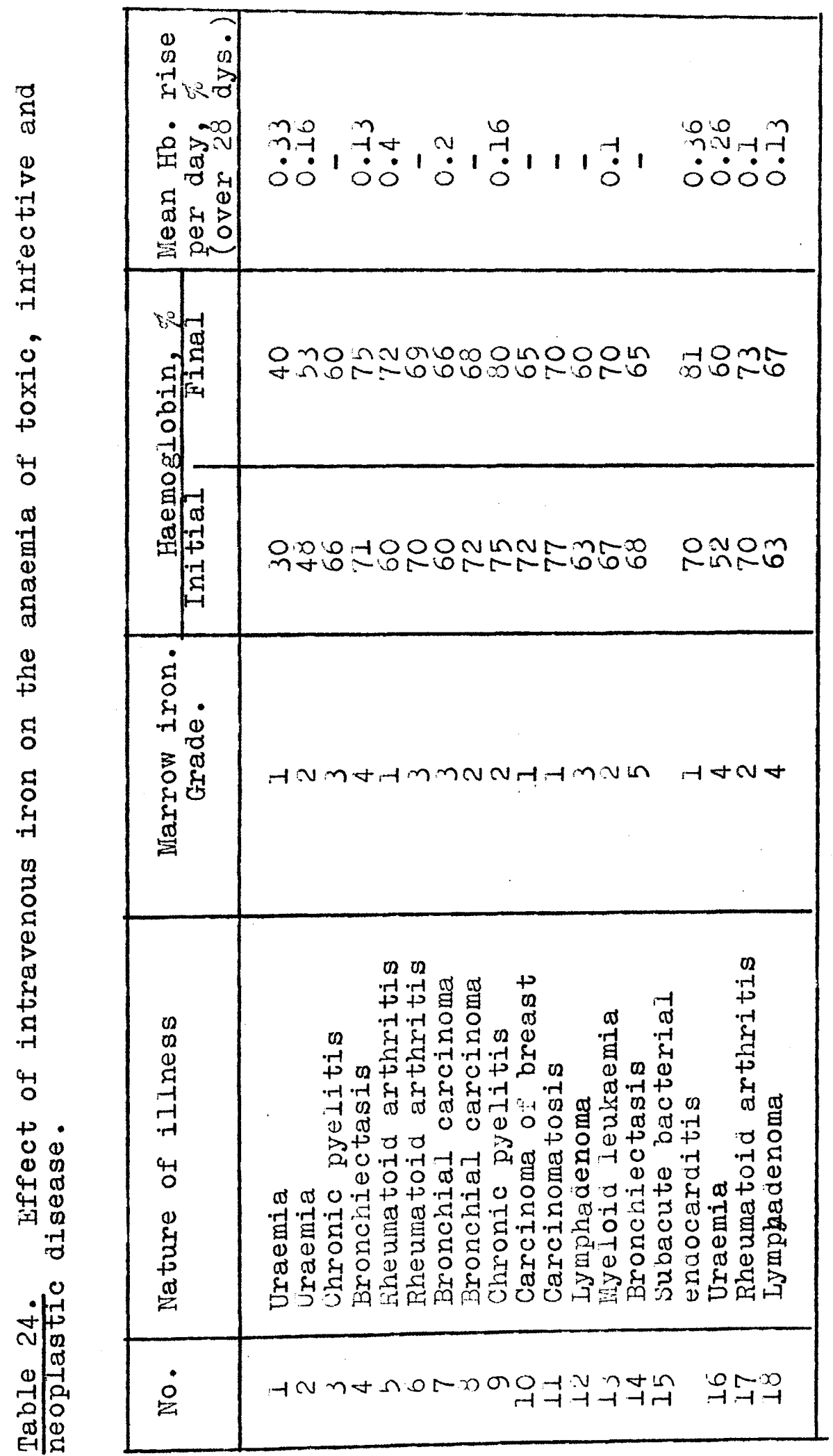


from the aspect of stainable marrow iron as an indication or otherwise for parenteral iron therapy. In so doing, three facts have to be borne in mind. Firstly, a marrow which is negative for haemosiderin may nevertheless contain the non-stainable ferritin iron. Secondly, a considerable amount of haemosiderin iron must be present in the tissues before it is demonstrable histologically (in the case of liver, $10-12 \mathrm{mg}$. per $100 \mathrm{~g}$. wet tissue). Thirdly, haemosiderin, even although demonstrated, is not necessarily available for haemoglobin synthesis. Eighteen of the patients with refractory normoblastic anaemia received full courses of iron intravenously. Haematologicel data are given in Table 24. The results of therapy in this small series cannot be considered conclusive but only in patients $I$ and 15 was there any significant rise in haemoglobin and this was slight. In the latter, the patient's general condition also improved, making it impossible to say whether the haemoglobin rise was attributable to therapy or to recovery from the primary disease. As 13 of the 18 patients had iron present in the marrow, it is probably justifiable to suggest that in the presence of histological iron in the marrow a response to iron, given either orally or parenterally is unlikely. In the absence of marrow siderosis administration of parenteral iron is indicated if oral treatment has 
failed, but cannot be expected to be necessarily beneficial. It is quite possible that in the latter cases there is in fact no iron lack in the marrow but that such metal as is present is in the form of ferritin. Kulns et al. (1950) and Slack and Wilkinson (1949) were equally unsuccessful in correcting similar types of refractory anaemia by intravenous iron administration. On the other hand, Sinclair and Duthie (1949) claimed significant but long delayed haematological improvement in patients with rheumatoid arthritis and anaemia, when iron was given intravenously over several weeks. The fall in blood sedimentation rate in their patients who "responded" makes it difficult to exclude general clinical improvement as the actual basis for the haemoglobin increase. On the whole, if iron is given intravenously there seems little justification for continuing it in massive doses over a long period if no rise in haemoglobin is occurring. In simple iron deficiency anaemia the beneficial effect of intravenous iron is immediate and dramatic. In refractory anaemias of either normochromic or hypochromic type there is no reason to believe that excessive parenteral administration of iron will be effective where normal dosage fails. Indeed, the case of a man with cirrhosis of the liver and hypochromic anaemia which was followed by the writer from 1948 to 1950 provides a clear illustration that tremendous 
accumulation of iron can occur at the actual site of blood formation and be ineffective, even in the presence of hypochromia and an active marrow, if the iron is being supplied to a haemopoietic system which is incapable of using it.

Case: The patient, a man aged 72 years, had been known to suffer from cirrhosis of the liver for 7-8 years. The liver extended to the umbilicus, and had a granular surface. The spleen was not palpable. There was no evidence of haemochromatosis. General ill health was associated with anaemia of haemoglobin deficiency type. The anaemia resisted all forms of oral iron therapy and in 1946 was of sufficient severity to necessitate blood transfusion. A prolong'ed course of intravenous iron was given subsequently by his own doctor, but the haemoglobin level remained unaffected. In 1948, examination of the sternal marrow revealed abundant stainable iron and unusually active normoblastic erythropoiesis (Fig.41). Blood transfusion had to be repeated. In view of the liver damage, choline ( $5 \mathrm{~g} \cdot /$ day) and vitamin $\mathrm{E}$ (400 $\mathrm{mg} \cdot /$ day) were recommended in addition to oral liver and anahaemin which had been given for 4 years. The administration of choline and vitamin $E$ was followed by regeneration of the haemoglobin from $40 \%$ to $176 \%$ without further iron being given. 


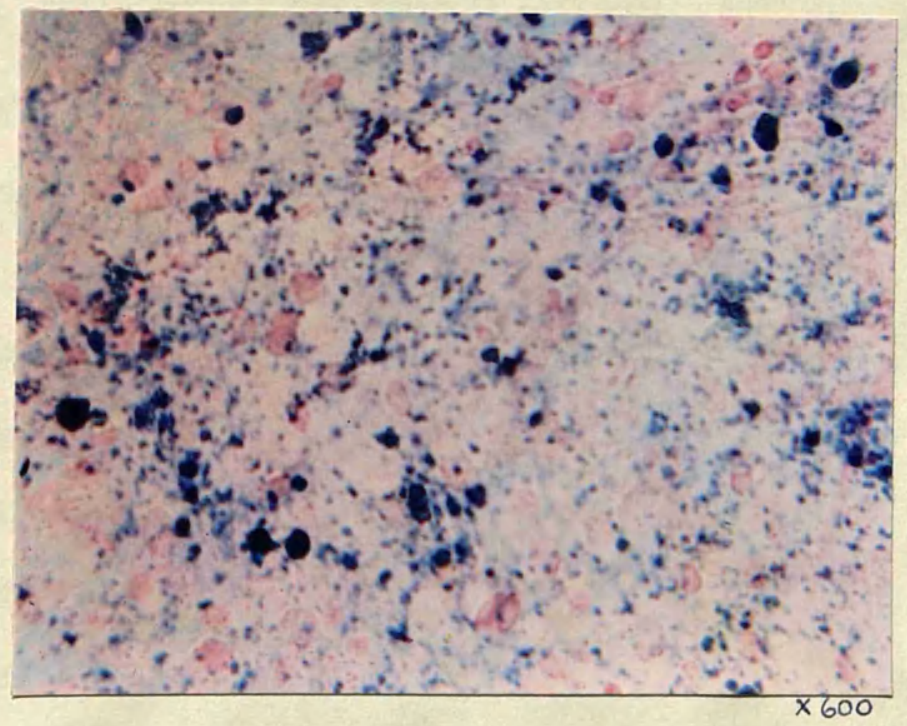

Fig. 4I. Marrow smear from case of cirrhosis of the liver after intravenous iron administration showing dense deposition of iron which obscures histological detail.

Prussian blue reaction counter-stained with methyl red 
Subsequent examination of the marrow in 1949 and again in 1950 still showed enormous amounts of iron present. Towards the end of 1950 the patient's general health declined, the liver became larger, the spleen just palpable, and the haemoglobin began to fall in spite of continued treatment.

Improvement of the blood levels in this patient must be related to the administration of choline and vitamin $E$, without which iron had been ineffective in overcoming the haemoglobin deficiency anaemia. The case supplies evidence that a marrow smear laden with haemosiderin is indicative that further iron administration either orally or parenterally is likely to prove useless if the basic disturbance is not first corrected. Conclusions.

Stainable iron in sternal puncture specimens is approximately representative of the body's storage iron reserve. It is consistently absent in chronic hypochromic anaemia and its absence in a few cases of pernicious anaemia can be accounted for by a tendency to concurrent haemoglobin deficiency. An excessive amount in refractory normoblastic anaemias increases evidence already available that such anaemias are not primarily the result of iron lack. Actual haemoglobin 
deficiency may persist in the face of large iron reserves in the marrow, if the fundamental illness remains uncorrected. In similar cases rapid disappearance of iron from the plasma has already been demonstrated, and also alimentary absorption of iron in amounts equal to normal. The cause for the rapid diversion of iron and its accumulation in the marrow is obscure, but the deviation cannot be made good by intravenous iron administration.

Absorption of iron in the presence of replete body stores makes Granick's "mucosal block" theory open to question. Exhausted stores, such as are demonstrable in chronic iron deficiency anaemia may be responsible for promoting the very high absorption levels characteristic of this group, but well-filled stores do not appear to suppress absorption below nomal.

As a guide to the need for intravenous iron therapy, histological iron in the marrow is of definite but limited value. The fact that it is present and even excessive in a considerable proportion of cases of anaemia associated with toxic, infective, and neoplastic disease and that this anaemia is unaltered by parenteral iron administration indicates that parenteral iron is unlikely to be of any benefit if the marrow iron is positive.. A nesative result for histological iron does not, however, mean an assured response to iron even when this is given intravenously. 
Summary: The nature and distribution in the body of the iron storage compounds haemosiderin and ferritin is discussed and evidence for regarding them as functionally similar is described. Histological iron in the marrow is found to be approximately representative of expected body stores. In iron deficiency anaemia the depleted stores probably influence the rate at which iron disappears from the blood, and the amount of iron which is absorbed from the intestine. In the refractory normoblastic anaemias associated with toxic, infective, and neoplastic disease iron reserves are considerable yet normal alimentary iron sbsorption occurs. In view of this and of the increased rate of disappearance of iron from the serum in these patients it appears that Granick's mucosal block theory may be modified under certain circumstances. The possibility of stainable marrow iron being a guide to the use of intravenous iron in refractory anaemias is discussed. If iron is demonstrable, it seems unlikely that parenteral iron will prove beneficial. 


\section{PART IX.}

\section{GENERAI SUMMARY AND CONCLUSIONS.}

The historical development of existing knowledge concerning iron metabolism has been reviewed. Attention is drawn to the discovery of iron as an element of the blood in 1746, to the differentiation of haemoglobin and non-haemoglobin fractions between 1898 and 1915, and to the identification during the last quarter century of the non-haemoglobin iron as the transport iron of the body.

From this review it is evident that little attention has been given to the assessment of iron balance in the individual pationt from a clinical point of viow, an aspoct of investigation which has gained significance since the introduction of an intravenous iron preparation satisfactory for therapeutic use.

The original observations described in this thesis consist essentially of serum iron estimation on human beings, under varying conditions, and the histo-chemical demonstration of iron in bone marrow material obtained by sternal puncture. The results and their significance are summarised under the following headings:

(I) Reliability of selected methods for estimation of serum iron. 
(2) The serum iron in health

(3) The serum iron in disease

(4) The value of oral iron absorption and Intravenous iron disappearance tests in conjunction with histo-chemical iron in the marrow

(5) Results in relation to iron metabolism

(6) Intravonous iron in therapeutics

Reliability of selected methods for estimation of serum iron.

There is no reason to doubt the reliability of Tompsett's orthophenanthroline technique and Fitzpatrick's ferricyanide techique for estimation of the serum iron provided scrupulous precautions are taken to avold iron contamination of glasswar $\theta$, reagents and serum. Closely comparable results obtained by each method, and consistently low levels in'iron deficiency anaemia give reassuring proof that a specific iron fraction is boing estimated and that experimental error plays little part in producing the wide variations recorded in health and in most other types of ansemia. 
The serum iron in health:

Work published by other authors in regard to the serum iron level in normal people, and the influence upon it of sex, age, and time of day has been substantiated.

An investigation of 120 healthy individuals from 18 to

65 years of age showed that the range of serum iron concentration is from 65 to $220 \mathrm{ug}$. \% with an average of $123 \mathrm{ug} . \%$. The range for each sex is similar, but the average for males is 129 ug.\%, while for females it is 113 ug. \%. Estimations made on 6 members of each sex over a period of 8 weeks, considered alone and in relation to published findings, indicate that this difference is more reasonably attributable to endocrine influence than to whole blood loss in women as a result of menstruation.

In 30 normal individuals followed during twenty-four hours it is evident that diurnal fluctuation in serum iron concentration occurs, this fluctuation having an average value of $25 \mathrm{ug} . \%$. A true cyclic pattern is not ostablished statistically. From the present work the fluctuation cannot be related to the taking of meals, and from investigation of the literature convincing evidence is still lacking for the claims that liver metabolism and autonomic activity play an important role in serum iron control.

The influence of age is difficult to dissociate from changes due to sex, but a definite reduction in serum 
iron with advancing years in males of this series suggests that old age is accompanied by a diminution in transport iron. The serum iron in disease:

Owing to the wide variation of the serum iron in health, alterations in disease have to be marked and consistent in order to be of significance. Single initial estimations were made on 179 cases of anaemia and, since accounts of serial observations in the literature are few, weekly estimations were continued on 32 of the cases for 8 to 12 weoks during treatment. Extreme hyposideraemia (serum iron less than 50 ug.\%) is most often indicative of chronic iron deficiency anaemia, but cannot be considered pathognomonic of such a state since equally low levels sometimes occur in the refractory normoblastic anaemias associated with toxic, infective or neoplastic disease, even when the anaemia is normochromic and there is no evidence of blood loss. On the whole, levels In the latter group are slightly higher and sometimes within the lower limits of normal. In the case of nephritis the reduction is more readily attributed to protein imbalance than to urea retention.

Fifty-eight patients with iron deficiency were re-investigated after treatment. The results emphasise the need for prolonged iron medication after the blood count is normal. Persistence of a subnormal serum iron in any 
patient whose hypochromic anaemia has responded satisfactorily to iron is probably indicative of an occult complicating factor. The hyposideraemia of chronic disease is, like the anaemia, extremely intractible to iron therapy even when this is given parenterally. Amongst infections, Infective hepatitis is exceptional in sometimes producing high serum iron levels, this being distinctive from the normal levels in obstructive jaundice.

In pernicious ansemia, a high average serum iron (152 ug. \%) in 34 patients examined is in agreement with published results. Occasional low values in the group can be accounted for by minor degrees of concurrent iron deficiency as indicated by absence of stainable iron in the marrow and subnormal mean corpuscular haemoglobin concentration. A sharp fall in serum iron concentration after giving liver confirms previous accounts of this finding.

Abnormally high serum iron levels are usually the result of severe haemolysis, but it is possible that an abnormality of the serum globulin may also lead to a high serum iron level.

The value of oral iron absorption and intravenous iron disappearance tests in conjunction with histological iron in the marrow.

The value of oral iron absorption and intravenous iron disappearance tests in clinical work has not previously 
boen exhaustively explored. In the course of the present investigations 85 oral tests and 77 intravenous tests were carried out. Both types of test were found to be practicable procedures for routine use. For oral tests a relatively large dose of iron is required before consistent results in individual subjects are procured. A dose of $45 \mathrm{gr}$. of ferric ammonium citrate is well tolerated and satisfactory curves are obtained by estimation of the serum iron at 2,4 , and 7 hours after its administration. For intravenous tests, $100 \mathrm{mg}$. of saccharated iron oxide in the form of "Iviron" is satisfactory as a test substance, and the serum jron level 5 minutes after its injection can be used as a guide to serum iron-combining capacity, and during the next 7 hours for assessing the rate of disappearance of iron from the blood. A constant experimental error occurs in the estimation of colloidal iron mixed with serum, but the orror is sufficiently consistent to allow of comparative studies being made.

Analysis of the amount of demonstrable iron in sternal puncture specimens of marrow obtained in 102 cases was used to supplement the information from oral and intravonous tests. From a diagnostic point of view in clinical work it can be concluded that the intravenous disappearance test adds little information to that which can be obtained by the 
simpler oral absorption test alone. For the oral test an arbitrary level of $100 \mathrm{ug} . \%$ may be set for the maximum reading. A rise in excess of this amount alnost certainly Indicates iron deficiency and an assured satisfactory response to oral iron therapy. Lesser absoprtion is not definitely Indicative of refractoriness to iron, because although characteristic of refractory normoblastic anaemia, it is also met with in a proportion of simple iron deficiency cases who subsequently respond normally to routine oral treatment . Histochemical demonstration of iron in the marrow is of particular value in these cases since a positive result indicates that administration of iron either orally or intravenously is unlikely to be effective, while a negative result warrants a trial of intravenous iron if oral treatment fails.

No opportunity was obtalned of investigating patients with uncomplicated iron deffciency anaemia, whose anaemia proved refractory to oral iron but amenable to intravenous iron, because such cases were not encountered during the course of treating 189 patients with simple iron deficiency. The view of Wilkinson \& Slack (1949) and Crawley (1951) that such cases occur and are due to intestinal malabsorption could not therefore be corroborated. 
Results in relation to iron metabolism.

The data obtained in this investigation have also been discussed in relation to their significance in the general problem of iron metabolism, although the need for caution in drawing sweeping conclusions has been stressed, because the oral iron was given in massive dosage, the intravenous iron was in colloidal form, and the histochemical preparations demonstrated only haemosiderin. It appears justifiable to conclude, however, that when body stores are depleted of iron and there is simple haemoglobin deficiency anaemia, the amount of iron absorbed from a single dose given orally is usually greatly in excess of normal. When stores are replete there is no evidence that absorption of iron can be depressed below normal. 'Here is a possibility that certain patients with simple iron deficiency cannot readily increase the proportion of iron absorbed from massive doess, but since all such patients showed a satisfactory response to oral iron treatment it is difficult to accept malabsorption of iron as a basic aetiological factor in their anaemia without more convincing experimental ovidence. Even in hypochromic anaemia following gastro-. enterostomy, the possibility that poor iron absorption plays a significant role in production of the anaemia could not readily be substantiated. 
In the refractory normoblastic anaemias, normal absorption of iron from the gut, rapid diversion of iron from the plasma, and a tendency towards accumulation of iron in the depots has been demonstrated. The site of interuption of blood formation would therefore appear to be the marrow, and even in the presence of hypochromia, excessive iron intravenously fails to force the block. Accumulated iron is probably available at a later date for hamoglobin formation if the basic illness can be corrected.

The amount of iron apparently absorbed from the gut is independent of the serum iron-binding capacity and of the serum iron concentration, and cannot be related to age, sex, gastric acidity or haemoglobin level. It could also not be related to the rate of disappearance of iron from the plasma, but this problem and the question of rate of utilization of iron require further investigation.

The significance of these views, in relation to those published by other workers in this field has been discussed. Intravenous iron in therapoutics.

In the cases of anaemia investigated there was little ovidence that intravenous iron is superior to oral iron in routine treatment. Adequate oral iron dosage given for long onough was effective in 189 patients with simple iron deficiency. 
Five of these, however, required hospital supervision betore recovery was complete, and in such cases intravenous iron is warranted to avoid hospitalization. No case of uncomplicated iron deficiency refractory to oral treatment but amenable to intravenous iron was encountered. In a very small number of cases in which there is an intrinsic intestinal abnomality parenteral therapy may be successful when oral treatment fails. In respect of refractory normoblastic anaemia associated with toxic, infective, or neoplastic disease, personal experience in the use of intravenous iron was Iimited to 18 cases. The results were uniformly unsuccessful. Among 43 similar cases, the finding of excessive accumulation of iron in the marrow increases evidence that further supplies of iron, however given, are unlikely to be utilized. There is no reason to believe that excessive iron given parenterally will prove beneficial. Use of intravenous iron may occasionally be justified to avoid troublesome alimentary disturbance due to oral iron. Nevertheless, it should be remembered that although unpleasant side effects with "Iviron" are few, their severity may occasionally be alarming leading to collapse and lumbar pain. Also, the slightest leak at the injection site causes intense pain, induration, and often thrombosis. 
Any beneficial effect from intravenous iron is usually immediate, and it is consequently unnecessary to prolong administration beyond a few hundred milligrams if no rise in haomoglobin or red cells is occurring. The late results and possible 111 effects of accumulated iron in the body are relatively unknown factors in the human subject. 
Abbot, W.0. \& Miller T.G. (1936). J. Aner. med. Assoc. $106: 16$

Aberderhalden, E. (1898). Z. physiol. Chem. 25 : 65 Albers, H. (1941). Eisen bei Hutter und Kind, Leipzig Balfour, W.M., Hahn, P.F., Bale W.F., Pommerenke, N.T. \& Whipple, G.H., (1942).J. exper. Med. $76: 15$ Bärer, A.P. \& Fowler, W.M. (1937). J. Lab. \& clin. Med. $23: 148$

Barkan, G.Z. (1925). Z. physiol. Chem. $148: 124$ Barkan, G.Z. (1927). Z. physiol. Chem. 171 : 179 Barkan, G.Z. (1933a). Z. physiol. Chem. 216 : 1 Barkan, G.Z. (1933b). Z. physiol. Chem. $216: 17$ Bergeim, O.\& Kirch, E.R. (1949). J. biol. Chem. 177 : 591 Blaud, P. (1832). Rev. Med. Hranc, et etrang. 1 : 337 Brock, J.F. \& Taylor, G. (1934). Biochem. J. 28 : 447 Bröchner Mortensen, K. (1943a). Acta. med. Scand. 113 : 345 Bröchner Mortensen, K. (1943b). Acta. med. Scand. 113 : 345

Cappell, D.F. (1930). J. Path. \& Bact. 33 : 175

Cartwright, G.E., Lauristion, M.A. Jones, P.M., Merrill, I.M. \& Wintrobe, M.M. (1946a) . J. clin. Invest. 25 : 65 .

Cartwright, G.E., Humphreys, S.R., Jones, P.M., Merrill, I.M. 今 Wintrobe, II.II. (1946b). J. clin. Invest. 25 : 81 
Cohn, E.J., Strong, L.E., Hughes, W.I., Mulford, D.J., Ashworth, J. Melin, M. \& Taylor, H.S. (1946). J. Amer. chem. Soc. 68 : 459

Copp, D.H. \& Greenberg, D.M. (1946). J. biol. Chem. $164: 377 \& 389$

Cullen, W. (1789). A Treatise of the Materia Medica. Edinburgh.

Crawley, J. (195I). personal communication

Dahl, S. (1948) Brit. med. J. I : 731

Day, T. \& Stein,S.(1938). J. Nutriz. $16: 525$

Dubach, R., Callender, S.T.E. \& Moore, C.V., (1948). Blood 3 : 526

Dubach, R., Moore, C.V. \& Minnich V. (1946). J. Lab. \& dlin. Med. 31 : 1201

Eckerstrom, S. (1944a). Nord. med. 21 : 276

Eckerstrom, S. (1944b). Nord. med. $24: 1843$

Finch, C.A., Wolff, J.A., Rath, C.A. \& Fluharty, R.G. (1949). J. Lab. \& clin. Med. $34: 1480$

Finch, C.A., Hegsted, M., Kinney, T.D., Thomas, E.D., Rath, C.A. Haskins, D., Finch, S. \& Fluharty, R.G. (1950). BIood $5: 983$

Fitzpatrick, J. \& Howells, K.W. (1949). J. clin. Path. $2: 290$ 
Foedisch, F. (1832). De morbosa sanguinis temperatione. Jena

Fontes, G. \& Thivolle, I. (1936). Sang 10: $144 \& 433$

Fowell, P.H. (1915). Quart, J. Hed. 6 : 179

Fowler, W.II. \& Barer, A.P. (1937). Arch. int. Med.

$59: 561 \& 1024$

Fowweather, F.S. (1934). Biochem. J. $28: 1160$

Gillman, J. \& Gillman, T. (1945). Arch. Path. $40: 239$

Gillman, T. \& Gillman, J. (1944). Nature, Iondon. $154: 148$

Gillman, J., Mandelstam, J. \& Gillman, T. (1945). S.

Afr. J. med. Sci. $10: 109$

Granick, S. (1946b). J. biol. Chem. 164: 737

Granick, S. (1946c). Chem. Rev. 38 : 379

Granick, S. \& Hahn, P.F. (1944). J. biol. Chem. 155 : 661

Granick, S. \& Michaelis, I. (1946a). Science. $103: 107$

Greenberg, G.R. Ashenbrucker, H., Lauriston, M. \& Wintrobe,

M.M. (1947a). J. clin. Invest. $26: 114$

Greenberg, G.R. Worth. W., Humphreys, S.R. \& Wintrobe, M.M.

(1947b). J. clin. Invest. $26: 121$

Grimstein, M. \& Moore, C.V. (1949). J. clin. Invest. 28 : 505 Gubler, C.J., Cartwright, G.E. \& Wintrobe, M.M. (1950a).

J. biol. Chem. $184: 563$

Gubler, C.J., Cartwright, G.E. \& Wintrobe, M.M. (1950b).

J. biol. Chem. $184: 575$

Guthmann, H., Brüchner, M.A., Ehrenstein, H. \&

Wagner, H.' (1931). Arch. f. Gynak, 147:469. 
Hahn, P.F. (1937). Medicine. $16: 249$

Hahn, P.F. (1943). J. exper. Med. $78: 169$

Hahn, P.F. Bale, W.F., Lawrence, E.O. \& Whipple, G.H.

(1939a).J. exper. Med. $69: 739$

Hahn, P.F., Bale, W.F., Hettig, R.A., Kamen, M.D. \&

Whipple, G.H. (1939b). J. exper. Hed. $70: 443$

Halvorsen, ¿ Starkey, (1927)

Hartfall, S.J. (1934). Brit. med.J. I : 136

Häserman, H. (1899). Z. physiol. Chem. $26: 436$

Hawkins, W.B. \& Hahn, P.F. (1944). J. exper. Med. 80 : 31 Heath, C.W. (1933). Arch. int. Hed. 51 : 459

Hegsted, D.M., Finch, C.A. \& Kinney, T.D. (1949). J. exper. Med. $90: 147$

Heilmeyer, I. \& Plötner, K. (1937). Das Serumeisen und die

Eisenmangelkrankheit. Jena

Hemmeler, G. (1946) Helvet. med. Acta. $13: 20$

Holmberg, C.G. (1941). Acta. physiol. Scand. 2 : 71

Holmberg, C.G. \& Laurell, C.B. (1945). Acta. physiol. Scand.

\section{$10: 307$}

Houghton, B.C. \& Doan, C.A. (1941). Amer. J. Clin. Path. Il :144 Hoyer; K. (1944a). Acta. med. Scand. 119 : 562 Hynes, M. (1948). J. clin. Path. I : 57 Hynes, M. (1949) J. clin Path. 2 : 99 Kellogg, F. \& Mettier, S.R. (1936). Arch. int. Med. 58 : 278 
Kennedy, R.P. (1927). J. biol. Chem. $74: 385$

Kinney, T.D., Hegsted, D.M. \& Finch, C.A. (1949). J. exper. Med. $90: 137$

Kuhns, W.J., Gubler, C.J., Cartwright, G.E. \& Wintrobe, M.N. (1950). J. clin. Invest. $29: 1505$

Laufberger, T. (1937). Bull. Soc. chem. Biol. 19 : 1575

Laurell, C.B. (1947). Acta. physiol, Scand. 14 : Supp. 46 Lederer, J. \& Hoet, J.P. (1939). C.R. Société Biologie $132: 491$

Lederer, J. (1939). Journal belge de Gastro - Entérologie. $7: 551$

Lederer, J. (1940). Sang. $14: 27$

Legge, J.W. \& Lemberg,. R. (194I). Biochem. J. $35: 353$

Iintzel, W. (1931). Ergebn.d. Physiol. 31 : 844

Lublin, H. (193I). Acta. med. Scand. I : Supp. 41

Mazur, A. \& Shorr, E. (1948). Biol. Chem. 176 : 771

Menghini, V. (1746). Bononiensi Scientiarum et Artium

Instuto atque Academia Commentarii 2(2) : 244

Mettier, S.R. \& Iinot, G.R. (193I) Amer. J. med. Sci.

$181: 25$

Michaelis, I. (1947) Advances in Protein Chemistry, New York Minot, G.R. \& Heath, C.W. (1932). Am. J. med. Sci. 183 : 110 Mitchell, H.H. \& Harilton, T.S. (1949) J. biol. Chem. 178 : 345 Monardes, N. (1596). Joyfull Newes out of the liew found Worlde. Translated by J. Frampton, London. 
Moore, C.V., Minnich, V. \& Welch, J. (1939a). J. clin. Invest. $18: 543$

Moore, C.V., Arrowsmith, W.M.R., Quilligan, J.J. \& Read, J.T. (1937a). J. clin. Invest $16: 613$

Moore C.V., Doan, C.A. \& Arrowsmith, W.R. (1937b). J. clin. Invest $16: 627$

Moore C.V., Arrowsmith, W.R., Welch, J. \& Minnich, V. (1939a). J. clin. Invest. $18: 553$

Morley, J. \& Roberts, W.M. (1928). Brit. J. Surg. $16: 239$ McCance, R.A. \& Widdowson, E.M. (1937a). Liancet $2: 680$ McCance, R.A. \& Widdowson, E.M. (1937b). Quart. J.Med.

$$
6: 277
$$

Nissim, J.A. (1947). Liancet $2: 49$

Pereira, J. (1854). The Elements of Materia Medica and Therapeutics, Iondon.

Polson,CJ(1928). J. Path. \& Bact. 31 : 445

Polson,CJ.(1929). J. Path. \& Bact. $32: 247$

Polson,CJ.(1933). Brit. J. Exper. Path. $14: 73$

Powell, J.F. (1944). Quart. J. Med. $13: 19$

Rath, C.E. \& Finch, C.A. (1948). J. Lab. clin. Med. $33: 81$ Rath, C.E. \& Finch, C.A. (1949). J. clin. Invest. $28: 79$ Rose, M.S. \& Hubbell, H.J. (1938). J. Nutrit. $15: 91$ Sandberg, M., Gross, H. \& Holly, O.M. (1942). Arch. Path. $33: 834$ 
Schade, A.I. \& Caroline, I. (1944). Science $100: 14$ Shaerer, E. \& Rechenberger, J. (1948). Virchows. Arch.

$$
315: 309
$$

Sinclair, R.J.G., \& Duthie, J.J.R. (1949). Lancet. 3 : 646 Skouge, E. (1939) Klinische und experimentelle Untersuchungen uber das Serumeisen. Oslo

Slack, H.G.B. \& Wilkinson, J.F. (1949). Brit. med. J. I : 753 Starkenstein, E. \& Weden, H. (1928). Arch. f. exper.

Path. u. Pharmakol. $134: 274$

Steenbock, H., Semb, J. \& Van Donk, E.C. (1936). J. biol. Chem. 116 : ci

Sydenham, T. (1848). The Works of Thomas Sydenham, M.I.

translated by R.G. Latham. London

Taylor, J., Stiven, I. \& Reid, E.W. (1931). J. Path.

\& Bact. 34 : 793

Taylor, J. Stiven, D. \& Reid, E.W. (1935). J. Path.

\& Bact. 41 : 397

Thedering, F. (1948). Z. innere Med. $3: 547$

Thedering, F. (1949). Klin. Wschr. $27: 496$

Tompsett, S.I. (1934). Biochem. J. $28: 1536 \& 1802$

Tompsett, S.I. (1935). Biochem. J. $29: 480$

Tompsett, S.I. (1940). Biochem. J. $34: 961$

Töttermann, L.E. (1949). Acta. Mied. Scand. 134 : Supp 230 Valquist, B. (194I). Acta. paediat. 28 : Supp 5 
Vannotti, A. \& Delachaux, A. (1942). Iron Metabolism and its Clinical Significance. Iondon

Vaughan, J.M. (1932). Lancet 1 : 122

Waldenstrom, J. (1944). Om jarn och jarnterapi. Malmo Walker, A.R.P. \& Arvidsson, U.B. (1950) Nature, Iondon $166: 438$

Walsh, E.D., Thomas E.D., Chow, S.K., Fluharty, R.G. \& Finch, C.A. (1951). Science $110: 396$ Whipple, G.H. \& Robscheit - Robbins, F.S. (1936) Amer.J. med. Sci. $191: 11$

Whitby, I.E.H. \& Britton, C.J.C. (1950). Disorders of the Blood. Iondon

Wilder, J. (1931). KIin. Wehschr. 10: 1889

Willis, T. (1684). Dr. Willis's Practice of Physik, being the whole works of that renowned and famous Physician. Iondon 